UNIVERSIDADE FEDERAL DE GOIÁS

ESCOLA DE ENGENHARIA ELÉTRICA E DE COMPUTAÇÃO

PROPOSTA DE UM SISTEMA HIPERMÍDIA ADAPTATIVO

EDUCACIONAL PARA A PERSONALIZAÇÃO DO

PROCESSO DE ENSINO ATRAVÉS DA WEB

ALEXANDRE MARTINS FERREIRA BUENO

GOIÂNIA 
ALEXANDRE MARTINS FERREIRA BUENO

\title{
PROPOSTA DE UM SISTEMA HIPERMÍDIA ADAPTATIVO EDUCACIONAL PARA A PERSONALIZAÇÃO DO PROCESSO DE ENSINO ATRAVÉS DA WEB
}

\begin{abstract}
Dissertação apresentada ao Programa de Pós-Graduação da Escola de Engenharia Elétrica e de Computação da Universidade Federal de Goiás, como requisito parcial para a obtenção do título de Mestre em Engenharia de Computação.
\end{abstract}

Área de Concentração: Engenharia de Computação

Orientador: Prof. Dr. Leonardo da Cunha Brito

GOIÂNIA 


\title{
FOLHA DE APROVAÇÃO
}

\author{
"Proposta de um Sistema Hipermídia \\ Adaptativo Educacional para a \\ Personalização do Processo de Ensino \\ Através da WEB"
}

\section{Alexandre Martins Ferreira Bueno}

Dissertação defendida e aprovada pela banca examinadora constituída pelos senhores:
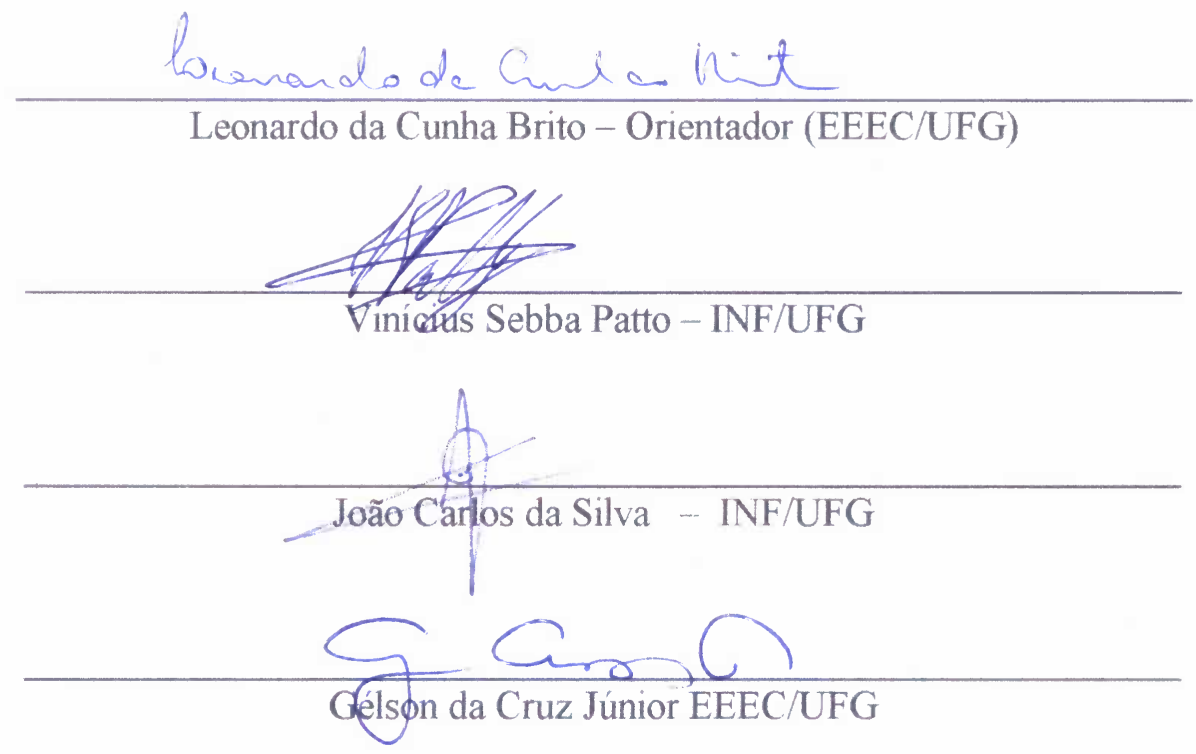

Goiânia, 13 de dezembro de 2011 


\section{TERMO DE CIÊNCIA E DE AUTORIZAÇÃO PARA DISPONIBILIZAR AS TESES E DISSERTAÇÕES ELETRÔNICAS (TEDE) NA BIBLIOTECA DIGITAL DA UFG}

Na qualidade de titular dos direitos de autor, autorizo a Universidade Federal de Goiás (UFG) a disponibilizar, gratuitamente, por meio da Biblioteca Digital de Teses e Dissertações (BDTD/UFG), sem ressarcimento dos direitos autorais, de acordo com a Lei no 9610/98, o documento conforme permissões assinaladas abaixo, para fins de leitura, impressão e/ou download, a título de divulgação da produção científica brasileira, a partir desta data.

\section{Identificação do material bibliográfico: [ X ] Dissertação [ ] Tese}

\section{Identificação da Tese ou Dissertação}

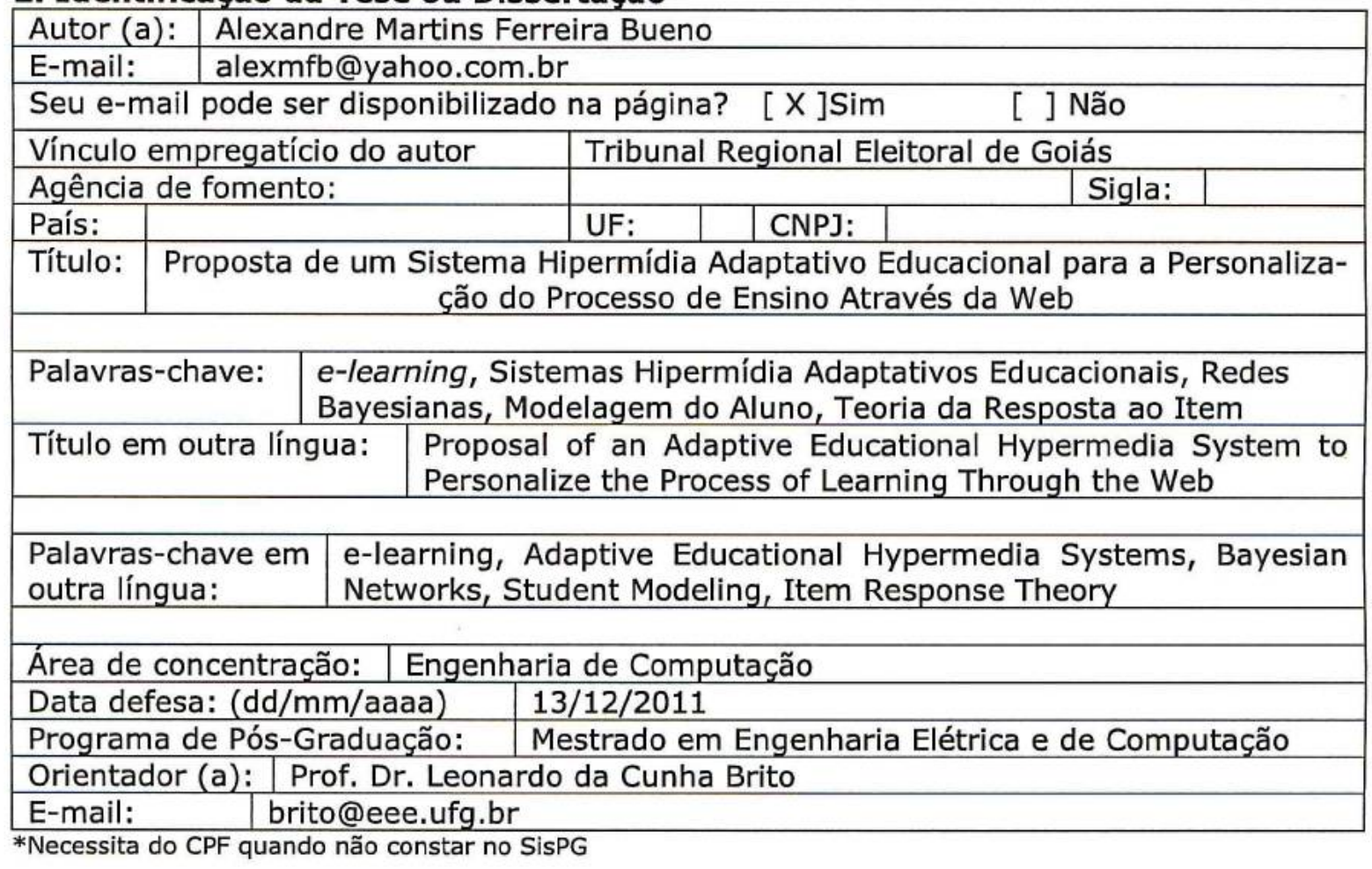

\section{Informações de acesso ao documento:}

\section{Concorda com a liberação total do documento [X] SIM [ ] NÃO ${ }^{1}$}

Havendo concordância com a disponibilização eletrônica, torna-se imprescindível o envio do(s) arquivo(s) em formato digital PDF ou DOC da tese ou dissertação.

O sistema da Biblioteca Digital de Teses e Dissertações garante aos autores, que os arquivos contendo eletronicamente as teses e ou dissertações, antes de sua disponibilização, receberão procedimentos de segurança, criptografia (para não permitir cópia e extração de conteúdo, permitindo apenas impressão fraca) usando o padrão do Acrobat.

Wexande Mutivy f. Bueno

Assinatura do (a) autor (a)

Data: $\underline{25} / \underline{01} / \underline{2012}$

\footnotetext{
${ }^{1}$ Neste caso o documento será embargado por até um ano a partir da data de defesa. A extensão deste prazo suscita justificativa junto à coordenação do curso. Os dados do documento não serão disponibilizados durante o período de embargo.
} 
Dados Internacionais de Catalogação na Publicação (CIP)

\begin{tabular}{|l}
\hline B928p \\
Bueno, Alexandre Martins Ferreira. \\
Proposta de um sistema hipermídia adaptativo educacional \\
para a personalização do processo de ensino através da WEB \\
[manuscrito] / Alexandre Martins Ferreira Bueno. - 2011. \\
139 f. : il., figs, tabs. \\
Orientador: Prof. Dr. Leonardo da Cunha Brito. \\
Dissertação (Mestrado) - Universidade Federal de Goiás, \\
Escola de Engenharia Elétrica e de Computação, 2011. \\
Bibliografia. \\
Inclui lista de figuras, siglas e tabelas. \\
Apêndices. \\
1. Sistema Hipermídia Adaptativo - Ensino a distância. 2. E- \\
learning. 3. Rede Bayesiana. I. Título. \\
CDU: 004:37.018.43
\end{tabular}


Aos meus pais, por tudo que me ensinaram e pelo apoio incondicional. 


\section{Agradecimentos}

São tantas as pessoas a agradecer...

A Deus, que me concedeu a vida e a força necessária para a conclusão deste trabalho.

A minha família, em especial aos meus pais, pelo suporte e incentivo que me deram durante esta fase da minha vida.

A minha namorada Lamara, pelo carinho, dedicação e compreensão.

Aos meus amigos, pelo companheirismo e apoio durante os momentos difíceis.

Em relação às pessoas já mencionadas, agradeço ainda pela paciência e compreensão recebidas durante os momentos em que estive ausente, principalmente em relação às dezenas (e provavelmente até mais de uma centena!!) de finais de semana nos quais me dediquei quase que exclusivamente às atividades do Mestrado.

Ao meu orientador Prof. Dr. Leonardo da Cunha Brito, por acreditar no meu trabalho e pela atenção e esclarecimentos prestados.

Aos professores e colegas do Programa de Pós-Graduação da Escola de Engenharia Elétrica e de Computação da UFG, que me forneceram o embasamento necessário para a criação e execução deste trabalho.

Aos meus amigos e colegas de trabalho da Secretaria de Tecnologia da Informação do Tribunal Regional Eleitoral de Goiás, pelo apoio sempre presente e prestativo.

A Prof ${ }^{\mathrm{a}}$. Dra ${ }^{\mathrm{a}}$. Sand Luz Corrêa e, principalmente, ao Prof. Dr. João Carlos da Silva, ambos do Instituto de Informática da UFG, que disponibilizaram parte do seu tempo e de seus alunos para a verificação do sistema proposto neste trabalho.

Enfim, agradeço de coração a todos que, direta ou indiretamente, contribuíram para a realização deste sonho que agora se torna realidade. Sem a participação de vocês com certeza eu não teria alcançado esta vitória. Espero um dia conseguir retribuir tudo o que fizeram por mim. Serei eternamente grato.

Meu muito obrigado! 
"Há momentos na vida em que sentimos tanto a falta de alguém que o que mais queremos é tirar esta pessoa de nossos sonhos e abraçá-la.

Sonhe com aquilo que você quiser.

Seja o que você quer ser, porque você possui apenas uma vida e nela só se tem uma chance de fazer aquilo que se quer.

Tenha felicidade bastante para fazê-la doce. Dificuldades para fazê-la forte. Tristeza para fazê-la humana.

E esperança suficiente para fazê-la feliz.

As pessoas mais felizes não têm as melhores coisas. Elas sabem fazer o melhor das oportunidades que aparecem em seus caminhos.

A felicidade aparece para aqueles que choram. Para aqueles que se machucam.

Para aqueles que buscam e tentam sempre.

E para aqueles que reconhecem

a importância das pessoas que passam por suas vidas.

O futuro mais brilhante

é baseado num passado intensamente vivido.

Você só terá sucesso na vida

quando perdoar os erros

e as decepções do passado.

A vida é curta, mas as emoções que podemos deixar duram uma eternidade.

A vida não é de se brincar porque um belo dia se morre." 


\section{Resumo}

Hoje em dia, o e-learning se tornou uma importante vertente na obtenção de conhecimento, fornecendo conteúdo sem a limitação de tempo ou espaço. Neste contexto, a educação baseada na $W e b$ tem recebido destaque. Inúmeras aplicações de e-learning têm se utilizado da Web para ensinar, principalmente para prover ensino à distância. Como consequência do crescimento substancial do e-learning houve um aumento na diversidade dos alunos que fazem uso deste meio para a obtenção de suas formações acadêmicas ou profissionais. Em geral, estes alunos possuem diferentes características pessoais, sócioculturais e cognitivas. Os Sistemas Hipermídia Adaptativos oferecem recursos para atender a este público diverso, eles são capazes de considerar as características individuais dos alunos durante o processo de aprendizagem. Sabe-se que na representação destas características frequentemente estão associadas informações que são incertas e imprecisas. Diante do apresentado, este trabalho propõe um Sistema Hipermídia Adaptativo Educacional (com conteúdo instrucional) que tem como objetivo a personalização do processo de ensino à distância através da Web. Ele possui um modelo do aluno que é capaz de lidar com as incertezas relacionadas ao conhecimento dos alunos (característica dos alunos considerada pelo sistema) através do uso de uma Rede Bayesiana. Este modelo é ajustado por respostas dadas pelos alunos em testes de habilidade, que são avaliadas por um modelo matemático da Teoria da Resposta ao Item. O experimento realizado comparou os resultados obtidos pelo sistema proposto, provido de mecanismos de adaptação (personalização), e outro sistema desprovido de adaptação, em que o mesmo conteúdo era apresentado a todos os alunos. A análise estatística dos dados coletados mostrou uma melhoria significativa na retenção de conhecimento por parte dos alunos que fizeram uso do sistema provido de adaptação. Entretanto, esperava-se, como consequência desta melhoria, que os níveis de satisfação informados pelos alunos que fizeram uso do sistema proposto fossem superiores aos níveis informados pelos alunos que fizeram uso do sistema desprovido de adaptação, fato não evidenciado pelos dados obtidos.

Palavras-chave: e-learning, Sistemas Hipermídia Adaptativos Educacionais, Redes Bayesianas, Modelagem do Aluno, Teoria da Resposta ao Item. 


\section{Abstract}

Nowadays, e-learning has become an important source of knowledge, providing content without the limitation of time or space. In this context, Web-based education became an important sector. A large number of e-learning applications have utilized the Web to teach, mainly to provide distance learning. As a result of the substantial growth in elearning there has been an increase in the diversity of students that uses this environment to achieve their academic or professional backgrounds. In general, these students have different personal, social-cultural and cognitive characteristics. Adaptive Hypermedia Systems provide resources to assist this diverse public, they are able to consider the individual characteristics of students during the learning process. It is known that the representation of these features are often associated with uncertain and imprecise information. Given this context, this work proposes a Web-based Adaptive Educational Hypermedia System (with instructional content) that aims to personalize the process of distance learning. It has a student model that is able to represent the uncertainties related to the student's knowledge (characteristic of the students considered by the system) through the use of a Bayesian Network. This model is adjusted according to the answers provided by students in ability tests, which in turn are evaluated by a mathematical model of Item Response Theory. The experiment realized compared the results obtained by the proposed system, that is provided with adaptation (personalization) mechanisms, and other system that has no such mechanisms, in which the same content was presented to all the students. Statistical analysis of the collected data has shown a significant improvement in knowledge retention by the students who used the system provided with adaptation. However, it was expected, as a result of this improvement, that the levels of satisfaction reported by the students who used the proposed system were better than the levels reported by the students who used the system without adaptation, which was not evidenced by the gathered data.

Keywords: e-learning, Adaptive Educational Hypermedia Systems, Bayesian Networks, Student Modeling, Item Response Theory. 


\section{Sumário}

Lista de Figuras

Lista de Tabelas

Lista de Siglas

1 Introdução

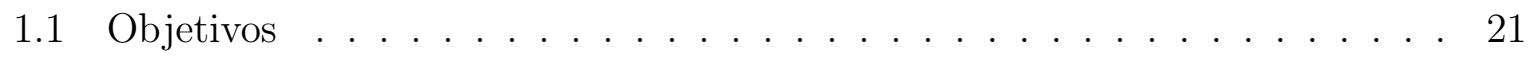

1.1 .1 Objetivo Geral . . . . . . . . . . . . . . . . 21

1.1 .2 Objetivos Específicos . . . . . . . . . . . . . . 21

1.2 Justificativa . . . . . . . . . . . . . . . . . . . . . . . 21

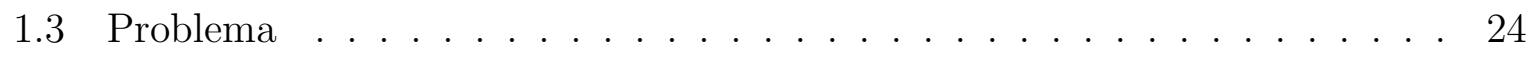

1.4 Hipóteses . . . . . . . . . . . . . . . . . . . . . . . . . . . 24

1.5 Visão Geral dos Capítulos . . . . . . . . . . . . . . . . . . . 24

2 Embasamento Teórico $\quad 26$

2.1 Fundamentos da Teoria da Probabilidade . . . . . . . . . . . . . . 26

2.1.1 Experimento Aleatório, Espaço Amostral e Evento . . . . . . . . . 26

2.1.2 Perspectivas sobre probabilidade . . . . . . . . . . 27

2.1.3 Axiomas da Probabilidade . . . . . . . . . . . . . . . . . . . 28

2.1.4 Probabilidade Incondicional e Probabilidade Condicional . . . . . . 29

2.1.5 Independência Condicional . . . . . . . . . . . . . . . 30

2.1.6 Variáveis Aleatórias e Proposições . . . . . . . . . . . . . . . . . . . 30 
2.1.7 Distribuição Condicional, Conjunta e Marginalização . . . . . . . . 31

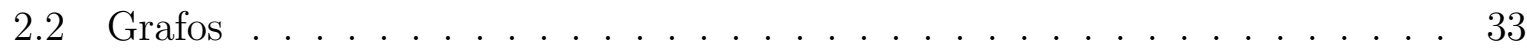

2.3 Redes Bayesianas . . . . . . . . . . . . . . . . . . . . . . 35

2.3.1 Regra de Bayes . . . . . . . . . . . . . . . . . . . . 35

2.3.2 Definições e Exemplo . . . . . . . . . . . . . . . . . . . . 36

2.3.3 Tipos de Raciocínio . . . . . . . . . . . . . . . . . . . . . . . 38

2.3.4 Representação do Domínio . . . . . . . . . . . . . . . . . . . 38

2.3.5 D-Separação . . . . . . . . . . . . . . . . . . . . . . . . . . . . 39

2.3.6 Causalidade . . . . . . . . . . . . . . . . . . . . . 42

2.3.7 Vantagens ......................... . . . 42

2.3 .8 Inferência . . . . . . . . . . . . . . . . . 43

2.3.8.1 Tipos de Evidência . . . . . . . . . . . . . . 45

2.3.8.2 Inferência Exata . . . . . . . . . . . . . . . 46

2.3.8.3 Inferência em Redes com Múltiplas Conexões . . . . . . . 47

2.3.8.4 Algoritmo de Árvore de Junção . . . . . . . . . . . . . . . 49

2.4 Teoria da Resposta ao Item . . . . . . . . . . . . . . . . . 52

2.4.1 Modelo Logístico de 3 Parâmetros . . . . . . . . . . . . . . . 54

2.4.1.1 Interpretação e Representação Gráfica dos Parâmetros do ML3P ..................... . . 55

2.4.1.2 Unidimensionalidade e Independência Local . . . . . . . . 57

2.4 .2 Invariância e Equalização . . . . . . . . . . . . . . . . . . . 58

2.4.3 Estimação para uma única população . . . . . . . . . . . . . . 58

2.4.3.1 Estimação das habilidades . . . . . . . . . . . . . . 60

2.4.3.1.1 Média a Posteriori ........... . 60

2.5 Sistemas Hipermídia Adaptativos . . . . . . . . . . . . . . . . 62

2.5.1 Sistemas Hipermídia Adaptativos Educacionais . . . . . . . . . . . 64 
2.5.2 Arquitetura dos SHAs . . . . . . . . . . . . . . 65

2.5.2.1 Modelo do Domínio . . . . . . . . . . . . . 66

2.5.2.2 Modelo do Usuário . . . . . . . . . . . . . . . . . . . 66

2.5.2.3 Modelo de Adaptação . . . . . . . . . . . . . . . . . . . . 69

2.5.2.4 Interface do Usuário . . . . . . . . . . . . . . . . . . . . . 69

2.5.3 O que pode ser adaptado . . . . . . . . . . . 70

2.5.3.1 Métodos e Técnicas de Adaptação . . . . . . . . . . . 70

2.5.3.1.1 Conteúdo adaptativo . . . . . . . . . 71

2.5.3.1.2 Apresentação adaptativa . . . . . . . . . 73

2.5.3.1.3 Navegação adaptativa . . . . . . . . . . 73

$\begin{array}{lll}3 & \text { Sistema Proposto } & 77\end{array}$

3.1 Modelo do Domínio . . . . . . . . . . . . . . . . . . . 77

3.2 Modelo do Aluno . . . . . . . . . . . . . . . . . . . . . . . . . 78

3.2.1 Mecanismo de ajuste do MA . . . . . . . . . . . . . . 79

3.3 Modelo de Adaptação . . . . . . . . . . . . . . . . . . . . . . . . . . . 81

3.4 Comportamento do Modelo do Aluno . . . . . . . . . . . . . . . . 84

4 Aplicação Experimental e Resultados $\quad 86$

4.1 Aplicação Experimental . . . . . . . . . . . . . . . . 86

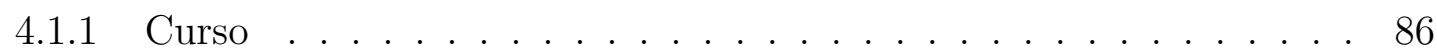

4.1.1.1 Organização do Curso e dos Níveis de Representação . . . 87

4.1.1.2 Rede Bayesiana . . . . . . . . . . . . . . . . 89

4.1.1.3 Testes de Habilidade . . . . . . . . . . . . . . . . . . . 91

4.1 .2 Sistema Tradicional . . . . . . . . . . . . . . . . . . . . 92

4.1 .3 Ambiente Tecnológico . . . . . . . . . . . . . . . 93

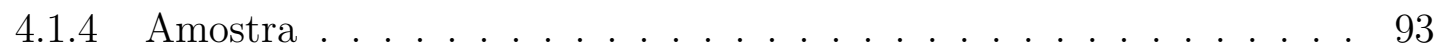


4.2 Resultados . . . . . . . . . . . . . . . . . . . . . . . 94

4.2 .1 Análise Descritiva e Inferencial _. . . . . . . . . . . . . . . . . 94

4.2 .2 SHAE Proposto . . . . . . . . . . . . . . . . . . . 100

$\begin{array}{llr}5 & \text { Conclusão } & 108\end{array}$

5.1 Principais Contribuições . . . . . . . . . . . . . . . . . . . 109

5.2 Trabalhos Futuros . . . . . . . . . . . . . . . . . . . 110

Referências $\quad 112$

$\begin{array}{ll}\text { Apêndice A - Conteúdos e Testes Criados } & 117\end{array}$

A.1 Conteúdo de Nível Básico . . . . . . . . . . . . . . . . . . . . 117

A.2 Conteúdo de Nível Intermediário _ . . . . . . . . . . . . . . . . 119

A.3 Conteúdo de Nível Avançado . . . . . . . . . . . . . . . . . . . . . . 121

A.4 Conteúdo Simplificado de Nível Intermediário . . . . . . . . . . . . . 123

A.5 Conteúdo Simplificado de Nível Avançado . . . . . . . . . . . . . . . 123

A.6 Pré-teste . . . . . . . . . . . . . . . . . . . . . . . . 124

A.7 Pós-teste . . . . . . . . . . . . . . . . . . . . . . . . . . . . . . . . . . . . 124

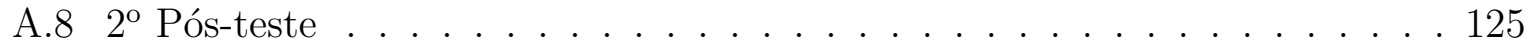

Apêndice B - Sistema Adaptativo $\quad 126$

B.1 TPCs da Rede Bayesiana . . . . . . . . . . . . . . . . . 126

B.2 Mecanismo de Mensagens e Dicas . . . . . . . . . . . . . 126

B.3 Questionários . . . . . . . . . . . . . . . . . . 131

Apêndice C - Resultados Complementares 133 


\section{Lista de Figuras}

2.1 Apesar de ambos os grafos possuírem as mesmas conexões entre os vértices, eles não representam o mesmo grafo. . . . . . . . . . . . . . . . . . 33

2.2 A sequência de nós $A-B-C-D$ é um caminho orientado. A sequência $B-C-D-B$ é um ciclo orientado. . . . . . . . . . . . . . . 34

2.3 O grafo acima, que contém os nós $A, B, \ldots, F$, é uma floresta. . . . . . . 35

2.4 RB típica, mostrando sua topologia e TPCs. Como as variáveis são booleanas, se a probabilidade para o estado verdadeiro é $p$, então, a probabilidade para o estado falso é $1-p$. Por este motivo, este segundo número foi omitido. 37

2.5 (a) conexão serial ou causal; (b) conexão divergente ou de causa comum;

(c) conexão convergente ou de efeito comum. . . . . . . . . . . . . . . . . . 40

2.6 GAO, retirado de Neapolitan (2004), para a análise das d-separações. . . . 41

2.7 RB em que os nós $X$ e $Y$ possuem dois estados cada, e o nó $Z$ possui três estados. . . . . . . . . . . . . . . . . . . . 44

2.8 Simples exemplos de uma poliárvore e de uma rede multiconectada. . . . . 47

2.9 Exemplo de transformação do GAO de uma RB em um grafo triangular, retirado de Huang e Darwiche (1996). As arestas acrescentadas pelos processos de moralização e triangulação estão indicadas em tracejado. . . . . . . 50

2.10 Árvore de Junção criada a partir do grafo triangular da Figura 2.9. Também está ilustrada a passagem de mensagens entre os cliques, em que o clique ACE foi escolhido como principal. . . . . . . . . . . . . . . . . . . 52

2.11 Exemplo de uma CCI, em que $c=0,2, a=1,2$ e $b=1 \ldots \ldots$. . . . 56

2.12 Ciclo clássico de adaptação em um SHA. Retirado de Bugay (2006) e adaptado de Brusilovsky (1996).

3.1 Mecanismo de ajuste do MA quando os testes são respondidos corretamente. 81

3.2 Mecanismo de testes utilizado para os conceitos. . . . . . . . . . . . . . 82 
3.3 Mecanismo geral para a adaptação do conteúdo. . . . . . . . . . . . . . . . 83

3.4 Sequência percorrida pelo aluno em caso de acerto do pós-teste, em que o conteúdo simplificado não é visualizado. . . . . . . . . . . . . . . . . . . . 84

3.5 Sequência percorrida pelo aluno em caso de acerto do pós-teste, em que o conteúdo simplificado é visualizado. . . . . . . . . . . . . . . . . . . . . . . 84

3.6 Sequência percorrida pelo aluno em caso de erro do pós-teste, em que o reforço e o $2^{\circ}$ pós-teste são apresentados. . . . . . . . . . . . . . . . . . . . 84

4.1 Estrutura da RB e as probabilidades iniciais (após a primeira compilação da rede) que os alunos têm de conhecer ou não os conceitos. As estimativas de conhecimento ou não dos conceitos podem variar de 0 a 100\%. . . . . . 89

4.2 Caminho percorrido pelo aluno, para cada conceito, quando ele acerta o pós-teste ou quando ele o erra mas opta por não rever o conteúdo anteriormente apresentado. . . . . . . . . . . . . . . . . . . . 92

4.3 Caminho percorrido pelo aluno, para cada conceito, quando ele erra o pósteste e opta por rever o conteúdo anteriormente apresentado. . . . . . . . . 93

4.4 Número de acertos e erros obtidos pelos grupos nas questões de pós-teste. . 97

4.5 Número de acertos e erros obtidos pelos grupos nas questões de $2^{\circ}$ pós-teste. 98

4.6 Distribuição das habilidades ao final de cada conceito calculada pelo método EAP para os alunos. . . . . . . . . . . . . . . . . . . . . 104

4.7 Distribuição das probabilidades de conhecimento ao final de cada conceito calculada pela RB para os alunos. . . . . . . . . . . . . . . . . . . . 105

4.8 Evolução das habilidades dos três alunos do grupo experimental selecionados.106

B.1 TPCs da RB criada. Em que o estado "Sim" representa o aluno conhecer o conceito envolvido e o estado "Não", o contrário. São apresentadas apenas as probabilidades referentes ao estado "Sim" de cada conceito. . . . . . . . 127

B.2 Mensagem apresentada ao aluno logo após o erro do pré-teste. . . . . . . . 129

B.3 Dica que permite ao aluno rever um cenário muito utilizado no curso. . . . 130

B.4 Questionário para o levantamento do histórico do aluno. . . . . . . . . . . 131

B.5 Questionário de avaliação do sistema. . . . . . . . . . . . . . . . . 132 


\section{Lista de Tabelas}

1.1 Números da EAD referentes à graduação no Brasil. . . . . . . . . . . . . . . . 22

2.1 Distribuição condicional $P(A \mid B)$ em que as variáveis $A$ e $B$ possuem, respectivamente, 2 e 3 estados. . . . . . . . . . . . . . . . . 32

2.2 Distribuição conjunta $P(A, B)$, obtida através da Tabela 2.1, aplicando a regra do produto nas probabilidades condicionais e adotando $P(B)=$

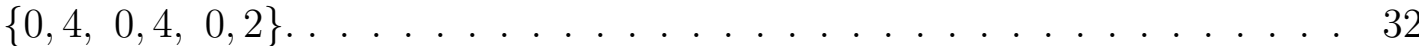

3.1 Determinação das probabilidades a serem inseridas como evidência virtual na RB. $R$ representa se o aluno acertou (1) ou errou (0) a questão e $s$ e $n$ representam, respectivamente, se ele conhece ou não o conceito envolvido. As probabilidades para cada estado de $R$ não necessariamente precisam somar 100\% . . . . . . . . . . . . . . . . . . 80

3.2 Mecanismo para apresentação do conteúdo simplificado após o acerto do pós-teste pelo aluno. . . . . . . . . . . . . . . . . . . . . . . . . . 84

4.1 Grupos que compõem a amostra por turma. . . . . . . . . . . . . . . . . . 94

4.2 Respostas obtidas pelos grupos no questionário para levantamento do histórico dos alunos. . . . . . . . . . . . . . . . . . . . . . 95

4.3 Estatística descritiva do tempo gasto nas atividades de ensino. . . . . . . . 95

4.4 Tempo médio gasto nas atividades de ensino pelo grupo experimental ao se desconsiderar os pré-testes e conteúdos simplificados apresentados. . . . 96

4.5 Tempo médio gasto para a realização de todo o curso. . . . . . . . . . . . . 96

4.6 Estatística descritiva do desempenho dos alunos nos pós-testes. . . . . . . . 96

4.7 Estatística inferencial (Teste t) do desempenho dos alunos nos pós-testes. . 98

4.8 Tempos médios gastos em algumas atividades do curso. . . . . . . . . . . . . 99

4.9 Respostas obtidas pelos grupos no questionário de avaliação do curso. . . 100 
4.10 Conteúdos apresentados após os pré-testes. . . . . . . . . . . . . . . . 101

4.11 Conteúdos simplificados apresentados após os acertos dos pós-testes. . . . . 102

4.12 Conteúdos de reforço apresentados após os erros dos pós-testes. . . . . . . 103

4.13 Probabilidades de conhecimento dos conceitos calculadas para o Aluno 1. . 106

4.14 Probabilidades de conhecimento dos conceitos calculadas para o Aluno 2. . 107

4.15 Probabilidades de conhecimento dos conceitos calculadas para o Aluno 3. . 107

B.1 Algumas mensagens utilizadas pelo sistema proposto para interagir com o aluno. . . . . . . . . . . . . . . . . . . . . . . 128

C.1 Acertos obtidos em cada conceito nos testes realizados no sistema tradicional.134

C.2 Acertos obtidos em cada conceito nos testes realizados no sistema adaptativo. 135

C.3 Tempo total gasto, habilidade final e o desempenho nos testes obtidos pelos alunos no curso oferecido pelo sistema adaptativo. . . . . . . . . . . . . 136

C.4 Tempo total gasto e o desempenho nos testes obtidos pelos alunos no curso oferecido pelo sistema tradicional. . . . . . . . . . . . . . . . . . 137

C.5 Sequência de conteúdos apresentada aos 3 alunos selecionados. . . . . . . . 138 


\section{Lista de Siglas}

$\begin{array}{ll}\text { AHAM } & \text { Adaptive Hypermedia Application Model } \\ \text { CAI } & \text { Computer Assisted Instruction } \\ \text { CCI } & \text { Curva Característica do Item } \\ \text { EAD } & \text { Educação à Distância } \\ \text { EAP } & \text { Expected a Posteriori } \\ \text { GAO } & \text { Grafo Acíclico Orientado } \\ \text { MA } & \text { Modelo do Aluno } \\ \text { MAP } & \text { Moda a Posteriori } \\ \text { MD } & \text { Modelo do Domínio } \\ \text { MER } & \text { Modelo de Entidade-Relacionamento } \\ \text { ML3P } & \text { Modelo Logístico de 3 Parâmetros } \\ \text { MMV } & \text { Método da Máxima Verossimilhança } \\ \text { MO } & \text { Modelo Overlay } \\ \text { MR } & \text { Modelo de Referência } \\ \text { MU } & \text { Modelo do Usuário } \\ \text { RB } & \text { Rede Bayesiana } \\ \text { SGBD } & \text { Sistema Gerenciador de Banco de Dados } \\ \text { SH } & \text { Sistema Hipermídia } \\ \text { SHA } & \text { Sistema Hipermídia Adaptativo } \\ \text { SHAE } & \text { Sistemas Hipermídia Adaptativo Educacional } \\ \text { STI } & \text { Sistema Tutor Inteligente } \\ \text { TCM } & \text { Teoria Clássica de Medidas } \\ \text { TPC } & \text { Tabela de Probabilidades Condicionais } \\ \text { TRI } & \text { Teoria da Resposta ao Item } \\ & \end{array}$




\section{Introdução}

O rápido desenvolvimento da Tecnologia da Informação modificou o estilo de vida do homem, criando novos caminhos para a aquisição de conhecimento. As aplicações educacionais desenvolvidas com este conjunto de tecnologias surgiram no início da década de 60 e foram classificadas como Instrução Assistida por Computador (CAI, do inglês Computer Assisted Instruction).

Estes sistemas se utilizavam da teoria comportamentalista como forma de aprendizagem e possuíam baixo nível de interação com o aluno. Estas ferramentas não consideravam as diferenças existentes entre os alunos em relação às suas características pessoais e experiências.

Com base na metodologia CAI e utilizando-se de técnicas de Inteligência Computacional $^{1}$, no início da década de 70, surgiu a Instrução Inteligente Assistida por Computador, na qual os sistemas buscavam considerar as características e habilidades dos alunos durante o processo de aprendizagem. Estes sistemas ficaram amplamente conhecidos por Sistemas Tutores Inteligentes (STIs).

Os STIs foram os primeiros sistemas que fizeram uso de técnicas de Inteligência Computacional com o intuito de desenvolver sistemas inteligentes e adaptativos, capazes de perceber as características do aprendiz e auxiliar o processo de ensino. Neles, o aluno tem pouco controle sobre o processo de ensino, que é estabelecido pelo sistema (KAPLAN; ROCK, 1995).

A popularização do acesso ao computador e à Internet ocorrida a partir da década de 90 possibilitou avanços no desenvolvimento dos STIs e no uso da hipermídia². A hipermídia foi considerada a melhor opção para a organização de material, de qualquer tipo, na $W e b$.

\footnotetext{
${ }^{1}$ Área de pesquisa da Ciência da Computação dedicada a buscar métodos ou dispositivos computacionais que possuam ou simulem a capacidade humana de resolver problemas, pensar ou, de forma ampla, ser inteligente (WIKIPÉDIA, 2011).

${ }^{2}$ Junção de hipertexto e multimídia (vídeo, som etc.) (BRUsiLOvsky, 2001).
} 
Os sistemas que fizeram uso da hipermídia para fornecer conteúdo foram chamados de Sistemas Hipermídia (SHs). Inúmeros destes sistemas foram utilizados para prover instrução. Entretanto, nestes sistemas, as características dos alunos não eram consideradas, o conteúdo apresentado por eles era sempre estático.

Para contornar este problema inúmeras pesquisas, que tiveram como base a experiência já obtida pelos STIs, foram realizadas, no sentido de permitir a adaptação do conteúdo e da navegação em SHs. Elas resultaram em uma classe de métodos e técnicas chamada de Hipermídia Adaptativa. Os sistemas que fizeram uso desta classe foram chamados de Sistemas Hipermídia Adaptativos (SHAs).

Deste modo, os SHAs são sistemas híbridos que surgiram da integração entre os STIs e os SHs para fins educacionais (BRUSILOVSKY, 2000). Estes sistemas fornecem um ambiente dinâmico, com maior liberdade ao usuário e adaptado às suas características e necessidades. A educação continua sendo uma importante área de pesquisa dos SHAs, entretanto, eles têm sido utilizados em inúmeras outras áreas, para diversos fins.

Um setor que vem recebendo grande destaque atualmente e que foi muito beneficiado pela forte expansão da Web é a Educação à Distância (EAD), que tem como objetivo principal o desenvolvimento de ambientes e de metodologias que propiciem o aprendizado à distância, onde um ou mais estudantes possam vivenciar experiências de aprendizagem em tempo e/ou locais fisicamente diferentes do qual o professor, o ambiente e os recursos instrucionais se encontram (SILVA, 2005).

Além desta separação de tempo e espaço, a EAD também se caracteriza pela comunicação não contínua entre o aluno e o professor. Nela, em geral, o controle do ritmo de estudo é definido pelo aluno; deste modo, o sucesso do aluno também depende da sua motivação e das suas condições de estudo.

Inúmeros dos sistemas citados (STIs, SHs e SHAs) fazem uso da Web para aplicar a EAD. A $W e b$ fornece um ambiente altamente propício para esta modalidade de ensino, visto que ela proporciona a flexibilização do acesso à informação (o acesso pode ser feito a qualquer hora e local), facilidades para a atualização e manutenção dos materiais publicados, troca de experiências (colaboração) entre os alunos e o acesso a diversos recursos multimídia e ferramentas de pesquisa e comunicação.

Este trabalho investiga os SHAs. Mais especificamente, é dado ênfase aos SHAs com conteúdo instrucional, também conhecidos por Sistemas Hipermídia Adaptativo Educacionais (SHAEs), utilizados para o ensino à distância através da Web. 


\subsection{Objetivos}

Como visto, a evolução da Tecnologia da Informação contribuiu para a viabilização de novas formas de ensino. A incorporação de novas tecnologias e metodologias impulsionaram setores como a EAD.

\subsubsection{Objetivo Geral}

Diante da importância adquirida pela EAD, este trabalho tem como objetivo global e abrangente apoiar professores e alunos na melhoria dos processos de aprendizagem nesta modalidade de ensino.

\subsubsection{Objetivos Específicos}

Dentre os objetivos específicos (concretos) que se deseja alcançar com este trabalho, destacam-se:

- Desenvolver um ambiente $W e b$ de ensino à distância que viabilize a oferta de cursos com conteúdo personalizado (adaptado) aos alunos, através do uso de técnicas de Hipermídia Adaptativa e Inteligência Computacional para fornecer adaptação e representar as características dos alunos;

- Melhorar os níveis de aprendizado (retenção de conhecimento) dos alunos;

- Melhorar os níveis de satisfação dos alunos.

\subsection{Justificativa}

O uso de meios eletrônicos ofereceu inúmeras novas possibilidades à educação. O eletronic-learning ou e-learning gerou uma indústria que movimentou cerca de 31 bilhões de dólares em 2010. O setor está em forte expansão, com perspectivas de crescimento anuais para os próximos cinco anos acima de $9 \%$, o que resultaria em um setor avaliado em cerca de 50 bilhões de dólares em 2015 (ADKINS, 2011).

O e-learning é naturalmente apropriado para aplicações de EAD. Inúmeras destas aplicações fazem uso de meios eletrônicos, como a $W e b$ e outras mídias digitais, para ensinar. 
Impulsionada pela expansão do e-learning, a EAD tem crescido mundialmente. No Brasil, este crescimento é evidenciado nos Censos da Educação Superior ${ }^{3}$ realizados em 2008 e 2009 pelo Instituto Nacional de Estudos e Pesquisas Educacionais Anísio Teixeira (INEP). A Tabela 1.1 apresenta os números obtidos por estes censos para a EAD no Brasil, considerando apenas os cursos de graduação entre os anos de 2007 e 2009. Pode-se observar que o número de cursos oferecidos e de alunos matriculados nesta modalidade de ensino mais que dobrou neste período.

\begin{tabular}{cccc}
\hline Característica & $\mathbf{2 0 0 7}$ & $\mathbf{2 0 0 8}$ & $\mathbf{2 0 0 9}$ \\
\hline Cursos de graduação em EAD oferecidos & 408 & 647 & 844 \\
Alunos matriculados em cursos de EAD & 369.766 & 727.961 & 838.125 \\
\hline
\end{tabular}

Tabela 1.1: Números da EAD referentes à graduação no Brasil.

De acordo com o CensoEAD.BR 2010 , publicado pela Associação Brasileira de Educação a Distância, mais de 2,6 milhões de brasileiros se valeram da EAD em 2008 e o e-learning é o segundo tipo de mídia mais utilizado pelos cursos a distância, sendo utilizado em 71,5\% das instituições de ensino que possuem EAD. A mídia mais utilizada continua sendo o material impresso, utilizado por 87,3\% destas instituições.

Este relatório ainda aponta que as tecnologias baseadas na $W e b$ são as mais utilizadas e preferidas pelas instituições que fazem uso de mídias virtuais em EAD. Em média, 93,4\% destas instituições fazem uso da Web em EAD de forma assíncrona (sem a troca de informações ao vivo) e 85,3\% a usam de forma síncrona.

Como pôde ser observado, o aprendizado através da Web ou aprendizado on-line, ou ainda educação baseada na $W e b$, se tornou uma importante vertente na obtenção de conhecimento. Ela fornece conteúdo digital através das redes de computadores, sem a limitação de tempo ou espaço e com independência de sala de aula e plataforma.

Uma grande quantidade de cursos e aplicações com fins educacionais que fazem uso da $W e b$ tem sido disponibilizada, agregando milhares de alunos, que se utilizam deste meio para a obtenção de suas formações acadêmicas ou profissionais. Estas aplicações, além da EAD, também podem ser utilizadas pelos professores como auxílio às suas aulas.

Na educação baseada na $W e b$, os cursos, em sua maioria, são disponibilizados através de Sistemas de Gerenciamento de Conteúdo. Estes sistemas, em geral, auxiliam na organização e controle das atividades programadas nos cursos. Entretanto, eles não auxiliam

\footnotetext{
${ }^{3}$ Disponíveis em: http://portal.inep.gov.br/web/censo-da-educacao-superior

${ }^{4}$ Disponível em: http://www.abed.org.br
} 
o professor na preparação ou escolha do conteúdo mais adequado a ser apresentado ao aluno. Neles, geralmente, os cursos possuem conteúdo estático, ou seja, as páginas em hipermídia são apresentadas aos alunos sempre com o mesmo conteúdo e ordenação.

Entretanto, em e-learning, e consequentemente na educação baseada na $W e b$, determinado curso pode ser acessado por milhares de alunos em todo o mundo, possuidores de diferentes culturas, estilos de aprendizagem, necessidades, habilidades, interesses, anseios e formações acadêmicas.

Portanto, a diversidade de características dos alunos é um aspecto central em elearning. Além disso, como nos sistemas de e-learning geralmente é o aluno quem toma a iniciativa de aprender, existe a necessidade de se fornecer conteúdos que contemplem esta diversidade. A criação de conteúdos hipermídia que consideram as características individuais dos alunos se tornou uma tarefa crítica (LEUNG; LI, 2006).

Diante disto, torna-se evidente a necessidade de se desenvolver aplicações em que os cursos se adaptem dinamicamente às características dos alunos. A metodologia "um curso para todos" utilizada pelos sistemas tradicionais não é mais apropriada em e-learning. A diversidade de características dos alunos demanda por conteúdo personalizado (LEUNG; LI, 2007).

A utilização de técnicas de Hipermídia Adaptativa e Inteligência Computacional em aplicações educacionais possibilita tais melhorias, pois elas são capazes de considerar as experiências, o conhecimento prévio, as habilidades e as demais características dos alunos que sejam relevantes para a melhoria do processo de aprendizagem.

Nos ambientes que fazem uso destas técnicas, tidos como "inteligentes", o acesso ao curso de forma mais adequada permite melhor aprendizado e experiência por parte dos alunos.

Segundo Brusilovsky e Millán (2007), não existe dúvida de que na modelagem do usuário (alunos, no contexto deste trabalho) muitas vezes é preciso lidar com informações que são incertas (quando não se tem certeza de que a informação obtida é totalmente verdadeira) ou imprecisas (os valores obtidos não estão completamente definidos). Técnicas de Inteligência Computacional como as Redes Bayesianas e Lógica Fuzzy permitem o tratamento das incertezas ou imprecisões que são inerentes aos usuários. Entretanto, ainda segundo estes autores, poucos sistemas na área da Hipermídia Adaptativa fazem uso de técnicas que permitem a representação das incertezas relacionadas aos alunos.

Deste modo, ambientes hipermídia que modelam as características do aluno de modo 
a representar as incertezas nelas presentes ainda é um tópico em aberto e que merece ser explorado.

\subsection{Problema}

Diante da grande diversidade de características dos alunos que fazem uso de aplicações de e-learning, este trabalho aborda o seguinte problema:

- Em um ambiente $W e b$ de ensino à distância, como prover cursos com conteúdo voltado às características individuais dos alunos?

\subsection{Hipóteses}

Diante do problema levantado, propõe-se alterar o ambiente $W e b$ da seguinte forma: acrescentar a ele as principais características de um SHA, utilizar uma Rede Bayesiana na modelagem das incertezas relacionadas às características do aluno e, para o ajuste deste modelo criado, utilizar um modelo matemático da Teoria da Resposta ao Item. Como resultado destas alterações, espera-se que o ambiente propicie a oferta de cursos com conteúdo personalizado aos alunos, proporcionando melhoria na retenção de conhecimento dos mesmos (hipótese básica).

Como consequência do conteúdo apropriado apresentado, espera-se também obter uma melhoria nos níveis de satisfação dos alunos em relação aos cursos oferecidos (hipótese secundária).

\subsection{Visão Geral dos Capítulos}

O Capítulo 2 apresenta a fundamentação teórica necessária para a o entendimento da metodologia proposta neste trabalho. São abordados os aspectos relevantes referentes à técnica de Inteligência Computacional utilizada, as Redes Bayesianas, assim como as principais características dos Sistemas Hipermídia Adaptativos e da Teoria da Resposta ao Item.

O Capítulo 3 se dedica à apresentação do SHA para fins educacionais, provido de mecanismos de adaptação (personalização), proposto neste trabalho. São apresentados os principais módulos que o compõem, sendo dado ênfase ao modelo utilizado para a 
representação das características do aluno, que possui como principal aspecto a capacidade de lidar com incertezas.

O Capítulo 4 apresenta o experimento que foi realizado e os resultados obtidos. Destaca-se os detalhes de implementação do sistema proposto e do curso que foi criado para a investigação deste sistema. Para que um estudo comparativo fosse realizado, também foi criado um sistema desprovido de mecanismos de adaptação. A análise e interpretação dos dados coletados permitiu a verificação da influência obtida pelos mecanismos de adaptação propostos.

O Capítulo 5 se dedica às conclusões obtidas pelo presente trabalho. São feitas algumas considerações finais, com destaque para as principais contribuições obtidas e alguns aspectos que podem ser melhorados em trabalhos futuros. 


\section{Embasamento Teórico}

Este capítulo apresenta as teorias que formam a base do sistema proposto por este trabalho (Capítulo 3). Inicialmente são apresentados alguns fundamentos das teorias da probabilidade e dos grafos que são empregados no contexto das Redes Bayesianas. O restante deste capítulo se dedica à apresentação das três principais teorias empregadas: as Redes Bayesianas, a Teoria da Resposta ao Item e os Sistemas Hipermídia Adaptativos.

\subsection{Fundamentos da Teoria da Probabilidade}

Frequentemente, são observadas situações em que a ocorrência de determinada alternativa, dentre as inúmeras existentes, é incerta. Para cada uma destas possíveis alternativas é atribuído um grau de "certeza" (representada através de uma probabilidade) e se decide, então, qual ação será realizada. Por exemplo, avaliar se vai chover hoje e quais serão os números sorteados na loteria desta semana.

A Teoria da Probabilidade teve início no século XVII através dos trabalhos dos matemáticos franceses Blaise Pascal e Pierre de Fermat. Porém, foi somente em 1933 que o matemático russo Andrei Kolmogorov desenvolveu os axiomas que definem esta teoria (KORB; NICHOLSON, 2004).

Esta seção foi desenvolvida tendo como base os trabalhos de Jensen e Nielsen (2007) e Luna (2004).

\subsubsection{Experimento Aleatório, Espaço Amostral e Evento}

Um experimento é um ensaio científico para a verificação de um fenômeno, e para isso, é necessária a adoção de um modelo matemático (determinístico ou probabilístico) que melhor o explique.

Um experimento que conduz sempre aos mesmos resultados, quando mantidas as 
mesmas condições, é chamado de experimento determinístico. Esta classe de experimentos utiliza o modelo matemático determinístico para representá-los.

A impossibilidade de predizer antecipadamente e com certeza os resultados de um experimento em sucessivas repetições, sempre sob as mesmas condições, caracteriza este experimento como aleatório (MINAYO; SANCHES, 1993). Para esta classe de experimentos se adota um modelo matemático probabilístico, definido pela Teoria da Probabilidade. Esta classe de experimentos é o objeto de estudo da Estatística.

Um experimento aleatório pode ser repetido indefinidamente sob condições inalteradas. Embora se possa definir o conjunto de todos os possíveis resultados, cada resultado individual parece ocorrer de forma acidental. Com a repetição em larga escala surge uma regularidade que permite construir um modelo matemático para analisar o experimento. Por exemplo, as proporções de caras e coroas após se lançar uma moeda honesta um grande números de vezes, são aproximadamente iguais (LUNA, 2004).

Em um experimento aleatório, o conjunto de todos os resultados possíveis é chamado de espaço amostral, denotado por $S$. Um evento é um subconjunto dos resultados possíveis de um experimento. O espaço amostral é em si um evento, também. Se $S$ é um espaço amostral e $A \subseteq S$ então $A$ é um evento de $S$. Por exemplo, considere o experimento em que se quer observar o número da face de cima ao se lançar um dado honesto; neste caso, o espaço amostral seria $S=\{1,2,3,4,5,6\}$ e um possível evento seria $A=\{3\}$.

Para que as regras da Teoria da Probabilidade sejam aplicadas, é necessário que os eventos do espaço amostral tenham as seguintes características: sejam mutuamente exclusivos, garantindo que no máximo um evento pode ocorrer a cada instante, e que o conjunto de todos os eventos possíveis seja exaustivo, ou seja, pelo menos um deles deve ocorrer.

\subsubsection{Perspectivas sobre probabilidade}

Existem diferentes interpretações filosóficas sobre o conceito de probabilidade, o que induz a diversas perspectivas e gera um amplo debate sobre qual delas se sobressai.

A perspectiva objetivista ou clássica afirma que as probabilidades são aspectos reais do universo, tendências de objetos a se comportarem de determinadas maneiras. Dado um experimento uniforme (em que todos os eventos são equiprováveis), com espaço amostral $S$, define-se a probabilidade de ocorrer um evento $A$, contido em $S$, como sendo a razão entre o número de elementos do evento $A, n_{A}$, e o número de elementos de $S, n_{S}$. Apesar 
de bastante intuitiva esta perspectiva apresenta sérias limitações, como a dificuldade de determinação, em muitos casos, dos eventos favoráveis $\left(n_{A}\right)$ e possíveis $\left(n_{S}\right)$ e, caso alguns dos eventos não sejam equiprováveis, esta perspectiva não pode ser aplicada.

A perspectiva frequentista tenta superar as limitações do modelo objetivista, nela, a distribuição de probabilidades para os eventos $A$ do espaço amostral $S$ pode ser obtida da seguinte forma:

$$
P(A)=\lim _{n \rightarrow \infty} \frac{n_{A}}{n},
$$

em que $n_{A}$ é o número de ocorrências do evento $A$ e $n$ é o número de repetições do experimento.

No contexto frequentista, as probabilidades só podem ser obtidas através de experimentos, e estes, devem ser passíveis de repetição. Do ponto de vista matemático, essa definição de probabilidade apresenta dificuldades, pois um número limite real pode não existir na realidade.

A perspectiva subjetivista interpreta a probabilidade de um evento como o grau de crença (certeza) de um agente na veracidade deste evento (aspecto pessoal); diferentemente do modelo frequentista, que assinala valores para as probabilidades baseado na frequência de ocorrência dos eventos em determinado experimento (aspecto físico). $\mathrm{O}$ agente utiliza suas experiências e conhecimento sobre o assunto para expressar a probabilidade de um sucesso, o que possibilita diferentes medidas de probabilidade para um mesmo sucesso.

\subsubsection{Axiomas da Probabilidade}

Para medir o grau de incerteza sobre um experimento é atribuída uma probabilidade $P(A)$ para cada evento $A \subseteq S$. Em virtude dos problemas apresentados pelas definições objetivista e frequentista foi desenvolvida a abordagem axiomática de probabilidade, em que ela é vista como um conceito abstrato (assim como a reta e o ponto o são na geometria) orientado pelo seguintes axiomas:

Axioma $1 P(S)=1$.

Axioma 2 Para todo $A \subseteq S, P(A) \geq 0$.

Axioma 3 Se $A \subseteq S, B \subseteq S$ e $A \cap B=\emptyset$, então $P(A \cup B)=P(A)+P(B)$. 
Muitas propriedades importantes podem ser extraídas dos axiomas acima, por exemplo:

- Se $A \subseteq B \subseteq S$, então $P(A) \leq P(B)$;

- Se $A \subseteq S, B \subseteq S$ e $A \cap B \neq \emptyset$ então $P(A \cup B)=P(A)+P(B)-P(A \cap B)$;

- Se $A \subseteq S$, então $0 \leq P(A) \leq 1$.

\subsubsection{Probabilidade Incondicional e Probabilidade Condicional}

A probabilidade incondicional ou a priori de um evento $A, P(A)$, é o grau de crença definido para $A$ na ausência de quaisquer outras informações. A partir do momento em que novas informações relevantes para o evento $A$ são obtidas, faz-se o uso da probabilidade condicional.

A probabilidade condicional ou a posteriori, $P(A \mid B)=p$, pode ser expressa por sentenças do tipo: "dado o evento $B$, a probabilidade do evento $A$ é $p$ ".

Deve-se ficar claro que $P(A \mid B)=p$ não significa que sempre que $B$ for verdadeiro, a probabilidade de $A$ será $p$. Ela apenas afirma que se $B$ for verdadeiro e todo o resto for irrelevante para $A$ (ou tudo o que se sabe é $B$ ), então, a probabilidade de $A$ será $p$ (JENSEN; NIELSEN, 2007).

Para dois eventos $A$ e $B$, com $P(B) \geq 0$, a probabilidade condicional de $A$ dado $B$ é:

$$
P(A \mid B)=\frac{P(A \cap B)}{P(B)} .
$$

Por exemplo, a probabilidade condicional de o lançamento de um dado honesto obter o número quatro, dado que ele retornou um número par é:

$$
P(A=\{4\} \mid B=\{2,4,6\})=\frac{P(\{4\})}{P(\{2,4,6\})}=\frac{1 / 6}{3 / 6}=\frac{1}{3} .
$$

A Equação 2.1.1 pode ser reescrita, obtendo-se a chamada regra do produto:

$$
P(A \cap B)=P(A \mid B) P(B) .
$$

Quando condicionada a outro evento $C$, a regra do produto pode ser escrita como $P(A \cap B \mid C)=P(A \mid B \cap C) P(B \mid C)$. 
Visto que $P(A \cap B)=P(B \cap A)$, obtém-se $P(A \mid B) P(B)=P(B \mid A) P(A)$ da regra do produto. Deste resultado obtém-se a regra de Bayes:

$$
P(A \mid B)=\frac{P(B \mid A) P(A)}{P(B)} .
$$

Esta regra provê um método para atualizar a crença sobre o evento $A$ dado que foi obtida alguma informação sobre outro evento $B$. A probabilidade $P(B \mid A)$ é chamada de verossimilhança de $A$ dado $B$. Maiores detalhes sobre esta regra serão fornecidos na Seção 2.3.1.

\subsubsection{Independência Condicional}

Dois eventos $A$ e $B$ são independentes se:

$$
P(A \mid B)=P(A)
$$

dado que $P(B)>0$. Esta relação significa que o evento $B$ não é informativo para o evento $A$, conhecer $B$ não altera a probabilidade de $A$. Quando dois eventos são independentes, a regra do produto pode ser reescrita como $P(A \cap B)=P(A) P(B)$. O conceito de independência é simétrico, ou seja, se $A$ é independente de $B$, então $B$ é independente de $A$.

Se o evento $B$ não altera a probabilidade do evento $A$ dado que é conhecido o evento $C$, então, diz-se que $A$ e $B$ são condicionalmente independentes dado $C$. Esta relação expressa como $P(A \mid B \cap C)=P(A \mid C)$.

Quando $A$ e $B$ são condicionalmente independentes dado $C$ a regra do produto pode ser assim reescrita: $P(A \cap B \mid C)=P(A \mid C) P(B \mid C)$. O conceito de independência condicional também é simétrico, ou seja, se $A$ é condicionalmente independente de $B$ dado $C$, então $B$ é condicionalmente independente de $A$ dado $C$.

\subsubsection{Variáveis Aleatórias e Proposições}

As probabilidades são sempre aplicadas a proposições, que são afirmações de que tal situação está ocorrendo. Uma variável aleatória pode ser imaginada como algo que se refere a uma parte do mundo cujo o status é inicialmente desconhecido (RUSSELL; NORVIG, 2004).

Uma variável aleatória $X$ tem natureza funcional, $X: S \rightarrow S_{X}$. Ela associa a cada 
elemento do espaço amostral (domínio) $S$ um elemento de seu contradomínio, $S_{X} \subset \mathbb{R}$, em que $\mathbb{R}$ é o conjunto dos números reais. Cada elemento do espaço amostral de uma variável representa um estado que ela pode assumir.

Por exemplo, seja $E$ o experimento de lançar duas moedas honestas ( $H$ em caso de cara e $T$ em caso de coroa) e $X$ a variável aleatória que indica o número de caras obtido neste experimento. Neste caso, $S=\{H H, H T, T H, T T\}$ é o espaço amostral associado a $E$ e $S_{X}=\{0,1,2\}$ é o conjunto de possíveis valores de $X$, pois, tomando-se $X: S \rightarrow S_{X}$, tem-se que: $X(H H)=2, X(H T)=X(T H)=1$ e $X(T T)=0$. As probabilidades do experimento são definidas através do contradomínio de $\mathrm{X}: P(X=0)=P(T T)=$ $1 / 4, P(X=1)=P(H T$ ou $T H)=2 / 4$ e $P(X=2)=P(H H)=1 / 4$.

As variáveis aleatórias ampliam os simples conceitos de eventos e seus espaços amostrais, citados até agora. Por isto, elas serão adotadas de agora em diante. Assim como os eventos, os estados das variáveis devem ser mutuamente exclusivos e seu conjunto deve ser exaustivo. Por uma questão de simplicidade, a partir de agora, as variáveis aleatórias serão tratadas apenas como variáveis.

Uma variável pode ser discreta, em que o conjunto de valores de seu contradomínio é finito ou infinito enumerável; ou continua, em que o conjunto de valores de seu contradomínio é infinito não enumerável, como, por exemplo, um intervalo numérico qualquer.

\subsubsection{Distribuição Condicional, Conjunta e Marginalização}

Seja $X$ uma variável qualquer e $D_{X}$ o seu domínio. Os valores $P(X=x)$, para todas as instâncias $x$ em $D_{X}$, constituem a distribuição de probabilidade de $X$. Por exemplo, seja $X$ o resultado de lançar um dado não viciado, então $D_{X}=\{1,2,3,4,5,6\}$ é o domínio de $X$. A distribuição de probabilidade de $X$ é dada por $P(X=x)=1 / 6$, para todo $x \in D_{X}$.

Uma distribuição das probabilidades condicionais que envolve duas ou mais variáveis é chamada de distribuição condicional. Se uma variável $A$ possui $n$ estados e a variável $B$ possui $m$ estados, então a relação $P(A \mid B)$ possui $n \times m$ probabilidades condicionais $P\left(A=a_{i} \mid B=b_{j}\right)$, que compõem a distribuição condicional de $A$ dado $B$. A Tabela 2.1 exibe um possível exemplo de distribuição condicional $P(A \mid B)$.

Como $P(A \mid B)$ representa a distribuição condicional de probabilidade para cada estado $B=b_{j}$, pelo Axioma 1 , as probabilidades dos estados de $A$ devem somar um para cada estado de $B$. 


\begin{tabular}{|l|ccc|}
\hline & $b_{1}$ & $b_{2}$ & $b_{3}$ \\
\hline$a_{1}$ & 0,4 & 0,3 & 0,6 \\
$a_{2}$ & 0,6 & 0,7 & 0,4 \\
\hline
\end{tabular}

Tabela 2.1: Distribuição condicional $P(A \mid B)$ em que as variáveis $A$ e $B$ possuem, respectivamente, 2 e 3 estados.

A probabilidade de se observar resultados conjuntos para diferentes experimentos pode ser expressa pela distribuição conjunta de duas ou mais variáveis. Considerando as variáveis $A$ e $B$, definidas anteriormente, sua distribuição conjunta de probabilidade, $P(A, B)$, também possui $n \times m$ probabilidades. $P(A, B)$ especifica a probabilidade de se observar $A$ e $B$. Como os estados de $A$ e $B$ são mutuamente exclusivos e seus conjuntos exaustivos, a combinação dos estados de $A$ e $B$ também formam estados mutuamente exclusivos e um conjunto exaustivo. Logo, essa combinação também pode ser considerada um espaço amostral e, pelo Axioma 1, o somatório de seus estados deve ser um. A Tabela 2.2 exibe um exemplo de distribuição conjunta $P(A, B)$.

\begin{tabular}{|l|ccc|}
\hline & $b_{1}$ & $b_{2}$ & $b_{3}$ \\
\hline$a_{1}$ & 0,16 & 0,12 & 0,12 \\
$a_{2}$ & 0,24 & 0,28 & 0,08 \\
\hline
\end{tabular}

Tabela 2.2: Distribuição conjunta $P(A, B)$, obtida através da Tabela 2.1, aplicando a regra do produto nas probabilidades condicionais e adotando $P(B)=\{0,4,0,4,0,2\}$.

A regra do produto pode ser generalizada para se obter a fórmula da regra da cadeia, nesta, dado que $X=\left\{X_{1}, X_{2}, \ldots, X_{n}\right\}$, a distribuição conjunta de $\mathrm{X}$ é dada por:

$$
P\left(X_{1}, X_{2}, \ldots, X_{n}\right)=\prod_{i=1}^{n} P\left(X_{i} \mid X_{1}, \ldots, X_{i-1}\right) .
$$

Da distribuição conjunta de probabilidade $P(A, B)$, a $P(A)$ pode ser calculada considerando os estados de $B$ que ocorrem junto com cada estado $a_{i}$ de A:

$$
P\left(a_{i}\right)=\sum_{j=1}^{m} P\left(a_{i}, b_{j}\right) .
$$

Este cálculo é chamado marginalização, diz-se que a variável $B$ é marginalizada para fora de $P(A, B)$, o que resulta na probabilidade $P(A)$. A notação é:

$$
P(A)=\sum_{B} P(A, B)
$$


Ao se marginalizar B para fora da Tabela 2.2, obtém-se:

$$
P(A)=(0,16+0,12+0,12,0,24+0,28+0,08)=(0,4,0,6) .
$$

\subsection{Grafos}

Esta seção apresenta os conceitos sobre grafos que serão utilizados no decorrer deste trabalho. Ela foi desenvolvida com base nos trabalhos de Bondy e Murty (2008) e Diestel (2005). Os conceitos que serão apresentados fazem parte da Teoria dos Grafos.

Um grafo é uma representação das relações existentes entre elementos (objetos), ele pode ser representado graficamente e é composto por vértices (nós) que são ligados por arestas. Portanto, os nós representam os objetos e as arestas as relações existentes entre eles. Cada aresta é composta por um par de nós. Matematicamente, um grafo é representado por $G=(V, E)$, em que $V$ é o conjunto de vértices e $E$ o conjunto de arestas.

Quando o sentido (orientação) das ligações não é considerado, como considerado no parágrafo anterior, o grafo é chamado de não orientado ou não direcionado. Quando o sentido dessas ligações é considerado, o grafo é denominado de orientado, direcionado ou digrafo. Nos grafos orientados, as arestas são comumente chamadas de arcos. A Figura 2.1 apresenta um grafo não orientado e outro orientado.

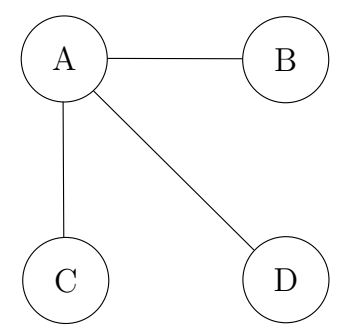

Grafo Não Orientado

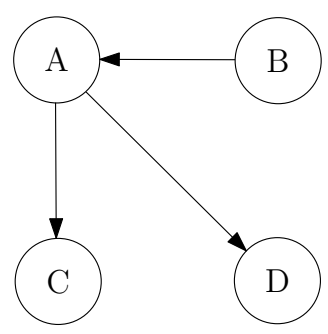

Grafo Orientado

Figura 2.1: Apesar de ambos os grafos possuírem as mesmas conexões entre os vértices, eles não representam o mesmo grafo.

Em um grafo orientado, a relação pai/filho ou antecessor/sucessor ocorre quando existe um arco $(X, Y)$, de $X$ para $Y$; neste caso, $X$ é chamado de nó pai (antecessor) de $Y$ e $Y$ é chamado de nó filho (sucessor) de $X$. A família de $X$ é o conjunto composto por $X$ e os seus pais. No grafo orientado da Figura 2.1, o nó $A$ é pai dos nós $C$ e $D$, que por sua vez, são filhos de $A$. A família de $A$ é composta por ele mesmo e por $B$.

Diz-se que $X$ é um vértice adjacente ou vizinho de um vértice $Y$ se eles estão ligados por pelo menos um arco ou uma aresta. Em outras palavras, se $G$ é um grafo orientado, 
então $X$ é um vizinho de $Y$ se, e somente se, $X$ é pai ou filho de $Y$; se $G$ é um grafo não orientado, então $X$ é um vizinho de $Y$ se, e somente se, existe a aresta $(X, Y)$.

Um caminho é uma sequência de nós distintos em que cada nó sucessor está conectado ao nó anterior por uma aresta. Nos grafos orientados, um caminho recebe uma orientação (motivo pelo qual é chamado de caminho orientado), ou seja, neste caminho os nós estão ligados por arcos, que são direcionados do nó anterior para o nó sucessor.

A relação ancestral/descendente estende a relação pai/filho da seguinte forma: um nó $Y$ é chamado de descendente do nó $X$ e $X$ é chamado de ancestral de $Y$ se existe um caminho direcionado de $X$ para $Y$.

Um ciclo é um caminho fechado (que começa e termina no mesmo nó). Nos grafos orientados, um ciclo orientado é um caminho orientado fechado. Um grafo é acíclico se não contém ciclos, um grafo orientado é acíclico se não contém ciclos orientados, esta última classe de grafos geralmente é chamada de Grafos Acíclicos Orientados (GAOs). A Figura 2.2 exemplifica alguns destes conceitos.

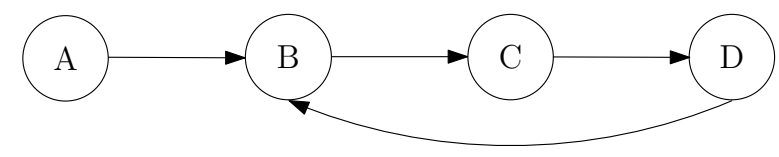

Figura 2.2: A sequência de nós $A-B-C-D$ é um caminho orientado. A sequência $B-C-D-B$ é um ciclo orientado.

Um grafo é conexo se existe pelo menos um caminho que liga cada par de vértices desse grafo, caso contrário, ele é chamado de desconexo. Um digrafo é conexo se ao se desconsiderar a orientação dos arcos, ou seja, transformá-los em arestas, obtém-se um grafo conexo. O grafo da Figura 2.2 é conexo.

Uma árvore é um grafo conexo sem ciclos, em que cada par de vértices está ligado por apenas um caminho, também chamado de caminho único. Uma árvore que possui $n$ vértices, possui $n-1$ arestas. Muitas vezes é conveniente definir um nó da árvore como especial, este nó recebe o nome de raiz. Os nós, à exceção do nó raiz, que possuem apenas um vizinho são chamados de nós folha.

Uma árvore também pode ser orientada. Neste caso, o nó raiz, caso exista, apresenta uma característica especial: todos os outros nós da árvore estão ligados a ele por um único caminho direcionado.

Uma floresta é um grafo cujos componentes conexos são árvores. Os grafos da Figura 2.1 são exemplos de árvores, um exemplo de floresta é mostrado na Figura 2.3. 


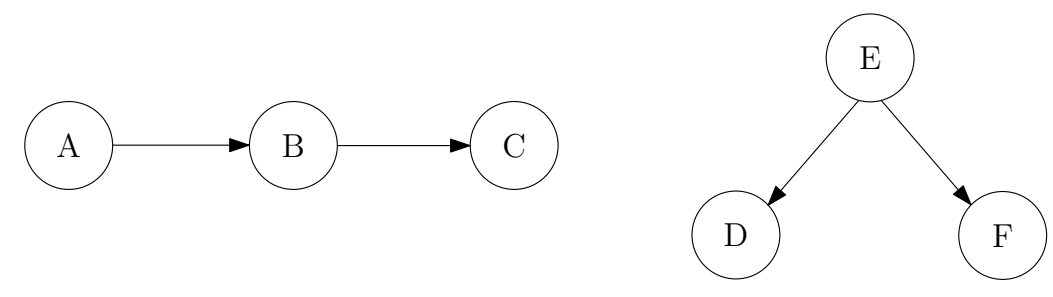

Figura 2.3: O grafo acima, que contém os nós $A, B, \ldots, F$, é uma floresta.

\subsection{Redes Bayesianas}

As Redes Bayesianas (RBs), também conhecidas por redes de crenças, redes causais ou redes probabilísticas, são modelos gráficos para raciocínio (inferência) baseado na incerteza, em que os nós representam as variáveis e os arcos as relações diretas entre eles (KORB; NICHOLSON, 2004). Os modelos gráficos são a união entre as teorias da probabilidade e dos grafos, resultando em uma poderosa ferramenta para o tratamento de problemas como incerteza e complexidade (KOSKI; NOBLE, 2009).

As RBs fornecem uma descrição completa do domínio que representam e apresentam de forma direta e estruturada as dependências entre as variáveis. Elas levam este nome porque trabalham com conhecimento incerto e incompleto, tratado inicialmente por meio da Teoria da Probabilidade Bayesiana, publicada por Thomas Bayes em 1763. Esta teoria provê um modelo matemático para raciocínio através do uso de probabilidades.

As RBs surgiram na década de 80 e logo se tornaram populares, sendo aplicadas nos mais diversos domínios, como: saúde (diagnóstico, localização de genes), indústria (controle de autômatos ou robôs), computação e redes (agentes inteligentes), finanças (análise financeira), gestão (tomadas de decisões e gestão do conhecimento e riscos) e mineração de dados (LUNA, 2004).

Por sua natureza de representação da incerteza e do conhecimento incompleto, as RBs estão fortemente associadas à perspectiva subjetivista de probabilidade. Por este motivo, neste trabalho, ao se falar de probabilidade, ela estará associada a esta perspectiva.

\subsubsection{Regra de Bayes}

A regra de Bayes ou fórmula da inversão é a base do raciocínio Bayesiano. Esta regra foi apresentada na Seção 2.1.4, mas terá seus conceitos estendidos nesta seção. A regra de Bayes possui a seguinte fórmula: 


$$
P(H \mid e)=\frac{P(e \mid H) P(H)}{P(e)} .
$$

Esta regra provê um método para atualizar a crença sobre a hipótese $H$ dado que foi obtida a evidência (nova informação sobre o estado de determinada variável) e. $P(H)$ é a probabilidade a priori de $H$, ela reflete o conhecimento anterior à evidência ser considerada, a determinação desta probabilidade geralmente é um dos aspectos mais subjetivos da Teoria da Probabilidade Bayesiana. A probabilidade $P(e \mid H)$ é chamada de verossimilhança (likelihood) e avalia a probabilidade da evidência ser obtida da hipótese. $P(e)$ é uma constante de normalização que é obtida pela soma das probabilidades $P(e \mid H) P(H)$ para todas as hipóteses contidas em $H$, ela faz com que a soma das probabilidades condicionais destas hipóteses seja igual a um. $P(H \mid e)$ é a probabilidade a posteriori, ela reflete a probabilidade da hipótese após a consideração da evidência.

Outra forma de se observar a fórmula da inversão é que ela representa conhecimento, ou seja, a transformação do conhecimento a priori em a posteriori reflete o que se conheceu sobre a veracidade das hipóteses através da consideração da evidência.

A fórmula da inversão também pode ser expressa em termos proporcionais, desconsiderandose a constante de normalização $P(e)$, resultando na seguinte equação:

$$
P(H \mid e) \propto P(e \mid H) P(H),
$$

que pode ser assim expressa: Posteriori $\propto$ Verossimilhana $\times$ Priori

\subsubsection{Definições e Exemplo}

Segundo Jensen e Nielsen (2007) uma RB consiste de:

- Um conjunto de variáveis e um conjunto de arcos que ligam estas variáveis;

- Cada variável possui um conjunto finito de estados mutuamente exclusivos;

- As variáveis juntamente com os arcos formam um GAO;

- Para cada variável $A$ com pais $B_{1}, \ldots, B_{n}$ existe uma Tabela de Probabilidades Condicionais (TPC) denotada por $P\left(A \mid B_{1}, \ldots, B_{n}\right)$. Se $A$ não possui pais, então a tabela é reduzida a uma tabela de probabilidades a priori $P(A)$.

Considere o GAO $G=(V, E)$, em que $V$ é o conjunto de variáveis e $E$ o conjunto de arcos, e seja $P$ a distribuição conjunta de probabilidade das variáveis de $V$. O conjunto 
$G$ e $P$, ou simplesmente $(G, P)$, satisfaz a condição de Markov se para cada $X \in V, X$ é condicionalmente independente de todos os seus não descendentes dado o conjunto de todos os seus pais. Uma RB é um $(G, P)$ que satisfaz a condição de Markov (NEAPOLITAN, 2004).

Considere o seguinte exemplo, retirado de Pearl (1988) e Russell e Norvig (2004): um novo sistema de segurança foi instalado em uma residência. O sistema é bastante confiável na detecção de um roubo, mas também responde ocasionalmente a pequenos terremotos. O dono da casa possui dois vizinhos, João e Maria, que se comprometeram a ligar caso ouvissem o alarme. João sempre liga quando ouve o alarme, mas às vezes se confunde com o som do telefone da residência e também liga. Maria gosta de ouvir música em alto volume e às vezes se esquece completamente do alarme. A RB para este exemplo está apresentada na Figura 2.4.

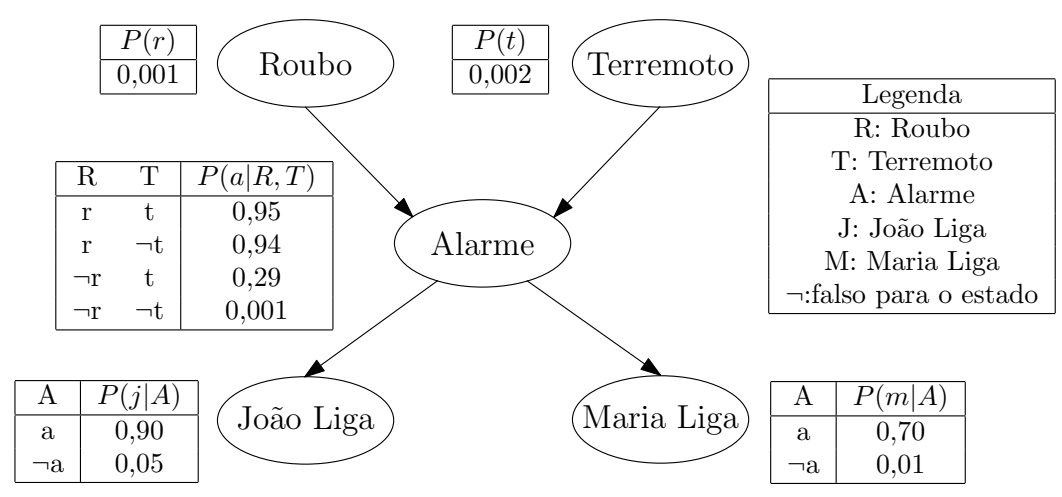

Figura 2.4: RB típica, mostrando sua topologia e TPCs. Como as variáveis são booleanas, se a probabilidade para o estado verdadeiro é $p$, então, a probabilidade para o estado falso é $1-p$. Por este motivo, este segundo número foi omitido.

A topologia da RB do exemplo apresentado diz muito sobre o que foi considerado em termos de dependência entre as variáveis do problema. Ela mostra, por exemplo, que roubos e terremotos afetam diretamente a probabilidade do alarme soar, que foi assumido que tanto Maria quanto João não percebem os roubos diretamente e que eles não se comunicam antes de ligar. A condição de Markov garante, por exemplo, que João Liga é independente de Roubo, Terremoto e Maria Liga, dado o valor de Alarme.

As probabilidades tentam sumarizar uma infinita gama de possibilidades para os eventos relacionados (do exemplo apresentado, as probabilidades consideram o fato de João e Maria não ligarem para informar que o alarme disparou por estarem de férias ou terem saído para almoçar). De outra forma, a representação se tornaria muito complexa ou mesmo inviável. Sendo assim, é possível enfrentar problemas complexos, pelo menos aproximadamente (MATURANA, 2009). 


\subsubsection{Tipos de Raciocínio}

As RBs proveem representações completas de distribuições de probabilidade sobre suas variáveis. Isto implica que estas redes podem estar condicionadas a qualquer subconjunto de suas variáveis, suportando qualquer direção de raciocínio (KORB; NICHOLSON, 2004). As RBs apresentam três tipos básicos de raciocínio (que podem ser combinados, de acordo com a necessidade), são eles:

- Predição (ou causa) - dadas as causas, deseja-se obter as probabilidades dos efeitos. Por exemplo, da Figura 2.4 deseja-se obter P(João Liga|Roubo);

- Diagnóstico - dados os efeitos, deseja-se obter as probabilidades das causas. Este raciocínio geralmente ocorre no sentido contrário aos arcos da rede. Por exemplo, da Figura 2.4, deseja-se obter P(Roubo|João Liga);

- Intercausal - este tipo de raciocínio ocorre entre causas que possuem um mesmo efeito. Neste caso, pode-se desejar determinar o efeito dado uma ou todas as suas causas, pode-se desejar determinar uma ou todas as causas dado o efeito e também, pode-se desejar determinar alguma causa dado o efeito e uma ou todas as outras causas. Por exemplo, da Figura 2.4 deseja-se obter P(Alarme|Roubo), $P($ Roubo|Alarme $)$, ou $P($ Roubo|Alarme, Terremoto $)$.

\subsubsection{Representação do Domínio}

Da definição de Neapolitan (2004) para RB apresentada na Seção 2.3.2, observa-se que esta possui uma distribuição conjunta de probabilidade associada a ela. Segundo Russell e Norvig (2004), uma distribuição conjunta de probabilidade total, que envolve todas as variáveis do domínio, pode responder a qualquer pergunta sobre este domínio, mas pode se tornar intratável na medida em que o número de variáveis cresce.

As RBs representam de forma sucinta qualquer distribuição conjunta de probabilidade. Como já foi dito, tanto o $\mathrm{GAO} G=(V, E)$ de uma RB quanto a distribuição conjunta de probabilidade das variáveis em $V, P$, devem satisfazer a condição de Markov. Desta forma, $P$ é igual ao produto das distribuições condicionais de todos os nós dados os valores dos seus pais, caso existam. Assim, a regra da cadeia (Equação 2.1.4) para uma RB pode ser assim definida:

$$
P(V)=P\left(X_{1}, X_{2}, \ldots, X_{n}\right)=\prod_{i=1}^{n} P\left(X_{i} \mid \operatorname{pais}\left(X_{i}\right)\right)
$$


em que pais $\left(X_{i}\right)$ é o conjunto das variáveis que são pais de $X_{i}$.

Da Equação (2.3.1) pode-se concluir que as TPCs fornecem uma representação decomposta da distribuição conjunta de probabilidade total.

Do exemplo da Figura 2.4, pode-se calcular a probabilidade do alarme ter tocado e de João e Maria terem ligado, mas sem ter ocorrido roubo nem terremoto:

$$
\begin{aligned}
P(j, m, a, \neg r, \neg t) & =P(j \mid a) P(m \mid a) P(a \mid \neg r, \neg t) P(\neg r) P(\neg t) \\
& =0,9 \times 0,7 \times 0,001 \times 0,999 \times 0,998=0,00062 .
\end{aligned}
$$

A quantidade de números (probabilidades) necessária para se preencher as TPCs de uma RB geralmente cresce linearmente com a quantidade de variáveis (nós), enquanto que na distribuição conjunta esta quantidade cresce exponencialmente. Por exemplo, se uma rede possui 10 variáveis booleanas em que cada uma possui 3 variáveis pais; então, a RB exigirá $10 \times 2^{3}=80$ números, enquanto que a distribuição conjunta total exigirá $2^{10}=1024$ números.

A complexidade de uma rede depende do grau de detalhamento que se deseja obter. Determinado detalhamento pode trazer dificuldades para a determinação das probabilidades necessárias ao preenchimento das TPCs. Por isto, deve-se ponderar entre os ganhos obtidos com o detalhamento e os custos necessários para se obter as informações necessárias a este incremento (MATURANA, 2009).

\subsubsection{D-Separação}

A condição de Markov para as RBs garante independência condicional de um vértice da rede em relação aos seus não descendentes dado o conjunto dos seus pais. Entretanto, essa condição garante também outras independências condicionais além daquelas baseadas nos pais de um nó. Para isso, o conceito de d-separação ("d" de grafo direcionado) em um GAO se faz necessário. Para o entendimento deste conceito é necessário antes o conhecimento dos tipos de conexões que podem existir em uma rede. Estes tipos estão apresentados na Figura 2.5.

As conexões (a) e (b) da Figura 2.5 produzem a seguinte relação de independência condicional: $P(C \mid A, B)=P(C \mid B)$; ou seja, $C$ e $A$ são independentes dado $B$. A conexão (c) produz uma relação oposta às obtidas pelas conexões (a) e (b). Nela, o nós $A$ e $C$ são independentes, mas eles se tornam dependentes dado alguma informação (evidência) 


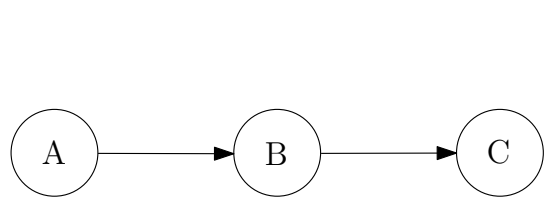

(a)

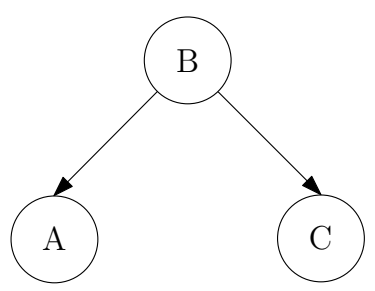

(b)

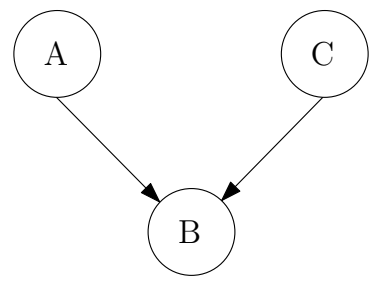

(c)

Figura 2.5: (a) conexão serial ou causal; (b) conexão divergente ou de causa comum; (c) conexão convergente ou de efeito comum.

sobre $B$, ou seja, $A$ e $C$ são condicionalmente dependentes dado $B$.

Segundo Korb e Nicholson (2004), nas conexões do tipo (a) e (b) o conhecimento do valor de $B$ bloqueia qualquer informação de $C$ relevante para $A$ ou vice-e-versa e nas conexões do tipo (c) a ausência de informação sobre $B$ bloqueia qualquer informação de $C$ relevante para $A$, enquanto que conhecer $B$ ativa a relação entre $C$ e $A$.

Vistos os tipos de conexões, considere agora um GAO $G$ cujo conjunto de vértices é $V$, $A \subseteq V, X$ e $Y$ nós distintos pertencentes a $V$ e não contidos em $A$. Diz-se que um caminho qualquer (desconsiderando os direcionamentos dos arcos) entre $X$ e $Y$ é bloqueado por $A$ se alguma das afirmações seguintes for verdadeira:

- Existe um nó $Z \in A$ no caminho de forma que a conexão entre $X$ e $Y$ através de $Z$ é serial;

- Existe um nó $Z \in A$ no caminho de forma que a conexão entre $X$ e $Y$ através de $Z$ é divergente;

- Existe um nó $Z$ no caminho, em que $Z$ e todos seus descendentes não estão em $A$, de forma que a conexão entre $X$ e $Y$ através de $Z$ é convergente.

Considere novamente o GAO $G$ cujo conjunto de vértices é $V, A \subseteq V, X$ e $Y$ nós distintos pertencentes a $V$ e não contidos em $A$. Diz-se que $X$ e $Y$ são d-separados por $A$ se todo caminho (desconsiderando os direcionamentos dos arcos) entre $X$ e $Y$ está bloqueado por $A$. 


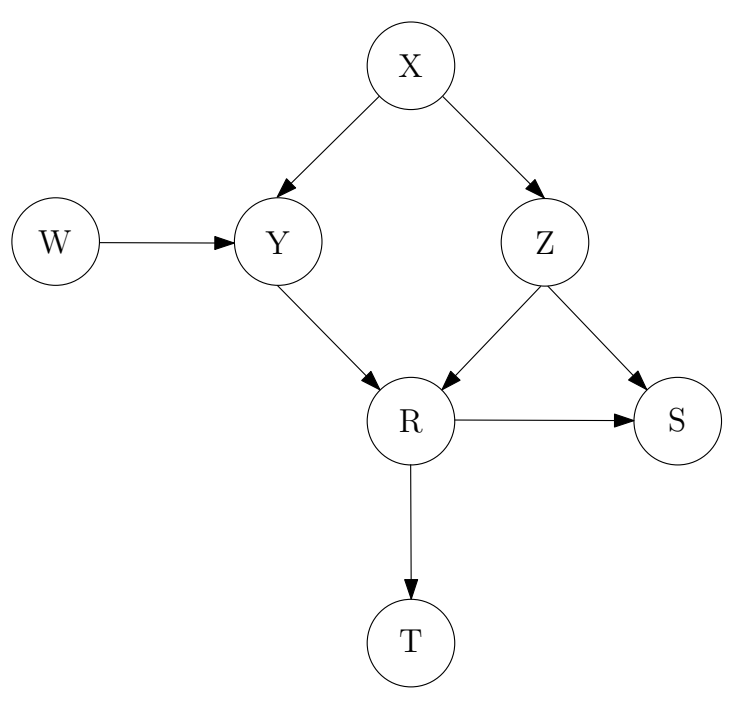

Figura 2.6: GAO, retirado de Neapolitan (2004), para a análise das d-separações.

Da Figura 2.6 pode-se verificar algumas d-separações, como:

- $X$ e $R$ estão d-separados por $A=\{Y, Z\}$ porque o caminho $X-Y-R$ está bloqueado por $Y$ e o caminho $X-Z-R$ está bloqueado por $Z$;

- $W$ e $S$ estão d-separados por $A=\{R, Z\}$ porque o caminho $W-Y-R-S$ está bloqueado por $R$ e os caminhos $W-Y-R-Z-S$ e $W-Y-X-Z-S$ estão ambos bloqueados por Z;

- $W$ e $S$ também estão d-separados por $A=\{Y, Z\}$ porque o caminho $W-Y-R-S$ está bloqueado por $Y$, o caminho $W-Y-R-Z-S$ está bloqueado por $Y, R$ e $Z$, e o caminho $W-Y-X-Z-S$ está bloqueado por $Z$;

- $W$ e $S$ também estão d-separados por $A=\{Y, X\}$;

- $W$ e $X$ não estão d-separados por $A=\{Y\}$ porque o caminho $W-Y-X$ não está bloqueado por $Y$ pois $Y \in A$ e ele não pode ser bloqueado em nenhum outro local;

- $W$ e $T$ não estão d-separados por $A=\{Y\}$ porque, apesar do caminho $W-Y-R-T$ estar bloqueado por $Y$, o caminho $W-Y-X-Z-R-T$ não está bloqueado por $Y$ pois $Y \in A$ e este caminho não está bloqueado em nenhum outro local porque não existem outros nós em A e não existe outra conexão convergente nele.

O conceito de d-separação também pode ser estendido para conjuntos de nós. Seja o GAO $G$ cujo o conjunto de vértices é $V$ e $A, B$ e $C$ subconjuntos de $V$ que não apresentam 
nós em comum. Então, $A$ e $B$ são d-separados por $C$ se para cada $X \in A$ e $Y \in B, X$ e $Y$ são d-separados por $C$.

Seja uma RB representada por $(G, P)$, a condição de Markov garante que se $X$ e $Y$ estão d-separados por $A$ no grafo $G$, então, $X$ e $Y$ são condicionalmente independentes em $P$ dado $A$. Além disso, toda independência condicional conferida pela condição de Markov é identificada por uma d-separação em $G$. Isto é, se $(G, P)$ satisfaz a condição de Markov, então, toda d-separação em $G$ é uma independência condicional em $P$.

Um nó $X$ é d-separado de todos os outros nós da rede quando é dada a sua cobertura de Markov (Markov blanket). A cobertura de Markov de determinado nó $X$ é o conjunto dos nós que são pais de $X$, filhos de $X$ e dos nós que são pais destes filhos. Da Figura 2.6, a cobertura de Markov do nó $Y$ é $\{W, X, R, Z\}$.

\subsubsection{Causalidade}

Geralmente, a estrutura de uma RB é criada refletindo as relações causais (de causa e efeito) existentes no domínio que ela representa. Desta forma, um arco de X para Y indica que X é uma causa direta de Y.

Estruturas que são criadas refletindo o modelo causal geralmente apresentam menor complexidade (menor número de arcos) o que, consequentemente, torna a manutenção destas redes mais fácil (RUSSELL; NORVIG, 2004; KORB; NICHOLSON, 2004).

GAOs que são criados de forma causal geralmente satisfazem a condição de Markov com relação à distribuição conjunta de probabilidade das variáreis, ou seja, RBs podem ser construídas através de GAOs causais (NEAPOLITAN, 2004).

Entretanto, a estrutura de uma RB não precisa refletir necessariamente relações de causa e efeito. Neste caso, deve-se conferir as propriedades de d-separação do modelo e garantir que elas correspondam às percepções de independência condicional do domínio. $\mathrm{O}$ modelo não deve incluir independências condicionais que não existem no domínio (JENSEN; NIELSEN, 2007).

\subsubsection{Vantagens}

Dentre os motivos para o uso das RBs estão: permitem expressar as assertivas de independência de forma visual e fácil de perceber; representam e armazenam uma distribuição conjunta de forma econômica, explorando as relações de independência entre as 
variáveis; e tornam o processo de inferência (Seção 2.3.8) computacionalmente eficiente (SILVA; LADEIRA, 2002).

Segundo Naïm et al. (apud LUNA, 2004), as seguintes características das RBs as fazem preferíveis sobre outros métodos:

- Aquisição de conhecimento - a capacidade de mesclar conhecimentos de diversas naturezas no mesmo modelo, como dados históricos ou empíricos, experiência (expressa na forma de regras lógicas, equações, estatísticas ou probabilidades subjetivas) e observações;

- Representação do conhecimento - a representação gráfica de uma RB é explicita, intuitiva e compreensível para uma pessoa não especialista, o que facilita a validação do modelo, suas eventuais evoluções e sobretudo a sua utilização;

- Utilização de conhecimento - uma RB é multifuncional, o mesmo modelo pode ser utilizado para avaliação, predição, diagnóstico ou otimização das decisões;

- Quantidade e qualidade dos programas disponíveis - existem inúmeras aplicações que permitem a criação, inferência e análise das RBs. Estas ferramentas permitem, por exemplo, a aprendizagem das probabilidades e da estrutura da rede a partir de dados e a possibilidade de integrar variáveis contínuas ao modelo.

\subsubsection{Inferência}

A tarefa básica de qualquer sistema de inferência probabilística é calcular a distribuição de probabilidade a posteriori para um conjunto de variáveis (variáveis de consulta), dados valores que foram atribuídos a outro conjunto de variáveis (variáveis de evidência) devido a algum evento que foi observado. Desta forma, o sistema calcula probabilidades do tipo P(Consulta|Evidência) (RUSSELL; NORVIG, 2004). As RBs apresentam alta flexibilidade, nelas, cada nó pode ser utilizado como "consulta" ou "evidência".

O processo de inferência permite a atualização das crenças da rede à luz de novas evidências (QUEIROZ, 2008).

Como já foi mencionado, uma evidência sobre determinada variável é uma nova informação sobre o seu estado, esta variável que recebeu evidência pode ser chamada de evidenciada ou instanciada. Nesta seção serão consideradas variáveis do tipo discretas. 
A seguir é apresentado um simples exemplo, retirado de Queiroz (2008), de como o processo de inferência pode ser utilizado.

Considere a RB da Figura 2.7, com os dados fornecidos, deseja-se obter a distribuição de probabilidade da variável $Z$, dado que a variável $Y$ recebeu evidência e se encontra no estado $y_{1}$, ou seja, deseja-se calcular $P\left(Z \mid Y=y_{1}\right)$.

\begin{tabular}{|c|c|c|c|c|c|c|}
\hline $\mathrm{X}$ & $P(X)$ & & & & $\mathrm{Y}$ & $P(Y)$ \\
\hline$x_{1}$ & 0,6 & & X & & $y_{1}$ & 0,1 \\
\hline$x_{2}$ & 0,4 & & & & $y_{2}$ & 0,9 \\
\hline & $\mathrm{X}$ & $\bar{Y}$ & $P\left(z_{1} \mid X, Y\right)$ & $P\left(z_{2} \mid X, Y\right)$ & $P\left(z_{3} \mid X\right.$ & $, Y)$ \\
\hline & $\begin{array}{ll}x_{1} & y\end{array}$ & & 0,32 & 0,46 & 0,2 & \\
\hline & & $y_{2}$ & 0,60 & 0,24 & 0,1 & \\
\hline & $x_{2} \quad y$ & 11 & 0,54 & 0,18 & 0,2 & \\
\hline & $x_{2} \quad y$ & $y_{2}$ & 0,08 & 0,77 & 0,1 & \\
\hline
\end{tabular}

Figura 2.7: RB em que os nós $X$ e $Y$ possuem dois estados cada, e o nó $Z$ possui três estados.

Desenvolvendo $P\left(Z \mid Y=y_{1}\right)$, obtém-se:

$$
\begin{aligned}
P(Z \mid Y) & =\frac{P(Z, Y)}{P(Y)}=\frac{\sum_{X} P(V)}{\sum_{X} \sum_{Z} P(V)} \\
= & \frac{\sum_{X} \prod_{i=1}^{n} P\left(B_{i} \mid \text { pais }\left(B_{i}\right)\right)}{\sum_{X} \sum_{Z} \prod_{i=1}^{n} P\left(B_{i} \mid \text { pais }\left(B_{i}\right)\right)},
\end{aligned}
$$

em que $V=\{X, Y, Z\}, B \in V$ e $n$ é o número de variáveis em $V$.

A primeira igualdade se deve à regra de Bayes, a segunda à marginalização das variáveis e a terceira à regra da cadeia para as RBs. Continuando o desenvolvimento, obtém-se a probabilidade para cada estado de $Z$ condicionado a $Y=y_{1}$ : 


$$
\begin{aligned}
P\left(Z=z_{1} \mid Y=y_{1}\right) & =\frac{P\left(z_{1}, y_{1}\right)}{P\left(y_{1}\right)}=\frac{\sum_{X} P\left(X, y_{1}, z_{1}\right)}{P\left(y_{1}\right)} \\
& =\frac{P\left(x_{1}, y_{1}, z_{1}\right)+P\left(x_{2}, y_{1}, z_{1}\right)}{P\left(y_{1}\right)} \\
& =\frac{P\left(x_{1}\right) P\left(y_{1}\right) P\left(z_{1} \mid x_{1}, y_{1}\right)}{P\left(y_{1}\right)}+\frac{P\left(x_{2}\right) P\left(y_{1}\right) P\left(z_{1} \mid x_{2}, y_{1}\right)}{P\left(y_{1}\right)} \\
& =\frac{0,6 \times 0,1 \times 0,32}{0,1}+\frac{0,4 \times 0,1 \times 0,54}{0,1}=40,8 \% . \\
P\left(Z=z_{2} \mid Y=y_{1}\right) & =\frac{P\left(z_{2}, y_{1}\right)}{P\left(y_{1}\right)}=\frac{X}{P\left(y_{1}\right)} \\
& =\frac{P\left(x_{1}, y_{1}, z_{2}\right)+P\left(x_{2}, y_{1}, z_{2}\right)}{P\left(y_{1}\right)} \\
& =\frac{P\left(x_{1}\right) P\left(y_{1}\right) P\left(z_{2} \mid x_{1}, y_{1}\right)}{P\left(y_{1}\right)}+\frac{P\left(x_{2}\right) P\left(y_{1}\right) P\left(z_{2} \mid x_{2}, y_{1}\right)}{P\left(y_{1}\right)} \\
& =\frac{0,6 \times 0,1 \times 0,46}{0,1}+\frac{0,4 \times 0,1 \times 0,18}{0,1}=34,8 \% .
\end{aligned}
$$

A probabilidade para o estado $x_{3}$ pode ser calculada em função dos outros dois estados, visto que eles devem somar $100 \%$ :

$$
P\left(Z=z_{3} \mid Y=y_{1}\right)=1-P\left(Z=z_{1} \mid Y=y_{1}\right)-P\left(Z=z_{2} \mid Y=y_{1}\right)=24,4 \% \text {. }
$$

O mecanismo para se obter um resultado a partir de evidências é chamado de propagação de evidências, inferência probabilística ou simplesmente propagação.

O exemplo acima mostrou que para os cálculos de inferência foram necessários o uso da regra de Bayes e das suposições de independência condicional representadas pela rede. Porém, poucas redes apresentam estruturas tão simples, o que geralmente leva a mecanismos de inferência mais complexos.

\subsubsection{Tipos de Evidência}

Existem três tipos de evidências que podem ser aplicados às RBs. A seguir, é feita uma breve descrição sobre eles, tendo como base o trabalho de Ding (2005).

- Evidência certa (hard evidence) - instancia um nó $X$ para determinado estado $x_{i}$, 
ou seja, $P\left(X=x_{i}\right)=1$ e $P\left(X=x_{j}\right)=0$, em que $x_{j}$ representa todos os estados de $X$ diferentes de $x_{i}$. Desta forma, existe a certeza de que o nó $X$ está no estado $x_{i}$;

- Evidência "soft" (soft evidence) - em vez de fornecer o estado específico em que o nó $X$ está, a evidência "soft" fornece uma distribuição de $X$ em seus estados. A evidência certa é, então, um tipo especial de evidência "soft". A incorporação pela rede desta nova distribuição é feita através do uso da regra de Jeffrey. Maiores detalhes sobre este tipo de evidência podem ser obtidos em Koski e Noble (2009) e Chan e Darwiche (2005);

- Evidência virtual (likelihood evidence) - neste tipo de evidência, foi observado o estado $x_{i}$ para o nó $X$, porém existe uma incerteza quanto a isto, sendo fornecida uma confiança a respeito desta observação na forma de uma distribuição condicional de probabilidade $P\left(x_{i} \mid X=x_{j}\right)$, em que $x_{j}$, neste caso, representa todos os estados de $\mathrm{X}$. Estas probabilidades (likelihoods) podem ser assim entendidas: a probabilidade de se observar $X$ no estado $x_{i}$ dado que o seu estado verdadeiro é $x_{j}$. Deve-se ressaltar que o somatório destas probabilidades condicionais não necessariamente precisa ser 100\%. Pearl $(1988,1990)$ apresenta um método para lidar com evidência virtual em RBs. Neste método é criado um nó virtual, que é acrescentado na rede como filho do nó $X$ e cujo único pai é o nó $X$. A TPC deste nó virtual é criada tendo como referência as probabilidades fornecidas como evidências.

\subsubsection{Inferência Exata}

Um método para a propagação de evidências é exato se as probabilidades dos nós são calculadas sem outros erros senão os de arredondamento e precisão (CASTILLO; GUTIÉRREZ; HADI, 1997). O exemplo da Seção 2.3 .8 fez uso de um método de inferência exato.

Existem dois outros tipos de métodos para a realização da propagação de evidências, que não serão expostos neste trabalho, são eles: o aproximado e o simbólico. Os algoritmos de propagação aproximada utilizam técnicas de simulação para obter valores aproximados para as probabilidades. Em geral, estes algoritmos são utilizados em casos em que os algoritmos exatos não são aplicáveis ou o seu custo computacional é grande. Os algoritmos de propagação simbólica podem operar tanto com parâmetros numéricos e simbólicos, obtendo probabilidades na forma simbólica, em função dos parâmetros (CASTILLO; GUTIÉRREZ; HADI, 1997). 
Um método de propagação exato eficiente e muito utilizado é a computação local. Este método utiliza as relações de independência condicional e a topologia da rede para a realização de cálculos locais, que envolvem uma quantidade reduzida de variáveis.

Segundo Mayo (2001), a computação local em uma RB é o processo de calcular a distribuição de probabilidade a posteriori de determinada variável tendo como base as distribuições a posteriori dos vizinhos desta variável, e apenas destes vizinhos. Desta forma, quando uma evidência chega em um nó, este atualiza suas crenças e envia mensagens a seus vizinhos, que também atualizam suas crenças e enviam mensagens a seus vizinhos. Este processo se repete até que a rede "absorva" a evidência.

Em geral, a propagação de evidências através de métodos exatos é NP-difícil (COOPER, 1990). Entretanto, existe uma classe de redes em que a inferência probabilística pode ser eficientemente realizada em tempo linear quanto ao número de nós. Esta classe é chamada de redes simplesmente conectadas ou poliárvores.

Numa poliárvore existe apenas um caminho não direcionado entre quaisquer pares de nós da rede, ou seja, a rede não apresenta ciclos não direcionados. Pearl (1988) apresentou um algoritmo para propagação de evidências em RBs cujas estruturas são poliárvores e que faz uso das suposições de computação local.

Entretanto, em geral, as RBs apresentam estruturas mais complexas, em que os pares de nós podem estar ligados por mais de um caminho não direcionado, estas redes são denominadas redes com múltiplas conexões, multiconectadas ou multiconexas. A Figura 2.8 ilustra os tipos de redes apresentados.

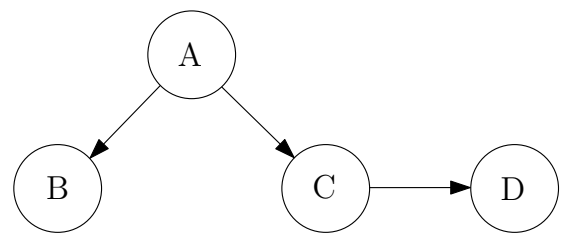

Poliárvore

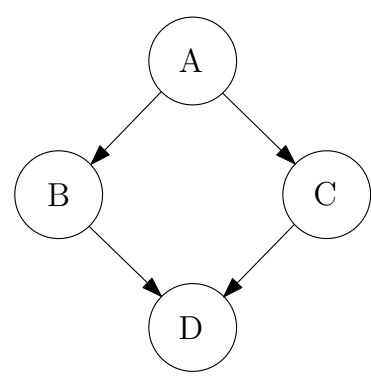

Rede Multiconectada

Figura 2.8: Simples exemplos de uma poliárvore e de uma rede multiconectada.

\subsubsection{Inferência em Redes com Múltiplas Conexões}

Nas redes com múltiplas conexões os algoritmos para propagação em poliárvores não podem ser aplicados, pois eles não preveem a possibilidade de um nó, ao receber evidências 
por dois caminhos diferentes, detectar se essas evidências se originaram de uma mesma fonte (evidência) e evitar, neste caso, de contá-la duas vezes.

Os algoritmos para propagação de evidências em redes multiconectadas geralmente fazem uso da seguinte estratégia: transformam uma rede multiconectada em uma poliárvore, sobre a qual pode ser aplicada os algoritmos para propagação em poliárvores, como o apresentado por Pearl (1988).

Entre os métodos mais comuns para propagação em redes multiconectadas estão os de condicionamento e de agrupamento. Os métodos de agrupamento têm se sobressaído e vêm recebendo grande destaque.

Os métodos de condicionamento modificam a conectividade de uma rede, transformandoa em múltiplas poliárvores, sobre as quais são aplicadas algum algoritmo de propagação em poliárvores. O resultado final é obtido ao se combinar os resultados obtidos em cada poliárvore (XIANG, 2002). Esta transformação em poliárvore é obtida através da seleção de um conjunto adequado de variáveis, de forma que quando instanciadas, elas eliminam ("cortarm") os múltiplos caminhos entre os nós. Estas variáveis formam o conjunto de corte. Nestes métodos, sua complexidade cresce exponencialmente em função do número de nós necessários para se quebrar os ciclos da rede (PEARL, 1988).

Os métodos de agrupamento se baseiam na construção de subconjuntos de nós, chamados de clusters ou agregados, que capturam as estruturas locais do modelo probabilístico associado ao grafo de determinada rede. Estes métodos calculam os agregados do grafo, realizam a conexão entre eles e depois obtém as probabilidades condicionais de cada agregado calculando de forma iterativa várias probabilidades locais. Nestes métodos, o processo de propagação de evidências pode ser realizado através do cálculo de probabilidades locais (que dependem de um número reduzido de variáveis), evitando o cálculo de probabilidades globais (que envolvem muitas variáveis). Por último, obtém-se a probabilidade de cada nó através do processo de marginalização em qualquer agregado que contenha esse nó. Nestes métodos, sua complexidade cresce exponencialmente em função do tamanho dos agregados (CASTILLO; GUTIÉRREZ; HADI, 1997).

A conexão entre os agregados resulta em uma poliárvore na qual as características de propagação em poliárvores podem ser utilizadas. Na próxima seção é apresentado um algoritmo de agrupamento que é amplamente utilizado. 


\subsubsection{Algoritmo de Árvore de Junção}

Baseado no método proposto por Lauritzen e Spiegelhalter (1988), Jensen, Lauritzen e Olesen (1990) propuseram um método geral para propagação de evidências em RBs chamado de algoritmo de Árvore de Junção. Segundo Jensen e Nielsen (2007), Korb e Nicholson (2004) e Neapolitan (2004), este método é um dos mais eficientes algoritmos para inferência exata. Ele é utilizado em diversas aplicações capazes de lidar com RBs, como o Hugin ${ }^{1}$ e o Netica ${ }^{2}$.

Este método transforma a estrutura da rede, criando uma uma estrutura intermediária, na forma de uma árvore com características especiais denominada Árvore de Junção, cujos nós são determinados por subconjuntos das variáveis da RB original. Nesta árvore os cálculos são realizados localmente (computação local), no sentido de que um nó necessite se comunicar somente com os seus vizinhos (LUNA, 2004).

Este trabalho não apresenta em detalhes o algoritmo de Árvore de Junção. Será apresentada uma visão geral do algoritmo e as suas principais características. Para um estudo mais aprofundado, os trabalhos de Huang e Darwiche (1996) e Ladeira, Vicari e Coelho (1999) podem ser consultados. Uma implementação deste algoritmo pode ser encontrada na framework UnBBayes $^{3}$.

Os principais passos para a criação de uma Árvore de Junção a partir de uma RB qualquer e para a realização de inferência nesta árvore são:

- Moralizar o GAO da RB - no qual são adicionadas arestas aos pais de cada nó do grafo que não possuem ligações. Após isto, remove-se a orientação dos arcos originais, resultando em um grafo não direcionado que é chamado de grafo moralizado;

- Triangulação do grafo moralizado - consiste em introduzir no grafo moralizado arestas entre nós não adjacentes em ciclos com mais de três nós. Estas arestas são denominadas cordas e o grafo resultante, grafo cordal ou triangular. A Figura 2.9 ilustra a obtenção de um grafo triangular;

- Identificação dos cliques a partir do grafo triangular - um clique em um grafo não direcionado é um subconjunto de vértices (subgrafo) desse grafo que é completo. O termo completo significa que cada par de nós distintos do clique esta conectado por

\footnotetext{
${ }^{1}$ http://www.hugin.com

${ }^{2}$ http://www.norsys.com

${ }^{3}$ Ferramenta de código-aberto para a modelagem e raciocínio em redes probabilísticas, disponível em http://unbbayes.sourceforge.net .
} 


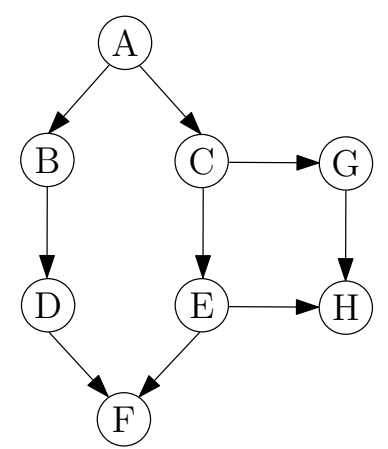

GAO da RB

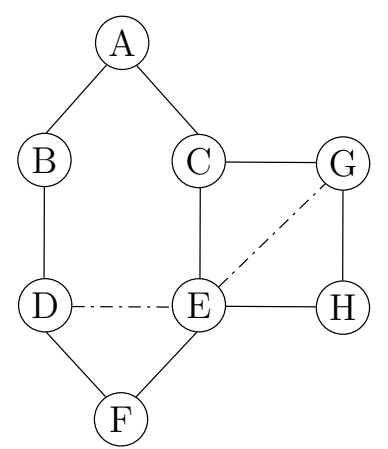

Grafo Moralizado

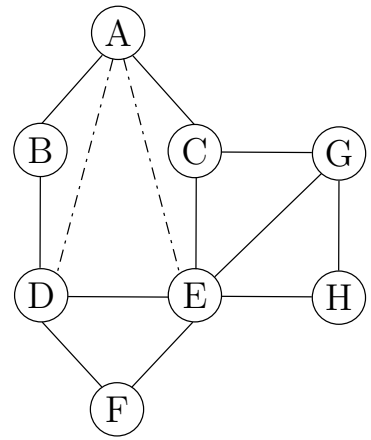

Grafo Triangular

Figura 2.9: Exemplo de transformação do GAO de uma RB em um grafo triangular, retirado de Huang e Darwiche (1996). As arestas acrescentadas pelos processos de moralização e triangulação estão indicadas em tracejado.

uma aresta. Os cliques selecionados para a criação da Árvore de Junção devem ser máximos. Um clique é máximo se ele não é subconjunto de outro clique;

- Construção da Árvore de Junção - nesta etapa, os cliques selecionados são utilizados como agregados. Eles são conectados de modo a formar uma árvore não direcionada. Existem diversos algoritmos para a construção de uma Árvore de Junção, merece destaque especial o algoritmo de Árvore de Junção Forte (JENSEN; JENSEN; DITTMER, 1994) que, em geral, apresenta melhor desempenho;

- Criação dos separadores - cada aresta da árvore criada tem associada a ela um separador, que consiste na intersecção dos nós adjacentes. Deste modo, um separador contém os nós que são comuns aos respectivos nós vizinhos;

- Cálculo das tabelas de potenciais - cada nó (clique) e separador da árvore criada possui uma tabela de potenciais de crenças, que representa uma tabela de probabilidades das variáveis que ele representa. O tamanho de uma tabela de potenciais é definido pelo produto dos estados presentes nas variáveis que compõem o respectivo clique ou separador. Inicialmente, estas tabelas são setadas com valores iguais a um. Logo após, cada variável da RB original é associada a um clique que contenha a sua família. Após esta associação, a tabela de potenciais de cada clique é multiplicada por $P(X \mid$ pais $(X))$, em que $X$ representa o conjunto das variáveis que foram associadas ao clique. Estas probabilidades estão definidas na RB;

- Propagação de mensagens - o último passo apresentado resulta em uma árvore inconsistente. Para que a consistência seja alcançada, realiza-se uma série ordenada de manuseios locais, chamados passagens de mensagens, que rearranjam as tabelas 
de potenciais dos cliques e separadores da árvore. A passagem de mensagens ocorre apenas entre nós que são vizinhos. Para esta passagem é selecionado um nó principal. Mensagens são envidadas por outros nós em sentido a este nó principal e, posteriormente, em sentido contrário a ele. Um nó só pode enviar mensagem a um vizinho apenas após ter recebido mensagens de todos os seus outros vizinhos. Deste modo, ao final da passagem de mensagens, por cada aresta da árvore terão passado duas mensagens, em sentidos diferentes;

- Marginalização - ao final do passo anterior obtém-se uma Árvore de Junção consistente, a partir da qual se calcula, através de marginalização (processo apresentado na Seção 2.1.7), $P(X)$ para qualquer variável $X$ de interesse;

- Inserção de evidências - considerando que existam evidências (sejam elas de qualquer tipo) a respeito de determinada variável, para que elas sejam consideradas, deve-se selecionar um clique qualquer da Árvore de Junção que contenha esta variável e multiplicar a sua tabela de potenciais pelas probabilidades obtidas como evidências. Ao final deste passo se obtém uma árvore inconsistente, sendo necessário realizar novamente a propagação de mensagens (conforme já apresentado), para uma correta marginalização da variável de interesse;

- Normalização - esta etapa é necessária apenas quando houver inserção de evidências na Árvore de Junção. Quando isto ocorre, o processo de marginalização de uma variável $X$ retorna a probabilidade conjunta $P(X$, evidência $)$. Entretanto, geralmente se está interessado em obter a probabilidade condicional $P(X \mid$ evidência $)$. O processo de normalização obtém esta probabilidade condicional dividindo $P(X$,evidência $)$ pela probabilidade da evidência na rede $P$ (evidência).

A Figura 2.10 ilustra uma Árvore de Junção que foi criada a partir do grafo triangular obtido no exemplo da Figura 2.9. Ela também apresenta a passagem de mensagens entre os cliques. É comum chamar o momento em que as mensagens estão sendo enviadas ao nó principal de "coleta evidência" e o momento em que elas estão sendo envidas em sentido contrário a este nó de "distribui evidência".

A criação da Árvore de Junção tem um grande custo, entretanto, esta criação precisa ser feita somente uma vez, a menos que a estrutura ou os parâmetros da RB sejam modificados. Quando a rede se torna muito grande ou altamente conectada, os cliques podem se tornar muito grandes, o que torna o algoritmo impraticável computacionalmente (KORB; NICHOLSON, 2004). 


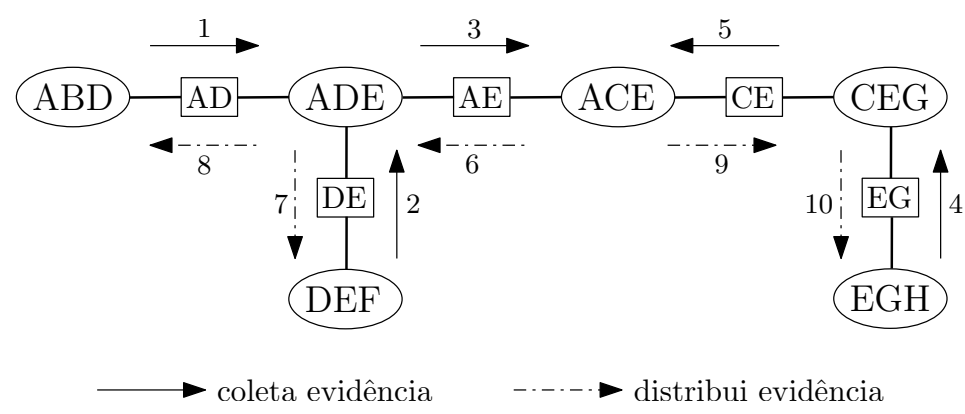

Figura 2.10: Árvore de Junção criada a partir do grafo triangular da Figura 2.9. Também está ilustrada a passagem de mensagens entre os cliques, em que o clique ACE foi escolhido como principal.

Uma Importante característica da Árvore de Junção, chamada de propriedade da Árvore de Junção ou simplesmente propriedade de junção, é que para cada par de agregados $\left(C_{i}, C_{k}\right)$, todos os agregados entre $C_{i}$ e $C_{k}$ contém $C_{i} \cap C_{k}$. Esta propriedade garante a consistência durante a passagem de mensagens entre os cliques.

Segundo Draper (1995), uma Árvore de Junção $T$ de um grafo $G$ é uma árvore cujos nós são agregados de $G$ e:

- Para cada nó $X$ de $G$, existem nós em $T$ que contêm a família de $X$;

- Para cada par de agregados a propriedade de Árvore de Junção é satisfeita;

- Cada aresta é rotulada com as variáveis comuns aos agregados presentes nela (separador).

Outra importante característica da Árvore de Junção é que ela representa a mesma distribuição conjunta de probabilidades das variáveis, $P(V)$, da RB da qual ela se originou. A $P(V)$ em uma Árvore de Junção é calculada como a razão entre o produto das tabelas de crenças dos agregados e o produto das tabelas de crenças dos separadores.

\subsection{Teoria da Resposta ao Item}

Esta seção foi desenvolvida tendo como base o trabalho de Andrade, Tavares e Valle $(2000)$.

Atualmente, uma das principais técnicas utilizada pela psicometria ${ }^{4}$ é a Teoria da Resposta ao Item (TRI) que, embora utilizada em diversas áreas, destaca-se especial-

\footnotetext{
${ }^{4}$ Conjunto de técnicas cujo objetivo é mensurar as habilidades cognitivas dos indivíduos expressas por meio do comportamento humano (SANTOS, 2009).
} 
mente em processos de avaliação educacional. Esta teoria é utilizada para analisar dados provenientes de respostas a itens presentes em instrumentos de avaliação de desempenho, questionários, entre outros (SANTOS, 2009).

A TRI, também chamada de Teoria dos Traços Latentes, propõe modelos para as habilidades (também referenciadas como proficiências ou traços latentes), ou seja, para características do indivíduo que não podem ser observadas diretamente. Esse tipo de variável deve ser inferida a partir da observação de variáveis secundárias que estejam relacionadas a ela. O que esta metodologia sugere são formas de representar a relação entre a probabilidade de um indivíduo dar uma certa resposta a um item e suas habilidades na área de conhecimento avaliada.

A TRI foi desenvolvida principalmente para suprir as limitações que apresentava a Teoria Clássica de Medidas (TCM), principal técnica utilizada pela psicometria até então. Outro nome usual para esta teoria é Teoria Clássica dos Testes. Na TCM, os resultados obtidos em testes ou questionários dependem do particular conjunto de itens (questões) que compõem o instrumento de medida, ou seja, as análises estão sempre associadas ao teste como um todo. Desta forma, torna-se inviável a comparação entre indivíduos que não foram submetidos aos mesmos testes. A TRI possui como elementos centrais os itens e não o teste como um todo, o que possibilita comparações entre as habilidades de indivíduos de populações diferentes quando são submetidos a testes que tenham alguns itens em comum. Ela permite, ainda, a comparação de indivíduos da mesma população submetidos a testes totalmente diferentes.

Os modelos propostos pela TRI geralmente são caracterizados pela da natureza dos seus itens, isto é, se eles são dicotômicos (corrigidos como certo ou errado) ou não dicotômicos (itens de resposta livre ou de múltipla escolha avaliados de forma graduada), pela quantidade de habilidades que estão sendo medidas (apenas uma ou mais de uma) e pelo número de populações envolvidas (apenas uma ou mais de uma).

Apesar de sua origem ter se dado no início do século passado, a TRI, nos moldes que se conhece hoje, foi apresentada por Lord (1952), que deu início ao desenvolvimento formal da teoria. Entretanto, a TRI passou a ser utilizada em larga escala apenas a partir da década de 80, devido à complexidade computacional dos algoritmos envolvidos.

Em seu trabalho, Lord apresentou o modelo unidimensional (que considera apenas uma habilidade) de 2 parâmetros para itens dicotômicos, baseado na distribuição normal acumulada (ogiva normal). Entretanto, o próprio Lord sentiu a necessidade da incorporação de um parâmetro que tratasse do problema do acerto casual ("chute"), desenvolvendo 
o modelo de 3 parâmetros. Birnbaum (1968) substituiu, em ambos os modelos de Lord, a função ogiva normal pela função logística, matematicamente mais conveniente, pois é uma função explícita da habilidade e dos parâmetros do item, além de não envolver a função de integração presente no modelo normal.

Na próxima seção é descrito em detalhes o modelo logístico de 3 parâmetros em que os itens são tratados de forma dicotômica, que avalia apenas um traço latente (modelo unidimensional) e que envolve uma única população. Este modelo é comumente chamado de Modelo Logístico de 3 Parâmetros (ML3P).

\subsubsection{Modelo Logístico de 3 Parâmetros}

No ML3P, a probabilidade de um indivíduo com traço latente $\theta_{j}$ responder corretamente o item $i$ é dada por:

$$
P_{j i}\left(\theta_{j}\right)=P\left(U_{j i}=1 \mid \theta_{j}\right)=c_{i}+\frac{\left(1-c_{i}\right)}{1+e^{-D a_{i}\left(\theta_{j}-b_{i}\right)}},
$$

em que:

- $i=1,2, \ldots, I$ representa os $I$ itens propostos para avaliar o traço latente;

- $j=1,2, \ldots, n$ representa os $n$ indivíduos que compõem a amostra;

- $U_{j i}$ é a variável dicotômica que assume o valor 1 quando o examinando $j$ responde corretamente o $i$-ésimo item ou 0 , caso contrário;

- $\theta_{j}$ representa a habilidade do $j$-ésimo indivíduo. $\theta_{j} \in(-\infty, \infty)$;

- $P\left(U_{j i}=1 \mid \theta_{j}\right)$ ou $P_{j i}\left(\theta_{j}\right)$ é a probabilidade de um indivíduo $j$ com habilidade $\theta_{j}$ responder corretamente o $i$-ésimo item;

- $a_{i}$ representa o parâmetro de discriminação (ou de inclinação) do i-ésimo item. $a_{i} \in[0, \infty)$

- $b_{i}$ representa o parâmetro de dificuldade (ou de posição) do $i$-ésimo item. $b_{i} \in$ $(-\infty, \infty)$

- $c_{i}$ representa a probabilidade de acerto casual ou ao acaso (ou "chute") do $i$-ésimo item. $c_{i} \in[0,1]$;

- $D$ é um fator de escala, constante e igual a 1. Utiliza-se o valor 1,7 quando se deseja que a função logística forneça resultados semelhantes ao da função ogiva normal. 
Os modelos da TRI geralmente apresentam o problema de falta de identificabilidade, que ocorre porque diferentes valores dos parâmetros dos itens ( $a, b$ e $c$ no ML3P) e da habilidade podem produzir a mesma probabilidade de um indivíduo responder corretamente um certo item. Esta não-identificabilidade do modelo está intimamente relacionada às características da população em estudo. Este problema pode ser eliminado através da especificação de uma medida de posição (como a média, por exemplo) e outra de dispersão (desvio-padrão, por exemplo) para as proficiências. Desta maneira, torna-se necessária a definição de uma escala (unidade de medida) para as proficiências e, consequentemente, os parâmetros dos itens também serão definidos nessa mesma métrica.

Como visto, na TRI a habilidade pode teoricamente assumir qualquer valor real entre $-\infty$ e $\infty$. Na prática, porém, é usual definir uma escala para a habilidade com $\mu=0$ e $\sigma^{2}=1$. Desta forma, espera-se que a habilidade apresente valores entre -3 e +3 e, consequentemente, que os valores de $b$ variem neste mesmo intervalo e que os valores de $a$ variem de $0 \mathrm{a}+3$. Embora a utilização desta métrica seja frequente, podem-se fazer transformações lineares de modo a apresentar os valores esperados em outra métrica qualquer.

\subsubsection{Interpretação e Representação Gráfica dos Parâmetros do ML3P}

Como mencionado, a probabilidade $P\left(U_{j i}=1 \mid \theta_{j}\right)$ pode ser entendida como a proporção de respostas corretas ao item $i$ dentre todos os indivíduos da população com habilidade $\theta_{j}$. A relação existente entre $P\left(U_{j i}=1 \mid \theta_{j}\right)$ e os parâmetros do item é expressa por uma curva, que é chamada de Curva Característica do Item (CCI). Um exemplo de CCI pode ser vista na Figura 2.11.

Da Figura 2.11, observa-se que:

- A CCI possui uma representação em forma de "S" (sigmoide);

- O modelo é acumulativo, ou seja, a probabilidade de um indivíduo dar ou escolher uma resposta correta ao item aumenta com o aumento do seu traço latente, apresentando um comportamento monotônico na CCI (ARAUJO; ANDRADE; BORTOLOTTI, 2009). Pode-se perceber também que esta relação é não-linear;

- O parâmetro $b$ representa o traço latente necessário para que a probabilidade de uma resposta correta ao item seja de $(1+c) / 2$. Desta forma, quanto maior o valor de $b$ mais difícil é o item, e vice-versa; 


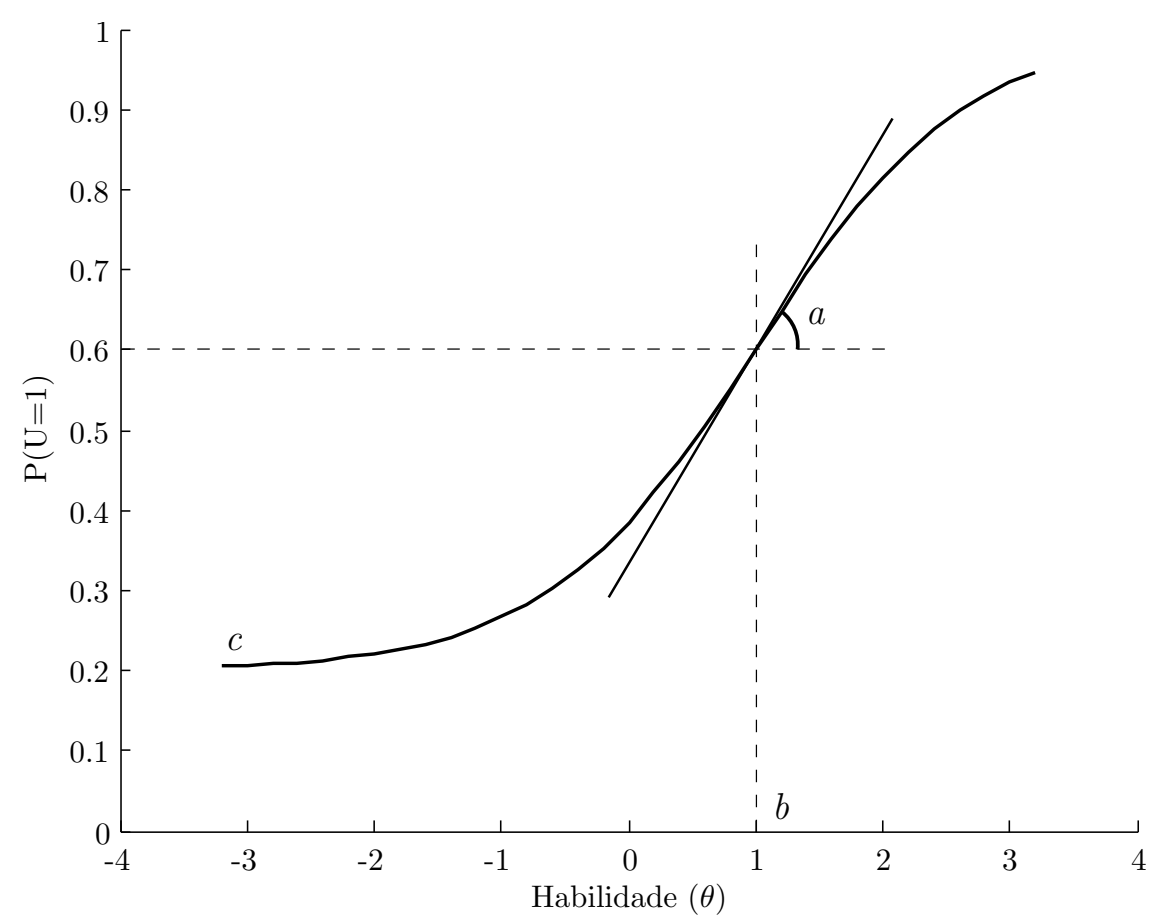

Figura 2.11: Exemplo de uma CCI, em que $c=0,2, a=1,2$ e $b=1$.

- O parâmetro $c$ representa a probabilidade de um indivíduo com baixa habilidade responder corretamente o item. A representação gráfica deste parâmetro é expressa pela assíntota inferior da CCI, ou seja, $\lim _{\theta \rightarrow-\infty} P\left(U_{j i}=1 \mid \theta, a, b\right)=c$. Se um item de múltipla escolha, por exemplo, é construído de tal forma que as alternativas incorretas (distratores) funcionem muito bem, ou seja, são bastante atrativas, mas sem chamar mais a atenção do que a resposta correta, provavelmente o valor do parâmetro $c$ estará em torno do inverso do número de alternativas do item (SANTOS, 2009). Valores para $c$ maiores do que 0,35 geralmente não são considerados aceitáveis (BAKER, 2001);

- O parâmetro $a$ é proporcional à derivada da tangente da curva no valor do ponto de inflexão ${ }^{5}$ (ponto com o valor do parâmetro $b$ ). Desta forma, itens com $a$ negativos não são esperados sob esse modelo, uma vez que indicariam que a probabilidade de responder corretamente o item diminui com o aumento da habilidade. Baixos valores de $a$ indicam que o item tem pouco poder de discriminação, ou seja, indivíduos com baixa ou alta habilidade terão probabilidades semelhantes de acertar o item. Valores muito altos para $a$ indicam itens com CCIs muito íngremes, que discriminam os alunos basicamente em dois grupos: os que possuem habilidades abaixo do valor de $b$ e os que possuem habilidades acima do valor de $b$. Segundo Baker (2001),

\footnotetext{
${ }^{5}$ Ponto em que a curva muda de concavidade.
} 
considerando o modelo logístico, itens cujos os valores de $a$ estão entre 0,01 e 0,34 são classificados como itens de discriminação muito baixa; entre 0,35 e 0,64, de baixa discriminação; entre 0,65 e 1,34, de discriminação moderada; entre 1,35 e 1,69, de discriminação alta; e maior que 1,70, de discriminação muito alta.

A probabilidade de um indivíduo responder corretamente a determinado item também pode ser expresso pelos modelos logísticos de 1 e 2 parâmetros (ML1P e ML2P, respectivamente). O modelo de 2 parâmetros pode ser obtido a partir do ML3P fixando-se $c=0$ para todos os itens, enquanto que o modelo de 1 parâmetro, também conhecido como modelo de Rasch, também pode ser obtido a partir do ML3P, fixando-se $c=0$ e $a=1$ para os itens.

\subsubsection{Unidimensionalidade e Independência Local}

O modelo apresentado, ML3P, faz uso de duas importantes suposições: unidimensionalidade e independência local.

A unidimensionalidade de um teste pressupõe que o conjunto de itens envolvidos deve medir apenas um único traço latente. De fato, geralmente o desempenho humano na execução de qualquer tarefa envolve mais de um traço latente; contudo, para satisfazer a suposição de unidimensionalidade, é suficiente admitir que existe apenas uma habilidade dominante responsável pelo conjunto de itens e que é esta habilidade que está sendo medida pelo teste.

A independência local ou independência condicional pressupõe que dada a habilidade dominante (também podem existir mais de uma habilidade dominante) as respostas aos diferentes itens da prova são independentes, ou seja, espera-se que a correlação entre essas respostas seja nula. Isto implica que o desempenho do indivíduo em um item não afeta o seu desempenho em outro item: cada item é respondido exclusivamente em função da sua habilidade dominante. A independência local também afirma que se houver correlação entre as respostas a diferentes itens ela se deve à influência das habilidades não dominantes e, se estas forem controladas (mantidas constantes), a habilidade dominante será a única fonte de variação e as respostas se tornam independentes (PASQUALI; PRIMI, 2003).

A independência local implica que a probabilidade para um determinado padrão de respostas de um indivíduo a um conjunto de itens é igual ao produto das probabilidades associadas à resposta do indivíduo para cada item. Ela é vista como consequência da correta determinação da dimensionalidade dos dados. A dimensionalidade consiste no nú- 
mero de fatores responsáveis para expressar o traço latente, ela pode ser verificada através da análise fatorial. A unidimensionalidade implica em independência local (HAMBLETON; SWAMINATHAN; ROGERS, 1991).

O pressuposto da independência local também é requerido nos outros modelos da TRI. Esta característica é de fundamental importância para o processo de estimação dos parâmetros do modelo (abordado na Seção 2.4.3).

\subsubsection{Invariância e Equalização}

Uma importante propriedade da TRI é a invariância dos itens e das habilidades; ela sustenta que os parâmetros dos itens não dependem da distribuição das habilidades dos indivíduos e que as habilidades dos indivíduos não dependem dos itens apresentados. Entretanto, os modelos de resposta ao item só podem ser considerados vantajosos quando o ajuste do modelo aos dados de interesse for satisfatório. Um modelo mal ajustado não fornecerá parâmetros invariantes para os itens e para as habilidades. A invariância possibilita a obtenção de um banco de itens, equalização, investigação da distorção (bias) do item e adaptação do teste ao que se propõe (HAMBLETON; SWAMINATHAN; ROGERS, 1991).

A equalização, mencionada no parágrafo anterior, é um conceito muito importante dentro da TRI. Ela permite colocar parâmetros de itens vindos de provas distintas ou habilidades de respondentes de diferentes populações na mesma métrica, isto é, numa escala comum, tornando os itens e/ou as habilidades comparáveis.

Existem dois tipos de equalização: na equalização via população, quando os indivíduos de uma mesma população são submetidos a testes distintos, os itens devem ser estimados conjuntamente para se ter a garantia de que todos estarão na mesma métrica; na equalização via itens comuns, provas com itens em comum são aplicadas a indivíduos de duas ou mais populações, sendo que estes itens servirão de ligação entre estas populações, garantindo que os seus parâmetros estarão em uma única escala.

\subsubsection{Estimação para uma única população}

Uma das etapas mais importantes da TRI e que faz parte do ajuste do modelo é a estimação dos parâmetros dos itens e das habilidades dos respondentes. O processo de estimação dos parâmetros também é chamado de calibração. 
O problema da estimação pode ser dividido em três situações: quando já se conhece os parâmetros dos itens, tendo que estimar apenas as habilidades dos respondentes; quando já se conhece as habilidades dos respondentes, sendo necessária a estimação apenas dos parâmetros dos itens; e a situação mais comum, quando as habilidades dos respondentes e os parâmetros são desconhecidos, sendo necessária a estimação conjunta de ambos.

Em qualquer uma das situações citadas acima, geralmente a estimação é feita pelo Método da Máxima Verossimilhança (MMV) através da aplicação de algum processo iterativo, como o algoritmo Newton-Raphson ou "Scoring" de Fisher, e por métodos Bayesianos.

Na situação em que é necessário estimar tanto os parâmetros dos itens quanto as habilidades dos respondentes, essa estimação inicialmente era feita através do Método da Máxima Verossimilhança Conjunta, que envolve um número muito grande de parâmetros a serem estimados simultaneamente e, consequentemente, apresentava grandes problemas computacionais. Em 1970, Bock \& Lieberman introduziram o Método da Máxima Verossimilhança Marginal, no qual a estimação é feita em duas etapas. Na primeira etapa estimam-se os parâmetros dos itens, assumindo-se uma certa distribuição para as habilidades. Na segunda etapa, assumindo os parâmetros dos itens conhecidos, estimam-se as habilidades dos respondentes.

Apesar do avanço que o Método da Máxima Verossimilhança Marginal trouxe, ele requeria que todos os parâmetros dos itens fossem estimados simultaneamente. Em 1981, Bock \& Aitkin propuseram uma modificação desse método, utilizando o algoritmo Expectation Maximization de Dempster, Laird \& Rubin, de modo a permitir que os itens pudessem ter seus parâmetros estimados em separado, o que facilitou em muito o aspecto computacional do processo de estimação. Em 1986, Mislevy propôs o Método de Estimação Bayesiana Marginal, que é uma generalização da proposta de Bock \& Aitkin.

Os métodos Bayesianos foram empregados na TRI com o propósito de contornar problemas apresentados pelos procedimentos de MMV, tais como: problemas de estimação dos parâmetros de itens respondidos corretamente ou incorretamente por todos os examinandos, problemas de estimação das habilidades de indivíduos que responderam corretamente ou incorretamente a todos os itens e a obtenção de estimativas fora do esperado, como valores para a negativos ou valores para $c$ fora do intervalo $[0,1]$.

Em termos gerais, a estimação Bayesiana consiste em estabelecer distribuições a priori convenientes para os parâmetros de interesse, construir uma nova função denominada distribuição a posteriori e estimar os parâmetros com base em alguma característica desta 
distribuição.

Segundo Valle (apud GUEWEHR, 2007), vários autores sugerem que obtêm-se estimativas para os parâmetros do modelo com erros-padrão pequenos quando o número de itens do teste é de pelo menos 30 e quando o número de respondentes para cada item é de pelo menos 300. Hambleton, Swaminathan e Rogers (1991) afirmam ainda que, para uma estimação satisfatória das habilidades dos indivíduos, os itens apresentados a eles devem ser compatíveis com seus níveis de habilidade e que, para uma estimação satisfatória dos parâmetros dos itens, é necessário que as distribuições de habilidades dos indivíduos sejam heterogêneas.

\subsubsection{Estimação das habilidades}

Entre os métodos mais utilizados para a estimação das habilidades estão o de Máxima Verossimilhança, Moda a Posteriori (MAP) e Média a Posteriori (EAP, do inglês Expected a Posteriori), sendo que estes dois últimos são métodos Bayesianos.

O MMV não existe para todos os padrões de resposta, enquanto que o MAP e o EAP geram estimativas para todos os padrões de repostas. Entretanto, o MAP apresenta estimativas que tendem mais à média do que as estimativas obtidas pelo EAP. Além disso, o MMV e o MAP são técnicas iterativas, enquanto o EAP não é iterativo e se baseia em métodos de quadratura numéricos, o que faz com que este método se torne potencialmente mais rápido. Observa-se também que o EAP produz erros quadráticos médios menores que os dois outros métodos (AYALA; SCHAFER; SAVA-BOLESTA, 1995).

Diante das vantagens apresentadas, a próxima seção apresentará em detalhes o método EAP, proposto por Bock e Mislevy (1982).

\subsection{Média a Posteriori}

Esta seção foi desenvolvida tendo como base o trabalho de Costa (2009).

O método EAP se baseia na avaliação numérica da média e variância de uma distribuição a posteriori para obter estimativas sobre a habilidade (BOCK; MISLEVY, 1982).

Como já visto, $U_{j i}$ é uma variável dicotômica que assume o valor 1 quando o examinando $j$ responde corretamente o item $i$ ou 0 , caso contrário. Desta forma, considera-se que a distribuição de $U_{j i}$ é a de Bernoulli de parâmetro $P_{j i}\left(\theta_{j}\right)$, dado por algum modelo da TRI (como o ML3P, por exemplo). Assim, a função de verossimilhança que relaciona 
a proficiência $\theta$ e as respostas do examinando $j$ aos $n$ itens já apresentados é dada por:

$$
L\left(\theta_{j} ; u_{1}, \ldots, u_{n}\right)=\prod_{i=1}^{n} P_{j i}\left(\theta_{j}\right)^{u_{i}}\left[1-P_{j i}\left(\theta_{j}\right)\right]^{1-u_{i}},
$$

em que $u_{n}$ representa a resposta dada ao $n$-ésimo item.

No EAP, é suposto que as proficiências dos indivíduos são estocasticamente independentes, ou seja, indivíduos diferentes não possuem informação de outros indivíduos, o que permite estimar cada proficiência separadamente. Também é suposto que os parâmetros dos itens, de acordo com o modelo utilizado, são conhecidos.

Na abordagem Bayesiana, uma distribuição a priori para os valores desconhecidos da habilidade, $g\left(\theta_{j}\right)$, é assumida. Combinando a função de verossimilhança e a distribuição a priori, tem-se a distribuição a posteriori para $\theta_{j}$ :

$$
g\left(\theta_{j} \mid u_{1}, \ldots, u_{n}\right)=\frac{L\left(\theta_{j} ; u_{1}, \ldots, u_{n}\right) g\left(\theta_{j}\right)}{\int L\left(\theta_{j} ; u_{1}, \ldots, u_{n}\right) g\left(\theta_{j}\right) d \theta} .
$$

Utilizando-se da Equação 2.4.3, o método EAP pode ser representado por:

$$
\theta_{j_{1}, \ldots, u_{n}} \equiv \int \theta_{j} g\left(\theta_{j} \mid u_{1}, \ldots, u_{n}\right) d \theta_{j}
$$

Na Equação 2.4.4, o procedimento Hermite-Gauss, usualmente denominado de Método de Quadratura Gaussiana, pode ser utilizado para aproximar a distribuição $g\left(\theta_{j}\right)$, resultando na Equação 2.4.4 em forma de quadratura:

$$
\theta_{j u_{1}, \ldots, u_{n}}=\frac{\int_{\mathbb{R}} \theta_{j} L\left(\theta_{j} ; u_{1}, \ldots, u_{n}\right) g\left(\theta_{j}\right) d \theta_{j}}{\int_{\mathbb{R}} L\left(\theta_{j} ; u_{1}, \ldots, u_{n}\right) g\left(\theta_{j}\right) d \theta_{j}} \approx \frac{\sum_{t=1}^{q} X_{t} L\left(X_{t} ; u_{1}, \ldots, u_{n}\right) A_{t} \Delta_{t}^{-1}}{\sum_{t=1}^{q} L\left(X_{t} ; u_{1}, \ldots, u_{n}\right) A_{t} \Delta_{t}^{-1}},
$$

em que $X_{t}$ representa os $q$ pontos de quadratura, $A_{t}$ é o peso associado a $X_{t}$ e $\Delta_{t}$ é o comprimento do intervalo.

A metodologia de Hermite-Gauss fornece pontos de quadratura e pesos para uma aproximação exata da integral de qualquer função, ponderada pela função erro Gaussiana, que pode ser expressa como uma função polinomial de $q$ graus. Infelizmente, essa classe não inclui a função de verossimilhança (Equação 2.4.2), tornando o uso dos pontos de quadratura Gaussiano não aplicáveis neste contexto.

Para contornar este problema, determina-se pontos igualmente espaçados dentro de 
um intervalo para $\theta$ ( -3 a +3 desvios-padrão, por exemplo) que serão os pontos de quadratura e os pesos serão iguais à probabilidade de uma distribuição a priori discretizada nestes pontos. Geralmente, a distribuição normal padrão $\left(\mu=0\right.$ e $\left.\sigma^{2}=1\right)$ é utilizada como a distribuição a priori.

Uma importante medida associada à estimativa EAP é a variância a posteriori, definida em forma de quadratura pela seguinte equação:

$$
\operatorname{Var}\left(\theta_{j} \mid u_{1}, \ldots, u_{n}\right) \approx \frac{\sum_{t=1}^{q}\left[X_{t}-\theta_{\left.j_{u_{1}, \ldots, u_{n}}\right]^{2} L\left(X_{t} ; u_{1}, \ldots, u_{n}\right) A_{t} \Delta_{t}^{-1}}^{q} .\right.}{\sum_{t=1}^{q} L\left(X_{t} ; u_{1}, \ldots, u_{n}\right) A_{t} \Delta_{t}^{-1}} .
$$

O nível de precisão em EAP é dado pela raiz quadrada da variância a posteriori, resultando no que é conhecido como desvio-padrão a posteriori. Segundo Bock e Mislevy (1982), após a consideração de 20 itens, a função de verossimilhança e a distribuição a posteriori são muito próximas e o desvio-padrão a posteriori é praticamente idêntico ao erro-padrão do que se está medindo.

Em relação ao número de pontos de quadratura necessários para se obter bons níveis de precisão e boas estimativas para as habilidades, é comum utilizar em torno de 40 pontos para intervalos de $\theta$ entre -3 a +3 desvios-padrão e entre $-4 a+4$ desvios-padrão.

\subsection{Sistemas Hipermídia Adaptativos}

A Hipermídia Adaptativa é uma alternativa ao o tradicional "formato único" utilizado no desenvolvimento dos Sistemas Hipermídia ${ }^{6}$. Nestes, o conteúdo é estático, sendo fornecido sempre o mesmo conteúdo e conjunto de links para todos os usuários, que precisam se adaptar ao funcionamento do sistema (BRUSILOVSKY, 2001).

O principal objetivo dos SHAs é fornecer ao usuário um ambiente hipermídia dinâmico e adequado às suas necessidades, preferências e características individuais. Para isso, o sistema deve ser concebido a partir de um modelo (perfil) de usuário capaz de armazenar as características necessárias à formatação do ambiente (PUGA, 2008).

Segundo Brusilovsky (1996), a Hipermídia Adaptativa pode ser útil em qualquer área

\footnotetext{
${ }^{6}$ Os SHs apresentam um conjunto de informações na forma de textos, imagens, vídeos e outros tipos de mídias, sendo organizados segundo o modelo associativo e de remissões (ação ou efeito de remeter, enviar a determinado ponto), próprio do hipertexto (BARBOSA, 2004).
} 
de aplicação cujo o conjunto de informações seja razoavelmente grande e onde se espera que um SH seja utilizado por usuários com diferentes objetivos e conhecimentos.

A pesquisa em Hipermídia Adaptativa se situa na fronteira dos estudos em hipermídia e modelagem do usuário, sendo estes os dois pilares básicos que sustentam o desenvolvimento de aplicações nesta área. O objetivo geral de tais sistemas é prover seus usuários com conteúdo atualizado, subjetivamente interessante, com a ilustração multimídia pertinente, num tamanho e profundidade adequados ao contexto e em correspondência direta com o modelo do usuário. Um SHA deve satisfazer três critérios básicos: ser um sistema hipertexto ou hipermídia, possuir um modelo do usuário e ser capaz de adaptar a hipermídia do sistema através do uso deste modelo (PALAZZO, 2002).

O SHA coleta informações sobre o comportamento do usuário, atualiza o modelo do usuário e, com estes novos dados, gera o efeito de adaptação da forma e conteúdo apresentados a este usuário (BUGAY, 2006). Este processo é ilustrado na Figura 2.12.

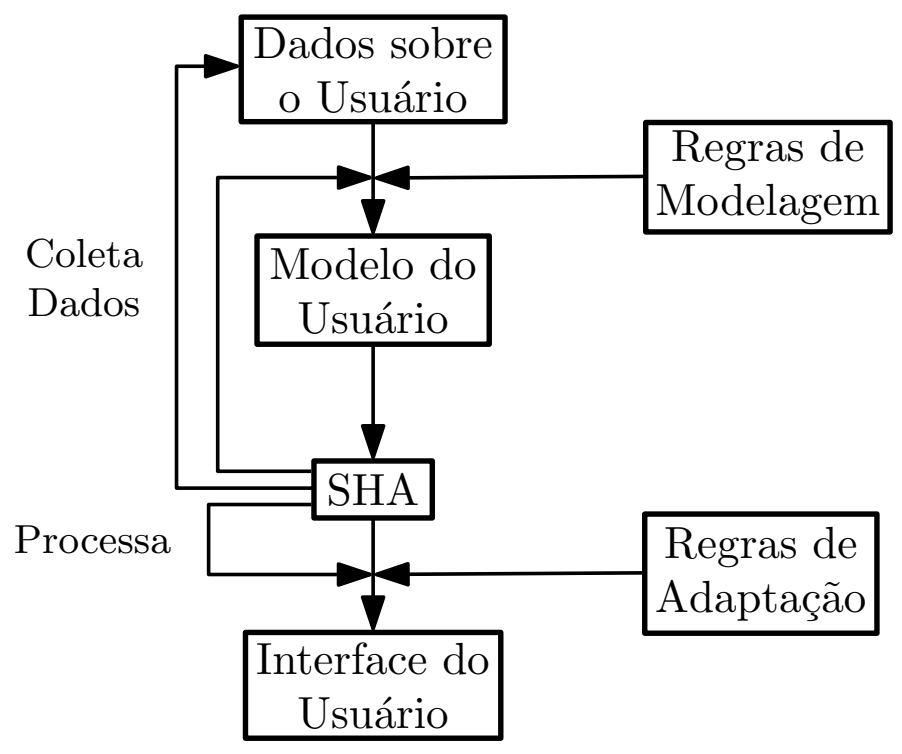

Figura 2.12: Ciclo clássico de adaptação em um SHA. Retirado de Bugay (2006) e adaptado de Brusilovsky (1996).

Muitos autores consideram que a palavra hipermídia surgiu da junção de hipertexto ${ }^{7}$ e multimídia. Desta forma, um documento hipermídia é a combinação de documentos hipertexto com diferentes tipos de mídias de apresentação, tais como, vídeo, som, imagem e animação.

\footnotetext{
${ }^{7}$ Um documento hipertexto é uma estrutura de informação organizada de maneira não linear, na qual os dados são armazenados em uma rede de nós conectados por ligações (links). Os nós contêm as unidades de informação compostas por texto, em geral, eles representam conceitos e ideias. Já os links definem as relações lógicas (semânticas) entre os nós, isto é, eles definem relações entre conceitos e ideias. Desta forma, os usuários podem navegar pelo documento através dos links (SILVA, 2005).
} 
Os SHAs surgiram da integração entre os STIs e os SHs voltados à educação. Eles inicialmente eram direcionados à educação (BRUSILOVSKY, 2000). Atualmente, a educação continua sendo uma importante área de pesquisa dos SHAs, mas eles já são utilizados em diversas outras áreas. Segundo Brusilovsky (2001), os SHAs têm sido utilizados em diversos tipos de aplicações, entre elas, aplicações educacionais, sistemas de informação on-line e de recuperação de informações hipermídia.

A pesquisa sobre Hipermídia Adaptativa teve um rápido crescimento a partir de 1996, devido à expansão da Web (cuja demanda por adaptação proporcionou estímulos e novos desafios às pesquisas) e devido ao grau de maturidade obtido, até então, pelas pesquisas na área (BRUSILOVSKY, 2001). A Web continua sendo o principal atrativo para o desenvolvimento de SHAs.

Em sistemas computacionais existe uma separação no conceito de adaptação, em adaptáveis (adaptabilidade) e adaptativos (adaptatividade). Sistemas adaptáveis permitem que o usuário modifique certas características do sistema (como, por exemplo, cor de fundo, fontes e ícones), adequando-o ao seu comportamento. Sistemas adaptativos possuem a capacidade de modificar automaticamente suas características (sejam elas de interface, conteúdo ou navegação), de acordo com a percepção das necessidades e características do usuário (OPPERMANN; RASHEV; KINSHUK, 1997).

\subsubsection{Sistemas Hipermídia Adaptativos Educacionais}

Os SHAs para fins educacionais (com conteúdo instrucional), que apoiam e facilitam o processo de ensino-aprendizagem, são chamados de Sistemas Hipermídia Adaptativos Educacionais.

De acordo com Oliveira (2004), os SHAEs podem abranger diversos tipos de aplicações para fins educacionais, sendo que os mais comuns são:

- Livros eletrônicos - são SHAEs com funcionalidades similares às dos livros tradicionais, com o diferencial de se adaptam ao conhecimento evolutivo do aprendiz. Logo, este tipo de sistema é capaz de sugerir o próximo conteúdo a ser aprendido, bem como os exemplos e exercícios mais recomendados ao aprendiz num dado momento;

- Ambientes de apoio à aprendizagem - geram atividades de forma adaptada às características e necessidades dos usuários. Estes ambientes muitas vezes estão interligados a outro sistema hipermídia que possui o conteúdo do domínio da aplicação. 
Com base nas atividades definidas pelo sistema de apoio, o aprendiz acessa o sistema hipermídia segundo sua conveniência;

- Cursos adaptativos - implementam cursos que apoiam o processo de aprendizagem e selecionam os conteúdos e materiais mais apropriados ao aprendiz.

\subsubsection{Arquitetura dos SHAs}

Não existe uma arquitetura clássica para os SHAs, entretanto, existem várias propostas de Modelos de Referência (MRs) para estes sistemas. De modo geral, um MR para SHAs provê um framework para expressar qualquer funcionalidade destes sistemas. Segundo Koch e Wirsing (2002), o objetivo de um MR é encontrar abstrações comuns existentes nos sistemas e prover uma base para o desenvolvimento destas aplicações.

Em geral, os MRs para SHAs se inspiraram nos modelos existentes para os SHs, como o Modelo Dexter (HALASZ; SCHWARTZ, 1994), que é o precursor de MRs para Hipermídia Adaptativa bastante difundidos, como o Adaptive Hypermedia Application Model (AHAM) (de BRA; HOUBEN; WU, 1999) e o Modelo de Referência Munique (KOCH; WIRSING, 2002).

O AHAM aprimora e ajusta o Modelo Dexter para o ambiente $W e b$, ele possui a capacidade de realizar adaptações baseadas em um modelo do usuário persistente ao longo de diferentes sessões de uso. O motor adaptativo deste modelo usa regras para gerar especificações de apresentação, além de atualizar o modelo do usuário depois de cada evento. O Modelo de Referência Munique adota uma arquitetura similar à do AHAM, porém, ele permite uma visão mais abrangente da aplicação, uma vez que ele se baseia na engenharia de software (o AHAM tem como base banco de dados), visando a formalização do projeto e a representação gráfica dos modelos (ZANCHETT, 2006).

As regras adaptativas dos modelos AHAM e Munique dependem da funcionalidade de três modelos: modelo do domínio, modelo do usuário e modelo de adaptação. A divisão destes MRs em modelos componentes proporciona a separação dos diferentes aspectos do sistema, o que facilita a estruturação, implementação e manutenção dos mesmos.

Neste trabalho não são apresentados os detalhes de um MR em específico. As próximas seções abordam os componentes básicos, que são comuns à maioria dos MRs para SHAs. 


\subsubsection{Modelo do Domínio}

O Modelo do Domínio (MD) é a base de conhecimento do sistema; ele contém os elementos que serão usados para que o usuário aprenda o domínio que será tratado. Estes elementos podem ser definições, exemplos, demonstrações, atividades, exercícios, questões, entre outros. O MD descreve como estes elementos são ligados e estruturados.

No contexto da Hipermídia Adaptativa, em geral, a estrutura do MD é representada por uma rede de conceitos do domínio envolvido. Estes conceitos se relacionam (possuem ligações), formando uma espécie de rede semântica, que representa a estrutura do domínio. Os conceitos (também chamados de tópicos, elementos do conhecimento ou objetos) são as peças elementares de conhecimento do domínio (BRUSILOVSKY, 1996).

Segundo Oliveira (2004), o MD descreve a forma de estruturação do domínio do sistema, que pode ser feita tanto no nível conceitual quanto no nível de fragmentos de informações de cada conceito, bem como no nível de composição de páginas.

A representação do conhecimento e modelagem de domínio são temas que vem recebendo, cada vez mais, a atenção da comunidade científica, em especial na Engenharia do Conhecimento e na Ciência da Informação. A construção de ontologias ${ }^{8}$ de domínio vem se tornando uma atividade comum, em grande parte devido às pesquisas relacionadas à Web semântica (GUEWEHR, 2007).

\subsubsection{Modelo do Usuário}

Esta seção foi escrita com base no trabalho de Brusilovsky e Millán (2007).

O Modelo do Usuário (MU) é responsável por armazenar toda e qualquer característica do usuário que possa influenciar nas decisões de adaptação tomadas pelo SHA. Ele representa a visão que o sistema possui do usuário. O MU funciona como uma referência para o sistema, que busca adaptar seu ambiente a ele (PALAZZO, 2002). Nos SHAs que lidam com alunos, o MU é frequentemente chamado de Modelo do Aluno (MA).

Existem algumas características importantes dos usuários que podem ser levadas em consideração pelos sistemas adaptativos, são elas:

- Conhecimento - o conhecimento do usuário sobre o assunto representado no hiperespaço $^{9}$ é considerada a característica mais importante na construção do MU.

\footnotetext{
${ }^{8}$ Técnica que utiliza redes de conceitos para representar o conhecimento.

${ }^{9}$ Rede de informações hipermídia com seus nós e links, representando o espaço de informações de uma
} 
Esta caraterística é utilizada na maioria dos SHAs; nos SHAEs, o conhecimento é frequentemente a única característica do usuário que é modelada. Quase todas as técnicas de adaptação (Seção 2.5.3.1) utilizam o conhecimento do usuário como fonte para prover adaptação. O sistema que se baseia nesta característica deve ser capaz de reconhecer as modificações no estado de conhecimento do usuário e atualizar adequadamente o MU;

- Interesses - o interesse tem competido com o conhecimento para tentar se tornar a característica do usuário mais importante a ser modelada nos SHAs. Sua ascensão se deve ao rápido crescimento do volume de informações e à crescente popularidade de SHAs orientados à informação, como enciclopédias, lojas eletrônicas, guias de museu e quiosques de informações. Nestes sistemas, o acesso às informações é basicamente dirigido à interesse;

- Objetivos - os objetivos do usuário estão mais relacionados com a tarefa do usuário dentro do sistema adaptativo do que com ele mesmo como indivíduo. Dependendo do tipo de sistema, tais objetivos podem ser objetivos de trabalho (em sistemas aplicativos), uma informação imediata necessária (em sistemas de recuperação de informações) ou objetivos de aprendizado (em sistemas educacionais). Em todos estes casos, o objetivo é a resposta à questão: "O que o usuário realmente deseja alcançar?". Os objetivos do usuário são a sua característica mais sujeita a mudanças;

- Histórico (background) - por histórico do usuário, entende-se toda informação relacionada com a experiência anterior do usuário, fora do domínio abordado pelo sistema hipermídia, que seja considerada relevante. Estas informações do usuário podem estar relacionadas à sua profissão, experiências de trabalho, entre outras. O histórico do usuário geralmente é mais utilizado para a adaptação do conteúdo do que para a adaptação da navegação. O histórico é similar ao conhecimento do usuário sobre determinado domínio, ele tenta mensurar o conhecimento que vai além deste domínio. Entretanto, a representação destas características pelo sistema é diferente. O histórico geralmente é fornecido explicitamente para o sistema, através do próprio usuário ou por superior (professor, por exemplo) que o conheça. Além disso, esta característica tipicamente não se altera durante o uso do sistema por parte do usuário;

- Características Individuais - representam o conjunto de características que definem o usuário como um indivíduo. Estas características podem ser estilos cognitivos (seri- 
alista ou holista, por exemplo), estilos de aprendizagem, características da personalidade (introvertido ou extrovertido, por exemplo), fatores cognitivos (capacidade de memória de trabalho), entre outros. Destas características, as duas primeiras são as mais utilizadas. Assim como o histórico, as características individuais também são estáveis, elas praticamente não se modificam. Ao contrário do histórico, entretanto, que pode ser extraído de uma simples entrevista ou questionário, as características individuais são determinadas através de complexos testes psicológicos.

Como pôde ser observado, várias das características apresentadas são dinâmicas, o que torna necessário o ajuste contínuo do MU (PALAZZO, 2002).

Como mencionado, o conhecimento é a característica do usuário mais importante e mais utilizada pelos SHAs. Exitem vários métodos utilizados para a modelagem desta característica, dentre os mais difundidos estão os modelos de esteriótipos e overlay.

O Modelo de Esteriótipos é uma das mais antigas abordagens para modelagem do usuário, ele agrupa os usuários do sistema em poucos grupos, chamados esteriótipos (por exemplo, um usuário, de acordo com seu conhecimento, pode ser classificado como iniciante, intermediário ou experiente). Todos os usuários pertencentes ao mesmo esteriótipo são tratados da mesma forma pelos mecanismos do sistema. Cada esteriótipo agrupa usuários com combinações específicas de características; apesar do sistema reconhecer estas características, é o esteriótipo que é levado em consideração pelo sistema. Mudanças significativas nas características do usuário podem tornar necessária a associação deste usuário a outro esteriótipo.

O Modelo Overlay (MO) é o mais popular dos métodos para a modelagem do conhecimento, seu objetivo é representar o conhecimento individual do usuário como um subconjunto do Modelo do Domínio, que reflete o conhecimento do especialista sobre o assunto. Desta forma, o MO se baseia na estrutura do MD. Para cada conceito presente no MD, o MO armazena uma estimativa sobre o nível de conhecimento do usuário para este conceito. Esta estimativa pode ser simplesmente binária (conhece ou não conhece), uma medida qualitativa (ruim, médio ou bom) ou uma medida quantitativa (como um valor numérico entre 0 e 100 ou a probabilidade do usuário conhecer o conceito).

Modelos overlay que se baseiam em probabilidades, ou qualquer outra forma de medida utilizada para medir incertezas, também são chamados de modelos baseados em incerteza. Tais modelos se utilizam de técnicas como Redes Bayesianas ou Lógica Fuzzy para o gerenciamento destas incertezas. Estes modelos vêm recebendo grande importân- 
cia.

Os modelos overlay são poderosos e flexíveis, eles podem mensurar de forma independente o conhecimento do usuário em diferentes conceitos. Não apenas o conhecimento pode ser modelado por métodos overlay, eles também podem ser generalizados, de forma a contemplar as demais características do usuário.

\subsubsection{Modelo de Adaptação}

No Modelo de Adaptação são definidas as regras que especificam as condições para a adaptação de conteúdo, navegação e apresentação (estas regras são apresentadas na Seção 2.5.3.1). Nele também são especificados como devem ser feitas as atualizações do MU após a observação do comportamento do usuário (ZANCHETT, 2006). Ainda segundo este autor, as regras adaptativas presentes neste modelo definem como os modelos do usuário e do domínio são combinados para prover adaptação em diferentes estágios.

Este modelo é utilizado para construir e adaptar os conteúdos e links que serão apresentados, oferecendo uma biblioteca de funções para construir páginas a partir de fragmentos com base nos modelos do usuário e do domínio (PUGA, 2008).

Em aplicações educacionais é comum chamar o Modelo de Adaptação de modelo de ensino ou pedagógico e, nestes casos, este modelo também contempla as regras e estratégias pedagógicas que serão utilizadas no processo de ensino-aprendizagem.

Segundo Prentzas e Hatzilygeroudis (2002), um importante aspecto do modelo de ensino é avaliar a performance do usuário tendo como base as respostas fornecidas em exercícios propostos. Desta forma, o MU pode ser atualizado corretamente e, consequentemente, conteúdos mais apropriados poderão ser apresentados.

\subsubsection{Interface do Usuário}

A interface do usuário constitui a camada de interação (comunicação) do sistema com o usuário, em que o conteúdo hipermídia, links e outros componentes são apresentados. Ela determina a forma como o usuário interage com o domínio que está sendo abordado e apresenta ferramentas para o acesso, visualização e manipulação da aplicação (PUGA, 2008). Os componentes apresentados são aqueles que foram selecionados de acordo com as regras presentes no Modelo de Adaptação.

Segundo Palazzo (2002), a ideia por trás dos SHAs é oferecer a cada usuário uma 
interface (composta por estilos, conteúdo, recursos, links, entre outros) modelada (adaptada) de acordo com suas características específicas. O autor também cita que um SHA acessado através da Internet, a interface seria composta por uma página qualquer do sistema visualizada através do navegador de Internet do usuário.

\subsubsection{O que pode ser adaptado}

Koch (2000) define que a adaptação em Hipermídia Adaptativa pode ocorrer em nível de conteúdo, apresentação e navegação. Já para Brusilovsky (1996, 2001), a adaptação pode ocorrer em nível de conteúdo (que engloba a apresentação) e de navegação.

Seguindo a abordagem de Koch (2000), um SHA oferece:

- Conteúdo adaptativo - adapta o conteúdo (informações, textos, sons, imagens, entre outros) a ser apresentado ao usuário;

- Apresentação adaptativa - diz respeito a adaptações de layout, que não afetam o conteúdo propriamente dito, mas sim elementos da interface como cor, tamanho e tipo do texto, idioma apresentado, tipos de mídia, entre outros;

- Navegação Adaptativa - manipula os links disponíveis ao usuário em determinado momento, auxiliando-o a encontrar seu caminho no hiperespaço. O sistema pode adaptativamente ordenar, anotar ou esconder parcialmente os links de uma página atual para facilitar a escolha dos próximos links a seguir.

Os SHAs moldam a informação apresentada (utilizando-se das diferentes possibilidades de adaptação) de acordo com as características do usuário presentes no MU. Por exemplo, determinado conteúdo pode ser selecionado de acordo com o conhecimento do usuário ou ele pode ser orientado através da remoção de links que o sistema considera pouco úteis, dado determinado estado do seu MU (KOCH, 2000).

\subsubsection{Métodos e Técnicas de Adaptação}

Para elucidar a diferença entre métodos e técnicas de adaptação em Hipermídia Adaptativa, Brusilovsky (1996) define assim estes conceitos:

- Técnicas - estão situadas no nível de implementação de um SHA, em que cada técnica pode ser caracterizada por um tipo especial de representação do conhecimento e por um algoritmo específico de adaptação; 
- Métodos - são generalizações de técnicas de adaptação existentes, em que cada método é baseado em uma ideia de adaptação, a qual pode ser representada conceitualmente. Um método pode ser implementado por diferentes técnicas e, ao mesmo tempo, uma técnica pode ser utilizada para implementar mais de um método.

Uma característica interessante das técnicas de adaptação é que muitas delas não são contraditórias e podem ser utilizadas em conjunto, conforme a necessidade.

Existem diversos métodos e técnicas que podem ser utilizados para prover adaptação, as próximas seções descrevem os mais difundidos. Para maiores detalhes, os trabalhos de Brusilovsky (1996, 2001) e Koch (2000) podem ser consultados.

\subsection{Conteúdo adaptativo}

Os métodos para adaptação do conteúdo apresentados por Brusilovsky (1996) são:

- Explicação Adicional - é um método muito utilizado, cujo objetivo é ocultar do usuário alguma parte da informação sobre determinado conceito que não é considerada relevante devido às características que ele possui. Desta forma, este método consiste em mostrar ao usuário apenas as partes relevantes da informação. Por exemplo, detalhes complicados podem ser ocultados de usuários com baixo nível de conhecimento em um conceito;

- Explicação de Pré-requisitos - também chamado de Explicação Requerida por Palazzo (2002), neste método, antes de se apresentar a explicação sobre o conceito, o sistema apresenta as explicações para todos os conceitos que são considerados seus pré-requisitos e que ainda não foram conhecidos pelo usuário;

- Explicação Comparativa - neste método, se um conceito similar ao conceito que está sendo apresentado é conhecido, o usuário recebe uma explicação comparativa em que se realça as semelhanças e diferenças entre estes dois conceitos;

- Explicação Variante - também chamado de Conteúdo Variante, este método assume que mostrar ou esconder certas partes da informação nem sempre é suficiente para prover a adaptação adequada. Através deste método, o sistema armazena diversas variantes para alguns dos conteúdos de uma página e o usuário obtém a variante que corresponde às suas características; 
- Classificação de Fragmentos - este método ordena fragmentos de informação sobre o conceito de modo que a informação mais relevante para o usuário seja apresentada primeiro.

Brusilovsky (1996) também descreve as principais técnicas utilizadas para a obtenção da adaptação do conteúdo, são elas:

- Texto Condicional - nesta técnica é possível dividir a informação contida no texto (que também pode conter elementos multimídia) em diversas partes. Cada parte é então associada a uma ou mais condições, que estão relacionadas às características do usuário. Ao apresentar a informação, são mostradas apenas as partes de texto que tiveram suas condições satisfeitas. Esta é uma técnica de baixo nível, que requer desenvolver todas as condições desejadas, entretanto, ela é muito flexível e permite implementar todos os métodos de adaptação citados, à exceção do Classificação de Fragmentos;

- Stretchtext - o stretchtext é um tipo especial de hipertexto, em que os links podem ser "expandidos" para seus fragmentos de conteúdos ou "contraídos" para uma palavra-chave ou frase. A ideia desta técnica é que o sistema determine quais conteúdos são "expandidos" e "contraídos" na apresentação inicial podendo o usuário, posteriormente, decidir qual fragmento deseja expandir ou contrair;

- Página Variante - esta técnica consiste em manter duas ou mais páginas alternativas para cada conceito, descrevendo-o de maneiras diferentes, e com cada uma delas adaptada a uma certo tipo (esteriótipo) de usuário. Esta técnica implementa o método Explicação Variante;

- Fragmentos Variantes - esta técnica implementa de forma mais refinada que a técnica anterior o método Explicação Variante. Nela, uma página pode conter vários conceitos que, por sua vez, podem possuir diversos fragmentos variantes. O sistema apresenta as variantes dos conceitos que melhor satisfazem as características do usuário;

- Frames - nesta técnica, toda a informação sobre determinado conceito é representada sob a forma de um frame. O frame pode conter explicações variantes sobre o conceito, links para outros frames, exemplos, entre outros. Regras especiais são empregadas para decidir o que um frame deve apresentar ao usuário e em que ordem isso deve ocorrer. 
Koch (2000) também descreve os métodos e técnicas de adaptação do conteúdo de forma similar ao que foi apresentado.

\subsection{Apresentação adaptativa}

Segundo Koch (2000), a apresentação adaptativa permite a adaptação do layout da interface às preferências e necessidades visuais do usuário. A autora define dois métodos para apresentação adaptativa, são eles:

- Multi-Idioma - o objetivo deste método é a adaptação do idioma da interface, de acordo com a preferência ou o contexto do usuário;

- Layout Variante - este método inclui a adaptação dos elementos presentes em uma apresentação, como cores, tipo e tamanho de fontes, tamanho de imagens, ordenação de fragmentos de informação, entre outros.

Koch (2000) também descreve que as mesmas técnicas utilizadas para a adaptação do conteúdo, à exceção do Stretchtext, também podem ser utilizadas para adaptar a apresentação. A autora apresenta outra técnica que pode ser utilizada para esta finalidade, chamada de Guia de Estilos, que consiste na criação de diferentes templates (modelos de apresentação) que são utilizados para fornecer variações de layout.

\subsection{Navegação adaptativa}

O objetivo da adaptação em nível de links é apoiar a navegação, prevenindo os usuários, de acordo com suas características, de seguirem caminhos no hiperespaço que são irrelevantes. A adaptação consiste de modificações da estrutura de navegação ou de como esta estrutura é apresentada ao usuário (KOCH, 2000).

Brusilovsky (1996) apresenta os seguintes métodos para navegação adaptativa:

- Condução Global - ocorre quando o usuário necessita de alguma informação que está localizada em dois ou mais locais do hiperespaço. Este método tem por objetivo auxiliar o usuário a seguir o melhor caminho no hiperespaço para a obtenção da informação desejada. Deve oferecer em cada passo o melhor link ou links classificados em ordem de importância. Um caso especial de condução global ocorre nos sistemas educacionais (como os SHAEs), em que o estudante tem um objetivo global, que é o 
objetivo de aprendizagem (obter conhecimento), que geralmente engloba boa parte ou todo o hiperespaço;

- Condução Local - possui um alcance menor que o do método anterior, preocupandose com um único passo em vez do caminho global. A navegação é reformulada a cada passo para que o usuário tenha o(s) $\operatorname{link}(s)$ mais relevante(s) de acordo com as suas características;

- Orientação Local - o objetivo deste método é auxiliar o usuário a entender o que as diferentes possibilidades de navegação (links) a partir do estado atual significam e ajudá-lo a seguir o link mais apropriado. Este método não guia diretamente o usuário, ele o auxilia a entender o que esta à sua volta e qual é a sua posição no hiperespaço;

- Orientação Global - este método auxilia o usuário a entender a estrutura global do hiperespaço e o seu posicionamento nela;

- Visualização Personalizada - consiste na utilização de agentes capazes de gerar e atualizar visualizações personalizadas de determinado hiperespaço, por meio da localização de links apropriados ao usuário. Deste modo, o usuário não fica exposto a todo o hiperespaço, que pode ser extenso e complexo.

A navegação adaptativa se dá através da alteração e adaptação de links e âncoras às características do usuário. Brusilovsky (1996) classifica os links em quatro tipos:

- Links locais, não contextuais - este tipo inclui os links que são independentes do conteúdo da página. Normalmente, encontram-se apresentados como um conjunto de botões, listas ou menus;

- Links contextuais - compreendem os links que estão embutidos no conteúdo da página e que, geralmente, não podem ser removidos. Estes links podem, por exemplo, explicar ou exemplificar certas palavras ou frases do texto;

- Links em índices e tabelas de conteúdos - um índice ou tabela de conteúdo pode ser visto como um tipo especial de página que contém apenas links, que geralmente são fixos e não contextuais;

- Links em mapas locais e globais - os mapas representam graficamente um hiperespaço ou apenas uma parte dele. 
As técnicas para prover navegação adaptativa, segundo Brusilovsky (1996), são:

- Orientação Direta - é a técnica mais simples, nela, o sistema decide qual é o próximo nó do hiperespaço que o usuário deve visitar, de acordo com as suas características. Geralmente, a orientação direta é expressa por um link chamado "Próximo", referente ao próximo conteúdo mais apropriado a ser visitado. Esta técnica é muito utilizada para implementar os métodos de condução global e local. O problema desta técnica é que ela não oferece apoio aos usuários que não querem seguir as recomendações do sistema. Deste modo, para promover maior liberdade de escolha ao usuário, esta técnica deve ser utilizada em conjunto com outra técnica menos restritiva. A orientação direta é muito utilizada para prover condução global em SHAEs, em que geralmente os usuários são novatos que apresentam problemas em fazer suas próprias escolhas e que por isso confiam nas sugestões do sistema. A orientação direta nestes sistemas nada mais é do que o ajuste dos tradicionais mecanismos de sequência curricular ${ }^{10}$ para o acesso à hipermídia;

- Classificação Adaptativa - consiste em ordenar um conjunto de links em ordem decrescente de relevância dos mesmos às características do usuário. Esta técnica apresenta aplicação limitada, ela pode ser utilizada em links não conceituais, mas seu uso em índices e tabelas de conteúdo é muito difícil, e ela não pode ser utilizada em links contextuais e em mapas. Outra desvantagem desta técnica é que cada vez que o usuário acessar a mesma página, os links podem ser ordenados de forma diferente;

- Ocultação Adaptativa - é uma técnica muito utilizada e consiste em restringir o espaço de navegação, ocultando links considerados não relevantes para o usuário. Seu uso protege o usuário da complexidade de um hiperespaço acessado sem restrições, o que reduz o volume de informações a que ele tem acesso. Esta técnica pode ser utilizada em todos os tipos de links;

- Anotação Adaptativa - a ideia desta técnica é aumentar a informação presente nos links com alguma forma de anotação ou comentário, que pode dizer mais sobre o estado atual dos nós a que se referem estes links. Esta informação adicional pode ser oferecida sob a forma de texto ou de indicadores visuais, como ícones especiais, cores ou tamanho dos caracteres. Esta técnica pode ser utilizada em todos os tipos de links;

\footnotetext{
${ }^{10}$ Técnica presente nos STIs e que tem como objetivo auxiliar o usuário a encontrar seu melhor caminho no domínio que está sendo abordado (BRUSILOVSKY, 1996).
} 
- Mapa Adaptativo - compreende as diversas formas de adaptação de mapas de hipermídia, globais ou locais, apresentados ao usuário. As técnicas de Orientação Direta, Ocultação e Anotação também podem ser usadas na adaptação destes mapas, entretanto, estas técnicas não modificam suas formas ou estruturas. 


\section{Sistema Proposto}

Este trabalho propõe um SHAE que provê cursos com conteúdo personalizado aos alunos e que faz uso do ambiente $W e b$ para ensinar. Para fornecer conteúdo adaptado, o sistema faz uso de uma Rede Bayesiana para a representação do Modelo do Aluno e da Teoria da Resposta ao Item na avaliação dos testes de habilidade dos alunos. Este capítulo apresenta, em detalhes, os principais componentes deste sistema.

Durante as fases de pesquisa e definição do sistema proposto houve uma dificuldade em classificá-lo como um SHAE ou um STI, visto que muitas das características dos SHAEs foram "herdadas" dos STIs e vários STIs atualmente fazem uso da Web e de hipermídia para fornecer instrução adaptada aos usuários. Segundo Wolf (2007) e Prentzas e Hatzilygeroudis (2002), esta proximidade (capacidade de adaptação e uso de conteúdo hipermídia) faz com que muitas vezes seja difícil e até mesmo inviável classificar um sistema como STI ou SHA.

Segundo Nicholas e Martin (2008), a Hipermídia Adaptativa é mais apropriada à instrução de conceitos, enquanto que o STI geralmente auxilia no uso destes conceitos para a solução de problemas. Ainda segundo estes autores, os STIs são criados primeiramente para auxiliar os usuários na aquisição de habilidades, em vez do completo entendimento de determinado domínio; já os SHAs são criados primeiramente para transmitir os conceitos de um domínio que os usuários devem saber para utilizar estas habilidades.

Pelos motivos apresentados no parágrafo anterior, o sistema proposto neste trabalho foi classificado como um SHAE.

\subsection{Modelo do Domínio}

O MD é composto pelos conceitos que serão ministrados pelo sistema e pelas relações existentes entre eles (rede de conceitos). Para cada conceito, foram elaborados três conteúdos (níveis de representação), que correspondem a níveis de dificuldade, são eles: 
- Básico - em que o conceito é exposto de forma bem acessível e didática, ao custo de alguma perda na exatidão;

- Intermediário - em que o conceito é exposto de forma abrangente e com a introdução de linguagem técnica;

- Avançado - em que o conceito é apresentado de forma mais abrangente e com uso de linguagem técnica.

O conteúdo de nível básico ou simplesmente nível básico (ou, ainda, conteúdo básico) é considerado o mínimo que o aluno deve aprender sobre o conceito. Os elementos (características, princípios, etc.) nele existentes também estão presentes nos outros dois níveis de representação. Neste nível, primeiramente são expostos exemplos ou problemas, a partir dos quais se busca ensinar os elementos. Este nível também faz uso de ilustrações para facilitar o entendimento dos elementos e exemplos apresentados. O nível básico é o conteúdo que possui o maior número de exemplos e ilustrações.

No nível intermediário, em geral, os elementos são apresentados de forma mais direta do que no nível básico, sendo primeiro introduzido um elemento e posteriormente apresentado um exemplo ou ilustração relativo a ele. O nível intermediário possui menos exemplos e ilustrações que o nível básico e, por ser mais abrangente, possui elementos que não estão presentes no nível básico.

No nível avançado, os elementos são apresentados de forma direta e os exemplos e ilustrações são apresentados após a introdução dos elementos. Muitas vezes, um único exemplo deste nível agrupa a explicação de vários elementos. Este nível possui menos exemplos e ilustrações do que o nível intermediário. Por ser o conteúdo mais abrangente, o nível avançado possui elementos que não existem no nível intermediário e que, consequentemente, também não estão presentes no nível básico.

Neste trabalho, o nível básico é tratado como inferior ao nível intermediário, que, por sua vez, é considerado inferior ao nível avançado. Diante isto, pode-se também concluir que o conteúdo avançado é considerado o nível superior.

\subsection{Modelo do Aluno}

O MA do sistema proposto tem como base a estrutura da rede de conceitos do modelo do domínio (Modelo Overlay), em que a característica do aluno que é modelada é o conhecimento. 
Este modelo é representado por uma Rede Bayesiana, em que cada nó (conceito) possui dois estados possíveis: conhece e não conhece. Deste modo, a rede armazena e fornece as estimativas (probabilidades) que os alunos têm de conhecer ou não os conceitos do domínio envolvido.

Por fazer uso de uma técnica capaz de lidar com incertezas, o MA é capaz de responder a questões como: "O aluno errou uma questão referente a determinado conceito, qual é a chance dele conhecê-lo? Dado que o aluno conhece um conceito que tem grande influência sobre outro conceito, qual é a chance dele conhecer este outro conceito?"

Deve-se ressaltar que os cursos criados para serem ministrados pelo sistema proposto, caso abordem domínios distintos, devem possuir modelos do domínio e do aluno que são específicos, ou seja, estes cursos devem possuir seus próprios MD e MA.

\subsubsection{Mecanismo de ajuste do MA}

Para cada conceito apresentado ao aluno o sistema faz uso de testes para avaliar a sua habilidade e desempenho. Estes testes de habilidade representam questões de múltipla escolha, cujas respostas são utilizadas para ajustar o MA. A seguir são apresentados os tipos de testes utilizados:

- Pré-teste - é uma questão que é apresentada antes do conceito ser visualizado pelo aluno. Ela não avalia se o aluno conhece ou não o conceito que será apresentado, mas sim se ele é capaz de abstrair as principais características ou ideias que estão presentes nele. Neste tipo de questão geralmente é apresentado um cenário ou situação, a partir do qual são feitas considerações. Esta questão faz pouco uso de termos técnicos e, quando eles estão presentes, referem-se apenas a termos que existem em conceitos que já foram explorados. Existe apenas uma questão de préteste para cada conceito existente;

- Pós-teste - é uma questão que é aplicada após a apresentação de algum dos níveis de representação do conceito envolvido. Ela avalia os principais elementos presentes no conceito que foi apresentado, indicando se o aluno os aprendeu ou não. Os alunos sempre respondem, para determinado conceito, a mesma questão de pósteste, independentemente do nível de dificuldade que eles visualizaram. Ela testa apenas os elementos que estão presentes em todos os níveis de dificuldade criados para o conceito. 
As questões de pré-teste, em geral, são simples. Já as de pós-teste são mais complexas e exigem maior capacidade por parte dos alunos para respondê-las.

Diante do que foi apresentado, percebe-se que o pré-teste tem por objetivo fazer uma análise prévia, indireta e pouco abrangente do aluno em relação ao conceito que será abordado, enquanto que o pós-teste objetiva realizar uma análise direta e abrangente do conceito que foi visualizado.

Após a resposta de cada pré ou pós-teste é feita uma estimação da habilidade $(\theta)$ do aluno, baseada em todas as respostas, inclusive a última, que ele informou nos testes já apresentados. Para esta estimação é utilizado o método EAP.

Para avaliar as respostas aos testes é utilizado o ML3P da TRI. Mais precisamente, este modelo é utilizado quando o aluno acerta o teste, retornando qual é a probabilidade que ele tem de acertar o teste, dada sua habilidade (obtida pelo método EAP). Deve-se ressaltar que quanto maior for a habilidade calculada para o aluno, maior será a probabilidade obtida. Esta estimativa é considerada a chance que o aluno tem, dado que ele acertou o teste, de conhecer o conceito ao qual ele se refere.

Mesmo em caso de acerto do teste, é atribuída uma estimativa que o aluno possui de não conhecer o conceito que foi apresentado, representada pela probabilidade que o aluno tem de acertar ao acaso ou "chutar" o teste. Esta probabilidade tem como valor o inverso do número de itens da questão.

Quando o aluno erra o teste, é atribuída uma pequena probabilidade dele conhecer o conceito envolvido, o que representa o fator comumente conhecido por slip, que indica que o aluno cometeu um deslize ou faltou com atenção ao responder o teste. Também é atribuída uma alta probabilidade do aluno não conhecer o conceito que foi ou que será apresentado, o que é de se esperar, visto que ele errou o teste. A Tabela 3.1 resume o processo de determinação das estimativas de conhecimento dos conceitos apresentado.

\begin{tabular}{cc}
\hline \multicolumn{2}{c}{ Questão de pré ou pós-teste } \\
\hline Acerto & Erro \\
\hline$P(R=1 \mid s)=$ prob. fornecida pelo ML3P & $P(R=0 \mid s)=15 \%($ slip $)$ \\
$P(R=1 \mid n)=$ prob. de acerto ao acaso & $P(R=0 \mid n)=80 \%$ \\
\hline
\end{tabular}

Tabela 3.1: Determinação das probabilidades a serem inseridas como evidência virtual na RB. $R$ representa se o aluno acertou (1) ou errou (0) a questão e $s$ e $n$ representam, respectivamente, se ele conhece ou não o conceito envolvido. As probabilidades para cada estado de $R$ não necessariamente precisam somar $100 \%$. 
As probabilidades obtidas pelos procedimentos dos parágrafos anteriores são inseridas como evidências virtuais na Rede Bayesiana que compõe o Modelo do Aluno. A propagação destas evidências pela rede é realizada através do algoritmo de Árvore de Junção. Após a propagação, a rede é capaz de fornecer as estimativas que determinado aluno possui de conhecer ou não cada conceito. A Figura 3.1 resume o mecanismo de ajuste do MA quando os testes são respondidos corretamente.

Deve-se ressaltar que em caso de acerto do teste, as evidências inseridas na rede reforçam o estado "conhece" do conceito, ou seja, elas buscam melhorar a estimativa que o aluno tem de conhecer o conceito. De modo inverso, quando o aluno erra algum teste, as evidências ressaltam o estado "não conhece" do conceito, o que tende a reduzir a estimativa que o aluno tem de conhecê-lo.

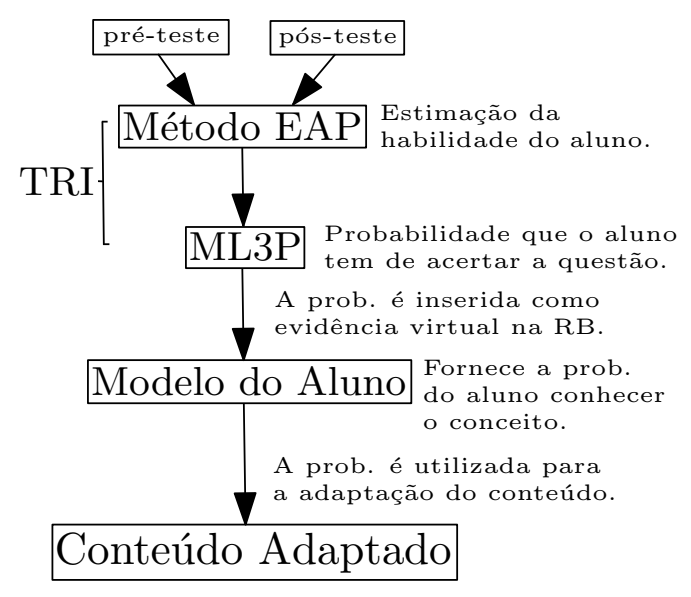

Figura 3.1: Mecanismo de ajuste do MA quando os testes são respondidos corretamente.

Neste trabalho, optou-se pela evidência virtual como o tipo de evidência a ser utilizado pelo fato de que, apesar da resposta dada pelo aluno a um teste ser considerada suficiente para indicar se ele conhece ou não o conceito envolvido, existem incertezas associadas e esta resposta. Algumas destas incertezas já foram apresentadas, por exemplo, quando o aluno "chuta" e acerta a questão e quando ele erra a questão apesar de conhecer o conceito, por falta de atenção. Também é natural considerar que os alunos, devido à diversidade de suas características, possuem probabilidades (que representam incertezas) diferentes de acertar determinada questão.

\subsection{Modelo de Adaptação}

Para fornecer navegação e conteúdo adaptados às características (conhecimento, neste caso) do aluno, o sistema proposto faz uso da combinação das técnicas de Página Variante 
e Orientação Direta. Esta combinação guia os alunos pelos conceitos e questões existentes no curso e determina quais dos níveis de dificuldade são apresentados para cada um destes conceitos. Este é o mecanismo geral utilizado pelo sistema para fornecer adaptação. Os próximos parágrafos explicam, em detalhes, a estratégia pedagógica utilizada pelo sistema para a determinação do plano de ensino (sequência de conteúdos e questões apresentados) dos alunos.

A navegação pelo sistema é feita através de links chamados "Próximo" ou "Continuar". Ao acessá-los, o aluno é direcionado para o próximo conteúdo mais apropriado ou questão a ser apresentado. De um modo geral, para cada conceito, o aluno segue os seguintes passos:

- Primeiro, é apresentado o pré-teste;

- Após a resposta do pré-teste, é visualizado um dos níveis de representação criados para o conceito;

- Por último, é apresentado o pós-teste.

Este é o mecanismo básico de navegação pelo qual o aluno é guiado em cada conceito. Ele é ilustrado na Figura 3.2. Entretanto, este mecanismo pode sofrer alterações devido ao desempenho do aluno nos testes. Estas alterações serão apresentadas no decorrer desta seção.

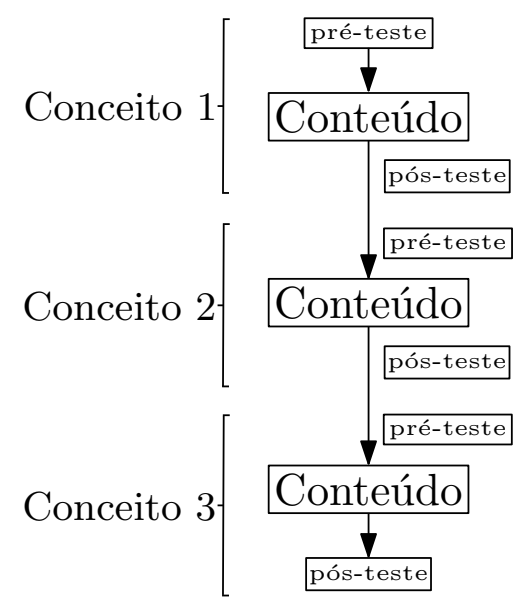

Figura 3.2: Mecanismo de testes utilizado para os conceitos.

A adaptação do conteúdo é feita através das estimativas (probabilidades) que o aluno tem de conhecer cada conceito que será ministrado pelo curso (fornecidas pelo seu Modelo do Aluno e atualizadas após cada teste realizado). Elas são utilizadas para gerar adaptação da seguinte forma: 
- Após acerto ou erro do pré-teste - neste caso, a probabilidade é utilizada para determinar qual será o conteúdo mais apropriado a ser apresentado ao aluno. A Figura 3.3 ilustra este processo;

- Após erro do pós-teste - em que o aluno já visualizou um conteúdo referente ao conceito, porém, como ele errou o teste apresentado, é visualizado outro conteúdo referente ao mesmo conceito, determinado pela probabilidade fornecida pelo MA. Este novo conteúdo é uma atividade de reforço, que tem por objetivo fazer com que o aluno assimile o conceito. A Figura 3.3 ilustra este processo;

- Após acerto do pós-teste - neste caso, a probabilidade é utilizada para determinar se o aluno está apto a visualizar os elementos adicionais existentes em algum conteúdo de nível superior ao conteúdo que foi apresentado antes do teste. Estes elementos são referenciados como conteúdo simplificado, pois representam apenas uma parte do conteúdo superior. A Tabela 3.2 apresenta este processo.

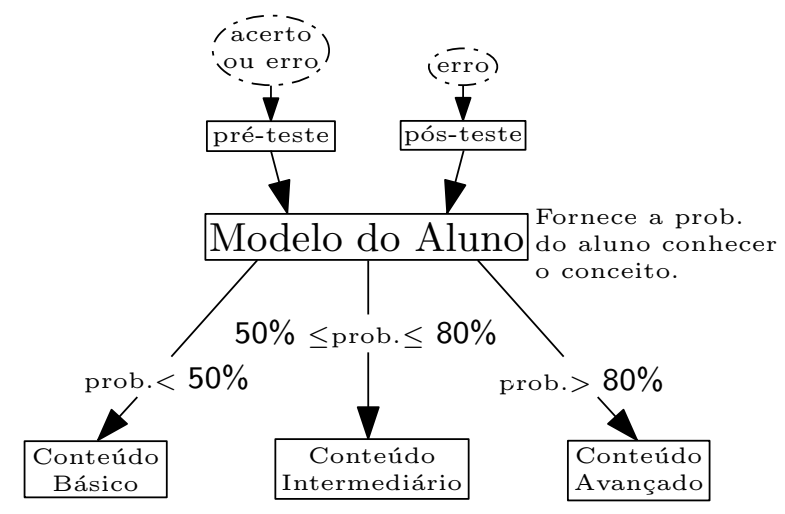

Figura 3.3: Mecanismo geral para a adaptação do conteúdo.

Duas restrições são impostas ao mecanismo de adaptação apresentado:

- Quando o aluno erra o pré-teste não pode ser apresentado a ele o conteúdo de nível avançado do conceito envolvido;

- O conteúdo apresentado após o erro do pós-teste (reforço) deve ser de nível inferior ou igual ao do conteúdo visualizado antes do erro.

Quando o aluno acerta o pós-teste e não é determinado a visualização de um conteúdo simplificado, o aluno avança para o pré-teste do novo conceito que será apresentado.

Quando o aluno erra o pós-teste, após a apresentação da atividade de reforço, é aplicado outro pós-teste, denominado de $2^{\circ}$ pós-teste, que tem por objetivo avaliar se o aluno 


\begin{tabular}{ccc}
\hline $\begin{array}{c}\text { Conteúdo anterior } \\
\text { ao pós-teste }\end{array}$ & $\begin{array}{c}\text { Prob. de conhecer o } \\
\text { conceito após o pós-teste }\end{array}$ & $\begin{array}{c}\text { Conteúdo } \\
\text { simplificado }\end{array}$ \\
\hline Nível Básico & $50 \% \leq$ prob. $\leq 80 \%$ & Nível Intermediário \\
Nível Básico & prob. $>80 \%$ & Nível Avançado \\
Nível Intermediário & prob. $>80 \%$ & Nível Avançado \\
\hline
\end{tabular}

Tabela 3.2: Mecanismo para apresentação do conteúdo simplificado após o acerto do pós-teste pelo aluno.

assimilou o conceito. Após respondê-lo, o aluno, mesmo em caso de erro, avança para o novo conceito a ser ministrado, sendo, então, apresentado o seu pré-teste. A resposta deste $2^{\circ}$ pós-teste também é utilizada para ajustar o MA, conforme já apresentado nesta seção.

As Figuras 3.4, 3.5 e 3.6 ilustram e resumem os caminhos que o aluno pode percorrer para determinado conceito no sistema proposto.

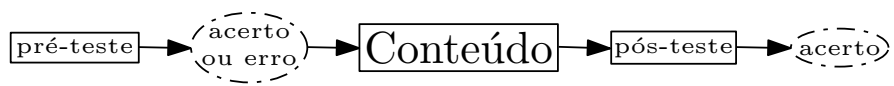

Figura 3.4: Sequência percorrida pelo aluno em caso de acerto do pós-teste, em que o conteúdo simplificado não é visualizado.

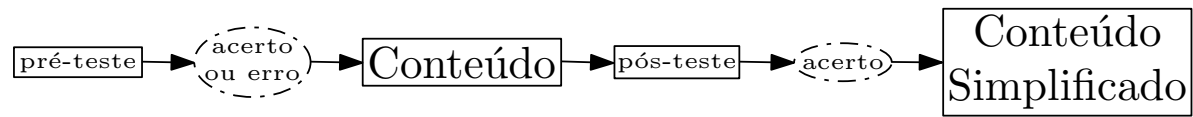

Figura 3.5: Sequência percorrida pelo aluno em caso de acerto do pós-teste, em que o conteúdo simplificado é visualizado.

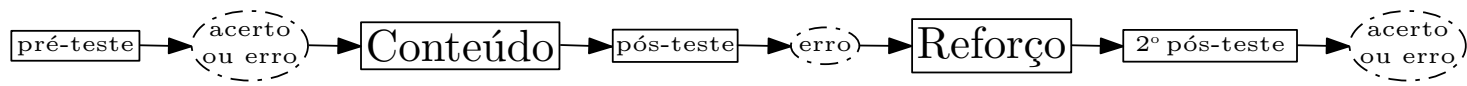

Figura 3.6: Sequência percorrida pelo aluno em caso de erro do pós-teste, em que o reforço e o $2^{\circ}$ pós-teste são apresentados.

\subsection{Comportamento do Modelo do Aluno}

Em geral, o mecanismo de ajuste do MA apresentado vai ao encontro das regras estabelecidas na estratégia pedagógica (presentes no Modelo de Adaptação), ele reduz, em caso de erro nos testes, as habilidades calculadas para os alunos e as estimativas que eles têm de conhecer os conceitos, o que permite que conteúdos com níveis de dificuldade 
inferiores sejam apresentados. Deste modo, os alunos têm acesso aos conteúdos expressos de forma mais didática e com mais exemplos.

De modo inverso, quando os alunos acertam os testes, ocorre uma melhoria das suas habilidades e das estimativas de conhecimento dos conceitos, o que permite o acesso aos conteúdos mais abrangentes e aos conteúdos simplificados.

Como pôde ser observado, as respostas dadas aos testes ajustam as estimativas que o sistema possui do aluno, permitindo que no decorrer do curso seja obtido um plano de ensino personalizado e dinâmico, atualizado a cada interação com o aluno. 


\section{Aplicação Experimental e Resultados}

Este capítulo apresenta o experimento realizado e os resultados obtidos. São expostos o curso e a Rede Bayesiana criados, além de outros aspectos relevantes do SHAE proposto.

Além do sistema proposto, provido de mecanismos de adaptação, foi criado e utilizado um sistema desprovido de adaptação, cujo objetivo era viabilizar um estudo comparativo. Desejava-se que os alunos que fizessem uso do SHAE retivessem mais conhecimento. Os resultados obtidos foram positivos, houve evidência de ganhos significativos na retenção de conhecimento por parte dos alunos que fizeram uso do sistema provido de adaptação.

\subsection{Aplicação Experimental}

Para avaliar o sistema proposto foi realizado um experimento, cujo principal objetivo era avaliar a influência dos mecanismos de adaptação nos resultados obtidos. A meta que se desejava alcançar era a melhoria nos níveis de aprendizado dos alunos. As próximas seções explicam, em detalhes, este experimento.

\subsubsection{Curso}

Para o experimento, foi criado um mini-curso que foi ministrado pelo SHAE. Este curso envolve os principais conceitos presentes no Modelo de Entidade-Relacionamento (MER), que é um modelo de dados conceitual muito utilizado durante o projeto de banco de dados. Foram selecionados 10 conceitos a serem ensinados, para os quais foram criados os níveis de representação e os testes. Estes conceitos, indicados na sequência em que são apresentados no curso, são: 1. Entidade, 2. Atributo, 3. Atributo Identificador, 4. Relacionamento, 5. Restrições de Relacionamento, 6. Entidade Fraca, 7. Especialização,

8. Generalização, 9. Restrições de Especialização e Generalização, 10. Herança. 
A criação dos conteúdos e testes do curso teve como base os trabalhos de Elmasri e Navathe (2006) e Silberschatz, Korth e Sudarshan (2005). O Apêndice A apresenta o material que foi criado para o conceito 2 .

\subsubsection{Organização do Curso e dos Níveis de Representação}

O curso criado é constituído por quatro etapas, são elas:

- Introdução - apresenta uma visão geral sobre o MER, contextualizando-o dentro do processo de projeto de banco de dados;

- Questionário do histórico do aluno - pequeno questionário (apresentado no Apêndice B) em que são coletadas informações que podem afetar o desempenho do aluno no curso. Estas questões avaliam qual é a proximidade ou familiaridade que o aluno tem em relação ao domínio que será abordado no curso (MER), em relação a banco de dados e à Orientação a Objetos (que também podem influenciar nos resultados);

- Atividades de ensino - é a principal etapa, em que os 10 conceitos selecionados são ensinados, seguindo a metodologia apresentada no capítulo anterior;

- Questionário de avaliação do curso - pequeno questionário (apresentado no Apêndice B) que busca avaliar a satisfação do usuário em relação ao curso que foi apresentado.

Para orientar os alunos durante a realização do curso, foi criado um mecanismo de mensagens que tem por objetivo indicar ao aluno qual será a próxima atividade a ser realizada (apresentação de conteúdo ou teste). Quando a atividade é um conteúdo, é indicado se ele é o primeiro conteúdo referente ao conceito envolvido (após a resposta do pré-teste), uma atividade de reforço ou um conteúdo simplificado. Quando a atividade é um teste, o mecanismo indica se ele é de pré ou pós-teste e, quando o aluno o responde, é indicado se ele o acertou ou não. O mecanismo também indica quando uma nova etapa do curso é alcançada.

O curso também apresenta um mecanismo para a visualização de "dicas", que podem ser visualizadas pelos alunos durante a leitura do texto posicionando o mouse sobre os links existentes (colocados em destaque) na página. Este mecanismo explica algum termo ou cenário existente no sistema. Ele é útil quando é preciso fazer referência a um termo que foi apresentado em um momento muito anterior do curso.

Os mecanismos de mensagens e de visualização de dicas, além de orientarem e tornarem o processo de ensino mais intuitivo e fácil, formam uma ferramenta de interação entre 
o sistema (representado pelo curso) e o aluno, aproximando-os e tornando a experiência do aluno com o sistema mais agradável. Exemplos de mensagens e dicas apresentadas aos alunos podem ser vistos no Apêndice B.

Os conteúdos criados para os conceitos selecionados não são extensos, de modo a não sobrecarregar os alunos com excesso de informações. Estes conteúdos são compostos por texto e imagens. Outros tipos de mídias, como vídeos e animações, não foram utilizados.

Para a elaboração do curso e dos conteúdos foram utilizados alguns dos princípios presentes na Teoria da Elaboração (REIGELUTH; STEIN, 1983). Esta teoria constitui um modelo de desenho instrucional para organização e sequência de conteúdos para aprendizagem. Nela, o aprendiz desenvolve um contexto significativo, no qual ideias e habilidades subsequentes podem ser assimiladas e integradas.

Os princípios da Teoria da Elaboração utilizados foram:

- Estrutura do curso - o curso deve possuir uma estrutura de organização que reflita o seu foco principal, seguindo um dos seguintes tipos: conceitual (utilizado quando são ensinados conceitos, eventos ou ideias que se relacionam), procedimental (utilizado quando tem-se uma tarefa ou informação complexa a ser ensinada) ou teórica (utilizado quando são ensinados regras ou princípios que se relacionam);

- Sequência de lições (conteúdos) apresentadas - a partir da definição da estrutura do curso, para que a aprendizagem se processe de modo mais eficiente e adequado, a apresentação das lições precisa seguir a seguinte sequência: da lição mais simples para a mais complexa, da lição geral para a particular;

- Sequência interna das lições - os elementos presentes em cada lição também devem ser apresentados do mais simples para o mais complexo e do geral para o particular;

- Analogias - fazem a ligação entre o conteúdo apresentado e o conhecimento prévio do aluno. Elas se utilizam de um conceito ou ideia que é familiar para introduzir ou definir um novo conceito ou ideia. Elas auxiliam o aluno a construir seu conhecimento;

- Ativadores das estratégias cognitivas - trata-se do uso de vários dispositivos (diagramas, organogramas, ilustrações, etc.) que podem ativar as estratégias cognitivas necessárias para que o aluno processe adequadamente os conteúdos apresentados.

Diante disto, o tipo de estrutura utilizado pelo curso ministrado pelo SHAE foi o conceitual. Neste curso, os conteúdos foram criados e apresentados seguindo o princípio "do 
simples para o complexo". Estes conteúdos também fizeram uso de analogias e ilustrações como recursos que visam melhorar o processo de ensino-aprendizagem.

Nos níveis de representação criados, os termos considerados importantes (palavraschave) foram colocados em destaque, através dos seguintes recursos de formatação de texto: negrito e itálico. Este destaque facilita a identificação dos termos que são mais importantes e para os quais deve ser dada uma maior atenção.

Os conteúdos simplificados criados, em geral, eram compostos por dois ou três parágrafos. Para dois conceitos, 8 e 9 , não foram criados conteúdos simplificados para o nível avançado, devido à falta de elementos adicionais que poderiam ser adicionados a este nível. Deste modo, nestes conceitos, os conteúdos intermediário e avançado possuem os mesmos elementos, apenas expressos de formas distintas.

\subsubsection{Rede Bayesiana}

A partir dos conceitos do MER selecionados e das suas principais relações foi criada uma rede de conceitos, cuja estrutura serviu como base para a criação da Rede Bayesiana que compõe o Modelo do Aluno. A Figura 4.1 apresenta a RB criada.

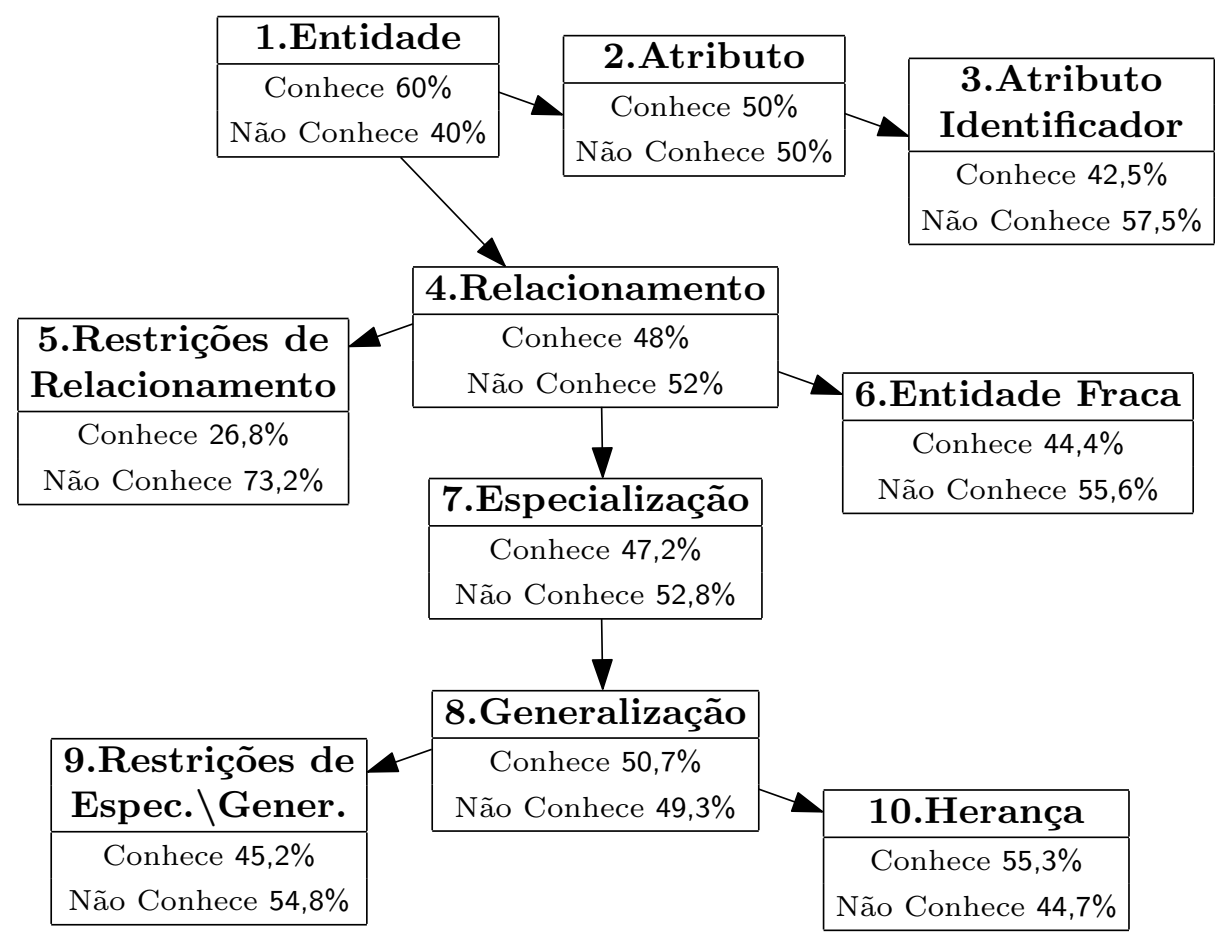

Figura 4.1: Estrutura da RB e as probabilidades iniciais (após a primeira compilação da rede) que os alunos têm de conhecer ou não os conceitos. As estimativas de conhecimento ou não dos conceitos podem variar de 0 a $100 \%$.

Da Figura 4.1, observa-se que a RB criada é simples e que ela é simplesmente conec- 
tada. Pode-se observar também que os alunos possuem, à exceção do conceito Restrições de Relacionamento, estimativas iniciais de conhecimento dos conceitos próximas de $50 \%$.

A criação da rede de conceitos e das partes qualitativa e quantitativa da $\mathrm{RB}$ foram determinadas com o auxílio de um especialista no domínio abordado (modelo de dados conceitual MER, neste caso). Para esta criação manual da RB foram seguidas as seguintes etapas, que tiveram como base as etapas apresentadas em Lucas, Gaag e Abu-Hanna (2004):

- Seleção das variáveis relevantes - nesta etapa foram identificadas as variáveis do domínio abordado que são relevantes. Esta identificação foi realizada através de entrevistas com o especialista do domínio e de extensa análise do domínio tratado. O propósito para o qual a rede estava sendo criada também foi um fator considerado durante este processo;

- Identificação dos relacionamentos entre as variáveis - nesta etapa foi realizada a análise das relações de dependência e independência existentes entre as variáveis selecionadas na etapa anterior. A noção de causalidade foi empregada como guia nesta análise. Por exemplo, durante a entrevista com o especialista, perguntas do tipo "O que causa tal efeito?" ou "Que manifestação essa causa pode ter?" auxiliaram na identificação dos relacionamentos;

- Identificação dos tipos e estados das variáveis - nesse estágio foram identificadas quais eram os tipos das variáveis selecionadas (discretas, neste caso) e quais eram os estados que elas poderiam assumir (conhece e não conhece, neste caso). Este processo auxiliou a estimação e verificação das probabilidades requeridas para a criação da rede;

- Estimação das probabilidades - neste estágio, as probabilidades condicionais (ou incondicionais) para cada nó da rede foram definidas. Esta foi a etapa mais complexa, que exigiu maior dedicação por parte do especialista envolvido. Ao final dela, a RB estava completamente criada;

- Análise de sensibilidade e avaliação da rede - em que foi verificada a validade da rede criada. Para isto, foi analisado se as relações de relevância e independência probabilística presentes na topologia da rede refletiam as relações reais existentes entre as variáveis do domínio. Também foi realizada a análise da sensibilidade dos resultados fornecidos pela rede em função de variações na distribuição de probabili- 
dades de uma ou mais variáveis de interesse. Esta etapa evidenciou ajustes que se mostravam necessários.

Ao final destas etapas foram realizadas simulações que envolviam a inserção de evidências virtuais, conforme o mecanismo de ajuste do MA já apresentado (Seção 3.2.1). Foi observado o comportamento da rede após a propagação destas evidências. Estas simulações também contribuíram para o ajuste das probabilidades condicionais que são inseridas como evidência na rede quando o aluno erra os testes (não conhece os conceitos envolvidos).

\subsubsection{Testes de Habilidade}

As questões de pós-teste e de $2^{\circ}$ pós-teste criadas para o curso possuem de quatro a cinco itens. Já as questões de pré-teste possuem de três a quatro itens. Como cada conceito ministrado pelo curso possui uma questão de cada um destes tipos, foram criadas um total de 30 questões de múltipla escolha.

Houve dificuldade durante a elaboração dos pré-testes, por representarem um tipo de questão que não aborda diretamente o conceito, mas sim algumas de suas características e ideias, para os quais nem sempre era simples uma abordagem de forma indireta ("genérica").

Os parâmetros dos testes, referentes ao Modelo Logístico de 3 Parâmetros da TRI, não foram calibrados, devido à falta de alunos disponíveis para a aplicação dos testes. Conforme apresentado na Seção 2.4.3, a calibração é um processo que, para resultados satisfatórios, necessita de um grande número de respostas às questões.

Por este motivo, o parâmetro de discriminação $(a)$ recebeu o valor fixo 1 para todos os testes. Para o parâmetro de dificuldade $(b)$, como os pré-testes são mais fáceis, foi definido para eles o valor 0,6 e o valor 1 para os pós-testes e $2^{\circ}$ pós-testes (foi considerado que eles possuem dificuldades semelhantes). A probabilidade de acerto ao acaso (c) de cada teste foi representada pelo inverso do número de itens que ele possui.

Para o cálculo da habilidade $(\theta)$ do aluno (utilizada pelo ML3P da TRI) através do método EAP, foi considerado que o intervalo de variação para $\theta$ é de -3 a +3 . Também se considerou o número de pontos de quadratura igual a 40 e a distribuição normal padrão $\left(\mu=0\right.$ e $\left.\sigma^{2}=1\right)$ como a distribuição a priori utilizada. 


\subsubsection{Sistema Tradicional}

Para que um estudo comparativo fosse realizado, foi criado um sistema desprovido de mecanismos de adaptação, que foi chamado de sistema tradicional. Nele, o curso é oferecido seguindo a metodologia "um curso para todos". Deste modo, sempre é apresentado o mesmo conteúdo a todos os alunos. Para uma fácil distinção entre os sistemas criados, o sistema proposto neste trabalho, provido de adaptação, foi chamado de sistema adaptativo.

O curso oferecido pelo sistema tradicional possui as mesmas etapas que estão presentes no curso ministrado pelo sistema adaptativo. A introdução e os questionários utilizados por ambos os sistemas são os mesmos. Entretanto, as atividades de ensino apresentam diferenças, apresentadas a seguir.

No sistema tradicional, em comparação com o sistema adaptativo, não são aplicadas as questões de pré-teste e sempre é apresentado ao aluno o conteúdo de nível intermediário de cada conceito. Após a visualização deste conteúdo é apresentada a questão de pós-teste do conceito envolvido.

Caso o aluno acerte o pós-teste, ele avança para o próximo conteúdo a ser ministrado. Em caso de erro, é dada a opção do aluno avançar para o próximo conceito ou de rever o conteúdo apresentado antes da questão (atividade de reforço, mas sem adaptação). Se ele optar por rever o conteúdo, logo após a visualização deste, é apresentada a questão de $2^{\circ}$ pós-teste do conceito. Após respondê-la, mesmo em caso de erro, o aluno avança para o próximo conceito a ser ensinado. Estes caminhos que o aluno pode percorrer estão ilustrados nas Figuras 4.2 e 4.3 .

O sistema tradicional faz uso dos mesmos pós-testes e $2^{\circ}$ pós-testes utilizados pelo sistema adaptativo. Nele, não é dada a opção de visualização de conteúdo simplificado quando o aluno acerta o pós-teste.

O conteúdo intermediário foi escolhido para uso neste sistema pois o seu entendimento pelos alunos já foi considerado satisfatório para os propósitos do curso.

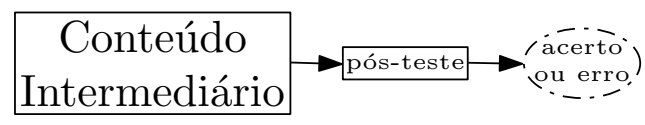

Figura 4.2: Caminho percorrido pelo aluno, para cada conceito, quando ele acerta o pósteste ou quando ele o erra mas opta por não rever o conteúdo anteriormente apresentado. 


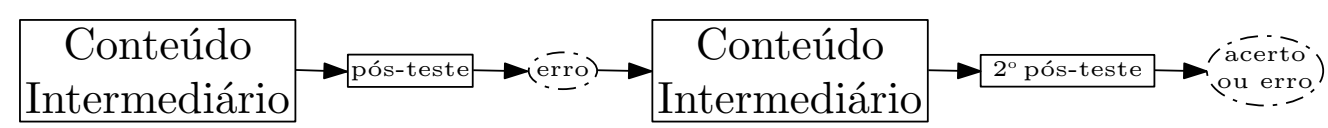

Figura 4.3: Caminho percorrido pelo aluno, para cada conceito, quando ele erra o pós-teste e opta por rever o conteúdo anteriormente apresentado.

\subsubsection{Ambiente Tecnológico}

Os sistemas utilizados foram implementados na linguagem de programação Java, versão 1.5, com o uso das tecnologias Servlets e Java Server Pages (JSP). Para o uso da Rede Bayesiana e do mecanismo de inferência (algoritmo de Árvore de Junção), foi agregado ao sistema adaptativo a framework UnBBayes, versão 3.52.7, que foi adaptada para dar suporte à inserção de evidências virtuais. Esta adaptação foi feita seguindo o modelo apresentado por Valtorta, Kim e Vomlel (2002), que se baseia no método proposto por Pearl $(1988,1990)$.

Cada conteúdo criado para os conceitos presentes no curso sobre o MER foi escrito na linguagem HyperText Markup Language (HTML).

Para armazenar os dados referentes aos sistemas e alunos foi utilizado o Sistema Gerenciador de Banco de Dados (SGBD) PostgreSQL, versão 9.0. O servidor de aplicações utilizado para gerenciar os sistemas criados foi o Apache Tomcat, versão 6.

Os sistemas e o SGBD foram hospedados em um computador desktop comum, que possuía um processador Intel Core 2 Duo de 2,8GHz e 4GB de memória RAM. O sistema operacional utilizado neste desktop era o Linux, distribuição OpenSuse.

Por se tratarem de sistemas voltados para a $W e b$, o acesso a eles era feito através de um navegador de Internet qualquer.

\subsubsection{Amostra}

A amostra contém 50 alunos pertencentes a duas turmas da disciplina de Banco de Dados do Instituto de Informática da Universidade Federal de Goiás. Os alunos, em sua grande maioria, não possuíam familiaridade com o modelo de dados MER.

Em cada turma participante, os alunos foram divididos entre os dois sistemas criados. A coleta de dados em cada turma foi realizada em momentos distintos. Neste trabalho, o grupo que fez uso do sistema adaptativo foi chamado de grupo experimental, enquanto que o grupo que fez uso do sistema tradicional foi chamado de grupo de controle. A 
Tabela 4.1 mostra a distribuição dos grupos por turma.

\begin{tabular}{ccc}
\hline \multirow{2}{*}{ Turma } & \multicolumn{2}{c}{ Grupo } \\
\cline { 2 - 3 } & Experimental & Controle \\
\hline Ciências da Computação & 19 & 18 \\
Sistemas de Informação & 6 & 7 \\
\hline Total & 25 & 25 \\
\hline
\end{tabular}

Tabela 4.1: Grupos que compõem a amostra por turma.

\subsection{Resultados}

Diante da grande diversidade de características presente nos alunos que fazem uso de sistemas de e-learning, este trabalho propôs um SHAE que fornece cursos com conteúdo personalizado aos alunos e que faz uso da $W e b$ para ensinar. Os alunos que fizeram uso deste sistema provido de adaptação, também chamado de sistema adaptativo, compõem o grupo experimental.

Para verificar se o uso dos mecanismos de adaptação resultam na melhoria dos níveis de aprendizado, uma parte dos alunos fez uso de um sistema desprovido de adaptação, chamado de sistema tradicional, formando o grupo de controle. As seções a seguir apresentam os principais resultados obtidos no experimento realizado, conforme análise e interpretação dos dados. Resultados complementares podem ser consultados no Apêndice C.

\subsubsection{Análise Descritiva e Inferencial}

Os dados obtidos são medidas do desempenho, do tempo gasto e da experiência dos alunos nos sistemas utilizados. Na forma descritiva, os dados são analisados em termos de mínimo, máximo, média e desvio padrão.

A Tabela 4.2 apresenta os resultados obtidos para cada grupo no questionário que realizou o levantamento do histórico dos alunos. Pode-se perceber que os resultados foram bastante próximos, o que indica que os grupos possuem familiaridades semelhantes em relação aos principais fatores que podem influenciar seus desempenhos no curso. Esta semelhança permite uma comparação "honesta" entre os resultados obtidos. Percebese também que os alunos, em sua grande maioria, eram iniciantes no domínio que foi abordado pelo curso. 


\begin{tabular}{cccc}
\hline \multirow{2}{*}{ Assunto } & \multirow{2}{*}{ Grupo } & \multicolumn{2}{c}{ Familiaridade } \\
\cline { 3 - 4 } & & Sim & Não \\
\hline \multirow{2}{*}{ Banco de Dados } & Experimental & 7 & 18 \\
& Controle & 6 & 19 \\
\hline \multirow{2}{*}{ MER } & Experimental & 4 & 21 \\
& Controle & 3 & 22 \\
\hline \multirow{2}{*}{ Orientação a Objetos } & Experimental & 25 & 0 \\
& Controle & 22 & 3 \\
\hline
\end{tabular}

Tabela 4.2: Respostas obtidas pelos grupos no questionário para levantamento do histórico dos alunos.

A estatística descritiva do tempo gasto pelos grupos nas atividades de ensino (conteúdos e testes apresentados) do curso está expressa na Tabela 4.3. Pode-se perceber maior heterogeneidade no grupo experimental (tendo em vista o desvio padrão maior obtido) e que ele gastou um pouco a mais de tempo (três minutos e 14 segundos, em média) que o grupo de controle para realizar as atividades. Estes fatos podem ser justificados pela maior complexidade presente nos mecanismos utilizados pelo sistema adaptativo, como a apresentação das questões de pré-teste, de conteúdos simplificados e das atividades de reforço adaptadas ao usuário (que são obrigatórias em caso de erro dos pós-testes).

\begin{tabular}{ccc}
\hline \multirow{2}{*}{ Estatística } & \multicolumn{2}{c}{ Grupo } \\
\cline { 2 - 3 } & Experimental & Controle \\
\hline Mínimo & $46 \mathrm{~min} 13 \mathrm{~s}$ & $46 \mathrm{~min} 27 \mathrm{~s}$ \\
Máximo & $2 \mathrm{~h} 14 \mathrm{~min} 40 \mathrm{~s}$ & $1 \mathrm{~h} 57 \mathrm{~min} 57 \mathrm{~s}$ \\
Média & $1 \mathrm{~h} 17 \mathrm{~min} 53 \mathrm{~s}$ & $1 \mathrm{~h} 14 \mathrm{~min} 39 \mathrm{~s}$ \\
Desvio Padrão & $23 \mathrm{~min} \mathrm{49s}$ & $18 \mathrm{~min} 58 \mathrm{~s}$ \\
\hline
\end{tabular}

Tabela 4.3: Estatística descritiva do tempo gasto nas atividades de ensino.

Quando desconsiderados os tempos gastos nas visualizações dos pré-testes e dos conteúdos simplificados, o grupo experimental obteve um tempo médio gasto nas atividades de ensino de dez minutos e treze segundos menor do que o obtido pelo grupo de controle, conforme pode ser observado da Tabela 4.4. Entretanto, desta tabela, pode-se observar que o desvio padrão obtido pelo grupo experimental ainda é um pouco maior do que o desvio obtido pelo grupo de controle nas atividades de ensino.

A Tabela 4.5 apresenta o tempo médio gasto por cada grupo para a realização de 
todo o curso (desde a introdução até o questionário de avaliação do sistema). Como já era esperado, o grupo experimental gastou um pouco a mais de tempo que o grupo de controle para concluir o curso; em média, foram três minutos e 34 segundos a mais.

\begin{tabular}{ccc}
\hline Grupo & Tempo Médio & Desvio Padrão \\
\hline Experimental & 1h $04 \mathrm{~min} 26 \mathrm{~s}$ & $20 \mathrm{~min} 32 \mathrm{~s}$ \\
\hline
\end{tabular}

Tabela 4.4: Tempo médio gasto nas atividades de ensino pelo grupo experimental ao se desconsiderar os pré-testes e conteúdos simplificados apresentados.

\begin{tabular}{cc}
\hline Grupo & Tempo Médio Total \\
\hline Experimental & 1h $26 \mathrm{~min} 42 \mathrm{~s}$ \\
Controle & 1h $23 \mathrm{~min} 8 \mathrm{~s}$ \\
\hline
\end{tabular}

Tabela 4.5: Tempo médio gasto para a realização de todo o curso.

O principal objetivo que se desejava alcançar com o experimento realizado era a melhoria nos níveis de aprendizado por parte dos alunos que fizeram uso do sistema adaptativo. A comparação entre os resultados obtidos pelos grupos nos pós-testes foi utilizada para medir se este objetivo foi alcançado.

A nota que cada aluno obteve no curso foi composta pelo número de acertos que ele obteve nestes testes. Deste modo, como foram selecionados 10 conceitos para serem ministrados pelo curso e para cada um deles era aplicado um pós-teste, a nota do aluno poderia variar entre 0 e 10. A Tabela 4.6 apresenta os resultados obtidos.

\begin{tabular}{ccc}
\hline \multirow{2}{*}{ Estatística } & \multicolumn{2}{c}{ Grupo } \\
\cline { 2 - 3 } & Experimental & Controle \\
\hline Mínimo & 2 & 2 \\
Máximo & 9 & 8 \\
Média & 5,84 & 5,04 \\
Desvio Padrão & 1,43 & 1,74 \\
\hline
\end{tabular}

Tabela 4.6: Estatística descritiva do desempenho dos alunos nos pós-testes.

Em termos percentuais, o grupo experimental obteve, em média, um desempenho 15,87\% superior ao obtido pelo grupo de controle. Ele também obteve um desvio padrão menor, indicando resultados mais homogêneos. A Figura 4.4 apresenta um resumo das respostas obtidas pelos grupos nos pós-testes. Pode-se observar que o grupo experimental acertou 20 destes testes a mais que o grupo de controle. 


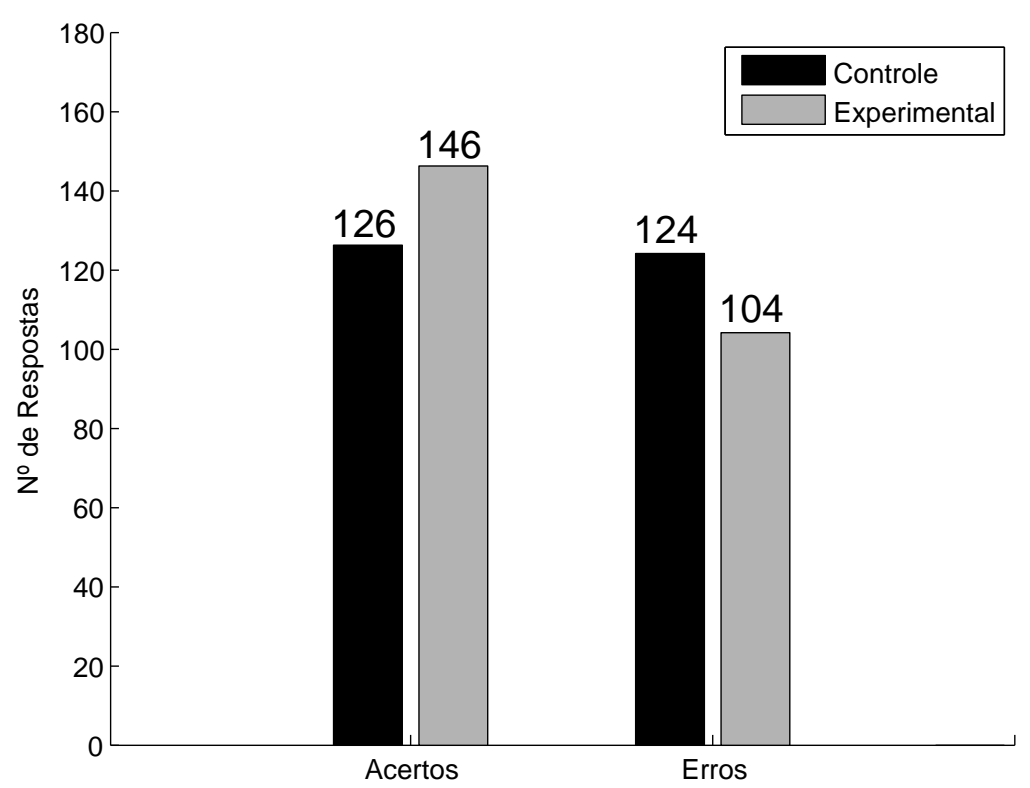

Figura 4.4: Número de acertos e erros obtidos pelos grupos nas questões de pós-teste.

Também foi realizado um teste estatístico para comparar o desempenho obtido pelos grupos. A partir dos testes estatísticos, a análise inferencial extrapola os resultados obtidos a partir das amostras pela estatística descritiva, generalizando as conclusões por ela obtidas para a população (COSTA, 2005).

Para a realização deste teste foi utilizado o Teste t (Student) para amostras independentes, em que a hipótese nula $\left(H_{o}\right)$ considerava que os grupos possuíam médias iguais e a hipótese alternativa $\left(H_{a}\right)$ admitia que a média do grupo experimental era superior à do grupo de controle. O nível de significância $(\alpha)$ adotado para a prova da hipótese nula foi de $5 \%$.

O teste estatístico, expresso na Tabela 4.7, retornou um nível de significância observado, também denotado por $\alpha$ efetivo ou p-value, igual a 4,15\%. Com este resultado, a hipótese nula foi rejeitada, o que, consequentemente, fortalece a hipótese alternativa e evidencia que houve ganho significativo na retenção de conhecimento por parte do grupo que fez uso do sistema adaptativo. Deste modo, o principal objetivo desejado foi alcançado. Em outras palavras, a hipótese básica proposta por este trabalho foi corroborada.

Uma característica bastante desejável para a utilização do Teste t é que as amostras envolvidas possuam variâncias iguais (homogêneas). Para tanto, foi realizado o Teste de Levene, que obteve um $\alpha$ efetivo igual 0,221, o que fortalece que as variâncias das amostras, embora desconhecidas, são equivalentes.

As respostas obtidas pelos grupos nas questões de $2^{\circ}$ pós-teste foram utilizadas para 


\begin{tabular}{ccc}
\hline \multirow{2}{*}{ Estatística } & \multicolumn{2}{c}{ Grupo } \\
\cline { 2 - 3 } & Experimental & Controle \\
\hline Média & 5,84 & 5,04 \\
Observações & 25 & 25 \\
t observado & 1,77 \\
$\alpha$ efetivo unicaudal & 0,0415 \\
t crítico & \multicolumn{2}{|c}{} \\
\hline
\end{tabular}

Tabela 4.7: Estatística inferencial (Teste t) do desempenho dos alunos nos pós-testes.

avaliar seus desempenhos nas atividades de reforço oferecidas pelos sistemas. No grupo de controle, em que o reforço não era obrigatório, os alunos optaram por visualizá-lo em 94 dos 124 erros obtidos nos pós-testes.

Enquanto o grupo de controle acertou $60,6 \%$ dos $2^{\circ}$ pós-testes que foram apresentados, o grupo experimental acertou $68,2 \%$ destes testes, o que sugere que as atividades de reforço fornecidas pelo sistema adaptativo possibilitaram um melhor desempenho. A Figura 4.5 mostra um resumo dos resultados obtidos nestes testes. Pode-se perceber que o grupo de controle errou um número maior de $2^{\circ}$ pós-testes, mesmo tendo realizado um número menor destes testes ( o grupo de controle respondeu a $942^{\circ}$ pós-testes, enquanto que o grupo experimental respondeu 104 destes testes).

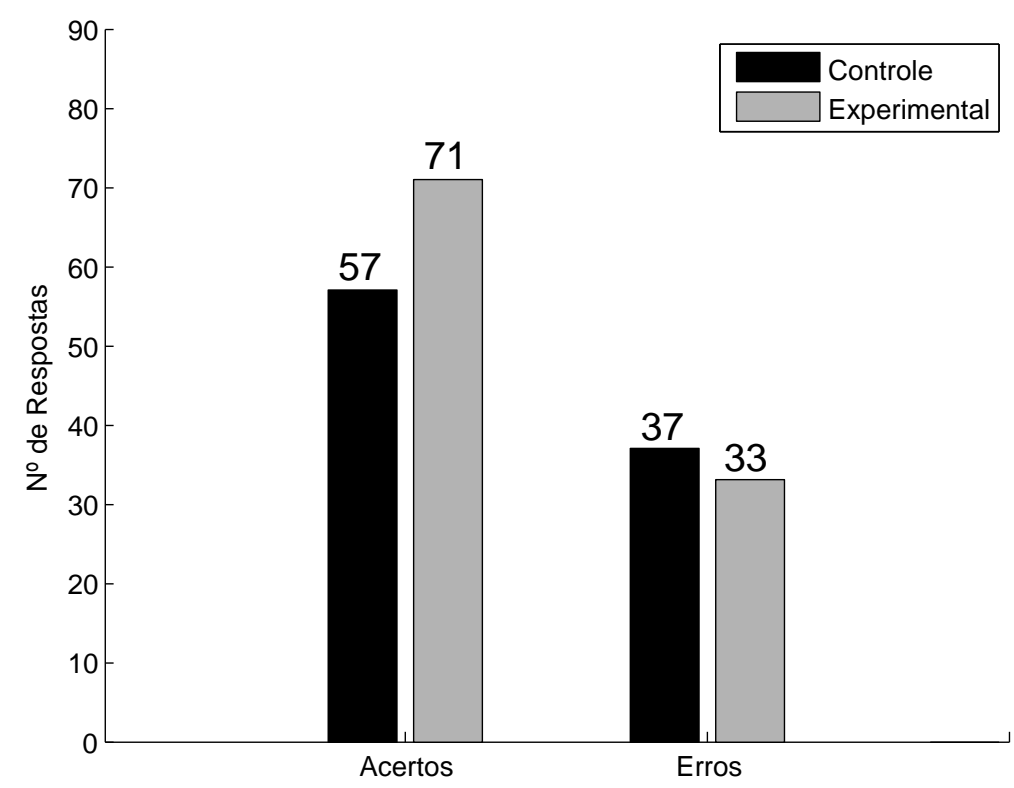

Figura 4.5: Número de acertos e erros obtidos pelos grupos nas questões de $2^{\circ}$ pós-teste.

Em relação ao tempo gasto na visualização das atividades de reforço, foi verificado 
que ambos os grupos gastaram, em média, 38 segundos. Considerando que as atividades de reforço são compostas pelos níveis de representação básico ou intermediário criados para os conceitos, esta média foi considerada baixa.

Mais especificamente, em 65 das 104 atividades de reforço apresentadas ao grupo experimental e em 58 das 94 atividades de reforço apresentadas ao grupo de controle os conteúdos foram visualizados em menos de 30 segundos, o que indica que estes alunos não demonstraram interesse pelo conteúdos de reforço, eles simplesmente avançaram para $2^{\circ}$ pós-teste logo após os reforços terem aparecido.

O tempo de 30 segundos foi considerado o mínimo necessário para que o aluno identificasse no texto os elementos nos quais teve dificuldade e os lê-se. Deve-se ressaltar que os conteúdos criados não foram extensos e que as palavras-chave eram apresentadas em destaque no texto, o que permitia a fácil localização dos principais elementos do texto.

A Tabela 4.8 apresenta os tempos médios obtidos em outras atividades do curso. Podese observar que o grupo experimental obteve melhores resultados. De um modo geral, a adaptação do conteúdo ao conhecimento do aluno proporcionou, além de um melhor desempenho, uma redução significativa nos tempos necessários para a visualização dos conteúdos apresentados antes dos pós-testes (aspecto abordado em detalhes na próxima seção) e para se responder os pós-testes e $2^{\circ}$ pós-testes.

\begin{tabular}{|c|c|c|c|}
\hline \multirow[b]{2}{*}{ Grupo } & \multicolumn{3}{|c|}{ Tempo Médio } \\
\hline & $\begin{array}{l}\text { Conteúdo Anterior } \\
\text { ao Pós-teste }\end{array}$ & Pós-teste & $2^{\mathrm{o}}$ Pós-teste \\
\hline Experimental & $4 \mathrm{~min} 23 \mathrm{~s}$ & $1 \mathrm{~min} 25 \mathrm{~s}$ & $56 \mathrm{~s}$ \\
\hline Controle & $5 \min 8 s$ & $1 \mathrm{~min} 40 \mathrm{~s}$ & $1 \mathrm{~min} 10 \mathrm{~s}$ \\
\hline
\end{tabular}

Tabela 4.8: Tempos médios gastos em algumas atividades do curso.

Para avaliar como foi a experiência que os alunos tiveram com o curso que foi apresentado, foram utilizadas as respostas dadas ao questionário de avaliação do curso. A Tabela 4.9 resume os resultados obtidos. Percebe-se que os resultados obtidos para os cursos oferecidos por ambos os sistemas são semelhantes, não houve destaque para um curso em específico. De um modo geral, todos os aspectos analisados pelo questionário obtiveram resultados bastante favoráveis em relação aos cursos que foram oferecidos. Diante disto, a hipótese secundária proposta neste trabalho não foi confirmada.

Vale destacar que os alunos foram quase unânimes, mesmo no grupo que visualizou apenas os conteúdos de nível intermediário, ao indicar que os conteúdos apresentados 
foram adequados, o que facilitou o processo de aprendizagem. Tal fato evidencia que os conteúdos criados foram de boa qualidade.

Observa-se, ainda em relação à Tabela 4.9, uma pequena vantagem do curso ministrado pelo sistema adaptativo em relação tempo proposto e ao grau de satisfação dos alunos. Nenhum dos alunos do grupo experimental julgou seu grau de satisfação em relação ao curso como "Insatisfeito". Entretanto, em relação ao conteúdo apresentado, o curso oferecido pelo sistema adaptativo obteve uma pequena desvantagem, sendo julgado como "Inadequado" por um aluno.

\begin{tabular}{lccc}
\hline \multirow{2}{*}{ Questão } & Opção & 24 & \multicolumn{2}{c}{ Grupo } \\
\cline { 3 - 4 } & & Experimental & Controle \\
\hline $\begin{array}{l}\text { Tempo proposto para } \\
\text { a realização do curso. }\end{array}$ & $\begin{array}{c}\text { Adequado } \\
\text { Poderia ter } \\
\text { sido maior }\end{array}$ & 1 & 21 \\
& Inadequado & 0 & 2 \\
\hline $\begin{array}{l}\text { Conteúdo exposto no } \\
\text { curso. }\end{array}$ & Adequado & 24 & 2 \\
\hline $\begin{array}{l}\text { Grau de satisfação em } \\
\text { relação ao curso. }\end{array}$ & Satisfeito & 21 & 0 \\
\hline
\end{tabular}

Tabela 4.9: Respostas obtidas pelos grupos no questionário de avaliação do curso.

Em relação ao desempenho computacional dos sistemas, apesar deles estarem hospedados em um computador desktop comum, eles exigiram, em média, menos de $8 \%$ da sua capacidade de processamento e o servidor de aplicações fez uso de pouco menos de $60 \mathrm{MB}$ de memória RAM, o que demostra a viabilidade de execução em tempo real dos algoritmos utilizados.

\subsubsection{SHAE Proposto}

Na seção anterior, foi apresentado um estudo comparativo entre os resultados obtidos pelos sistemas tradicional e adaptativo, em que foram analisados os desempenhos, tempos médios gastos e as experiências obtidas pelos grupos de alunos. Esta seção destaca alguns aspectos apresentados pelo sistema adaptativo, que é a principal contribuição deste trabalho, como os comportamentos obtidos pelos modelos de adaptação e do aluno. 
As Tabelas 4.10 , 4.11 e 4.12 apresentam as distribuições dos níveis de representação determinadas pelos mecanismos de adaptação utilizados.

A Tabela 4.10 indica que apenas 20,4\% dos conteúdos apresentados após os prétestes foram de nível avançado, o que é comum nos processos de ensino-aprendizagem, em que muitas vezes o aluno não está apto a visualizar diretamente o conteúdo mais abrangente e descrito de modo mais técnico. Esta falta de aptidão pode se dar pelo fato do aluno ser iniciante no domínio abordado, por possuir dificuldade natural em aprender e se concentrar, etc. A tabela também indica uma proximidade entre a frequência com que os conteúdos básico e intermediário foram apresentados ( 36,8\% e 42,8\% dos casos, respectivamente).

\begin{tabular}{ccc}
\hline $\begin{array}{c}\text { Nível de } \\
\text { Dificuldade }\end{array}$ & $\begin{array}{c}\text { No de }^{\text {Conteúdos }} \\
\text { Contrico }\end{array}$ & Tempo Médio \\
\hline Básin & 92 & $3 \min 5 \mathrm{~s}$ \\
Intermediário & 107 & $4 \min 35 \mathrm{~s}$ \\
Avançado & 51 & $4 \min 48 \mathrm{~s}$ \\
\hline
\end{tabular}

Tabela 4.10: Conteúdos apresentados após os pré-testes.

Em relação aos tempos médios gastos para a visualização de cada tipo de conteúdo, também apresentados na Tabela 4.10, percebe-se que o nível básico obteve a menor média, seguido pelos níveis intermediário e avançado, que obtiveram médias próximas. Estas médias vão ao encontro do que foi estabelecido para a criação dos conteúdos: o conteúdo básico seria o mais simples e menos abrangente e, portanto, de leitura mais fácil; o conteúdo intermediário seria mais abrangente e já faria uso de linguajar técnico em alguns momentos, o que exigiria mais para a sua leitura; e o conteúdo avançado seria o mais direto e abrangente entre os tipos de conteúdo e faria uso de linguajar técnico, o que tornaria sua leitura a mais complexa.

Dos tempos médios, percebe-se ainda que o tempo gasto para a visualização do conteúdo intermediário no sistema adaptativo foi, em média, 33 segundos menor (ou 11\% menor) que o tempo gasto para a visualização deste mesmo tipo de conteúdo no sistema tradicional (apresentado na Tabela 4.8). Apesar da diferença existente entre o número de apresentações deste tipo de conteúdo (107 no sistema adaptativo contra 250 no sistema tradicional), percebe-se que a apresentação destes conteúdos fornecida pelo SHAE proposto, considerados os mais apropriados aos alunos, resultou em um tempo médio melhor. 
Houve um total de 52 acertos nos pós-testes que foram apresentados após a visualização dos 92 conteúdos de nível básico. 64 pós-testes apresentados após a visualização dos conteúdos intermediários foram respondidos corretamente e houve um total de 30 acertos nos pós-testes apresentados após a visualização dos 51 conteúdos de nível avançado.

A Tabela 4.11 indica que um total 45 conteúdos simplificados foram apresentados, o que representa que elementos adicionais foram visualizados pelos alunos em 43,3\% dos casos em que os pós-testes foram respondidos corretamente (para este cálculo foram excluídos os casos em que o conteúdo avançado foi visto antes dos pós-testes e os casos em que poderia ser apresentado um conteúdo simplificado de nível avançado para os conceitos 8 e 9; nestas situações, não existe conteúdo simplificado a ser visualizado).

Este resultado foi considerado bastante expressivo; um número significativo de acertos dos pós-testes permitiu aos alunos a ampliação, de forma gradativa, dos seus conhecimentos sobre os conceitos envolvidos. Os alunos gastaram um minuto e seis segundos, em média, para visualizar os conteúdos simplificados, o que foi considerado satisfatório, visto que eles são compostos por dois ou três parágrafos que, em geral, não são extensos.

\begin{tabular}{cc}
$\begin{array}{c}\text { Nível de } \\
\text { Dificuldade }\end{array}$ & $\begin{array}{c}\mathbf{N}^{\mathbf{o}} \text { de } \\
\text { Conteúdos }\end{array}$ \\
\hline Intermediário & 10 \\
Avançado & 35 \\
\hline
\end{tabular}

Tabela 4.11: Conteúdos simplificados apresentados após os acertos dos pós-testes.

Apesar de não ter sido implementada nenhuma restrição, os mecanismos de adaptação do SHAE proposto não determinaram que um conteúdo simplificado de nível avançado fosse visualizado após o acerto de um pós-teste em que antes dele foi visualizado um conteúdo básico. Deste modo, os conteúdos simplificados de nível avançado foram apresentados após a visualização dos conteúdos intermediários e os conteúdos simplificados de nível intermediário foram vistos após a apresentação dos conteúdos básicos.

A Tabela 4.12 indica que na grande maioria das atividades de reforço, cerca de $84,6 \%$, foi apresentado o tipo de conteúdo expresso de forma mais simples e didática. Deste modo, após a maior parte dos casos de erro dos pós-testes, o sistema estimou que a probabilidade dos alunos conhecerem os conceitos envolvidos estava abaixo de $50 \%$.

Ainda em relação às atividades de reforço, em 64 delas foi determinado a apresentação de um conteúdo de nível inferior ao do conteúdo que foi apresentado antes do pós-teste. Mais especificamente, atividades de reforço adaptadas foram apresentadas em todos os 
casos em que esta adaptação era possível (nos 40 erros de pós-testes em que antes foram visualizados conteúdos de nível básico esta adaptação não era possível).

\begin{tabular}{cc}
\hline $\begin{array}{c}\text { Nível de } \\
\text { Dificuldade }\end{array}$ & $\begin{array}{c}\mathbf{N}^{\mathbf{o}} \text { de } \\
\text { Conteúdos }\end{array}$ \\
\hline Básico & 88 \\
Intermediário & 16 \\
\hline
\end{tabular}

Tabela 4.12: Conteúdos de reforço apresentados após os erros dos pós-testes.

Os alunos gastaram, em média, um minuto e nove segundos para visualizar os prétestes. Estes testes foram respondidos incorretamente 56 vezes (ou em 22,4\% dos casos). Como os pós-testes foram respondidos incorretamente em 41,6\% das vezes, conforme pode ser obtido da Figura 4.4, pode-se concluir que as questões de pré-teste são mais fáceis, pois elas obtiveram pouco mais de 53,8\% do número de erros obtidos nos pós-testes. Este resultado foi ao encontro do estabelecido para o parâmetro de dificuldade do Modelo de 3 Parâmetros da TRI, em que o valor definido para este parâmetro nos pré-testes foi consideravelmente menor ao do estabelecido para os pós-testes.

Os acertos e erros obtidos nos testes resultaram na distribuição das habilidades calculadas pelo método EAP para os alunos ao final de cada conceito (após a resposta do pós-teste ou do $2^{\circ}$ pós-teste, caso exista) apresentada na Figura 4.6. Pode-se verificar que uma grande diversidade de habilidades foi obtida. Tal diversidade contribuiu para a heterogeneidade obtida nas probabilidades que os alunos tinham de conhecer os conceitos, discutida a seguir.

A Figura 4.7 apresenta as probabilidades de conhecimento ao final de cada conceito calculadas para os alunos. Observa-se que o Modelo do Aluno, já a partir do conceito 2, gerou estimativas bastante diferenciadas para os alunos. Este resultado era esperado, pois, como já mencionado, a diversidade de características dos alunos é um aspecto central em e-leaning. Como estas probabilidades são utilizadas para fornecer adaptação, tem-se que conteúdos diferenciados (adaptados) foram apresentados aos alunos. As distribuições dos conteúdos apresentadas nas Tabelas 4.10 , 4.11 e 4.12 comprovam este fato.

Outro aspecto que contribuiu para a diversidade das estimativas calculadas foi a estrutura da RB criada, que reflete as relações de dependência entre os conceitos. Nela, um conceito recebe influência de outros conceitos além dos que estão diretamente ligados a ele. Por exemplo, o conceito 3 recebe influência direta do conceito 2 e indireta do conceito 1. Assim, as respostas obtidas nos testes do conceito 1 também irão influenciar nas 


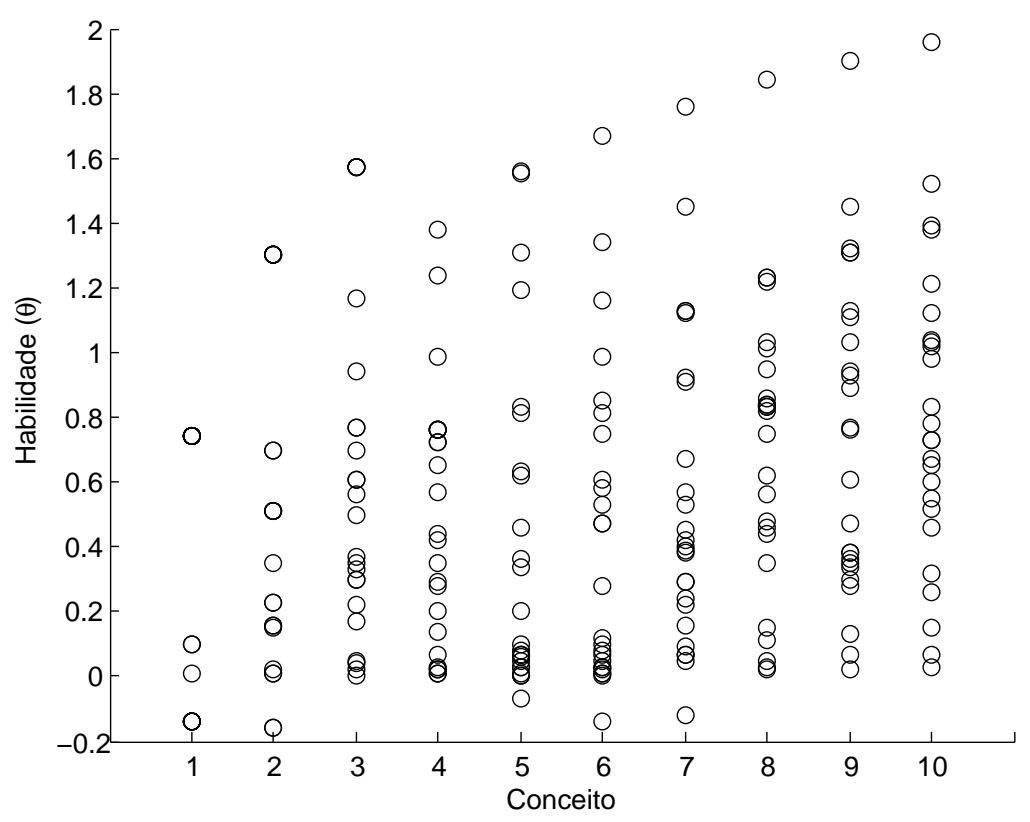

Figura 4.6: Distribuição das habilidades ao final de cada conceito calculada pelo método EAP para os alunos.

estimativas que serão geradas para o conceito 3. O mesmo também ocorre em relação ao conceito 7, que recebe influência direta do conceito 4 e indireta dos demais conceitos que o antecedem na topologia da rede.

Das Figuras 4.6 e 4.7 observa-se, de um modo geral, o bom resultado obtido pelos alunos do conceito 7 em diante. Estes conceitos pertencem ao que é frequentemente chamado de recursos estendidos do MER, nos quais os conceitos apresentam proximidade com conceitos existentes na Orientação a Objetos, com a qual os alunos possuíam familiaridade, conforme expresso na Tabela 4.2.

O mecanismo de ajuste do Modelo do Aluno (Seção 3.2.1) resultou, em caso de erro em algum teste (seja ele de pré-teste, pós-teste ou $2^{\circ}$ pós-teste), numa redução de $66,9 \%$, em média, na probabilidade de conhecimento do aluno no conceito envolvido. Quando um aluno acertou algum teste, o mecanismo de ajuste resultou em um aumento, em média, de 39,4\% da estimativa que ele tinha de conhecer o conceito envolvido. Estas taxas indicam que o mecanismo "penaliza" o aluno em uma proporção maior do que o "beneficia". Este comportamento reflete os efeitos da alta probabilidade (80\%) do aluno não conhecer o conceito envolvido, inserida como evidência na $\mathrm{RB}$, em caso de erro nos testes.

Este comportamento era desejado, uma vez que, de modo geral, a evidência de que o aluno não conhece o conceito em caso de erro do teste é mais forte do que a evidência que o aluno tem de conhecer o conceito em caso de acerto do mesmo teste (devido a fatores como a possibilidade do aluno "chutar" e acertar a questão, por exemplo). 


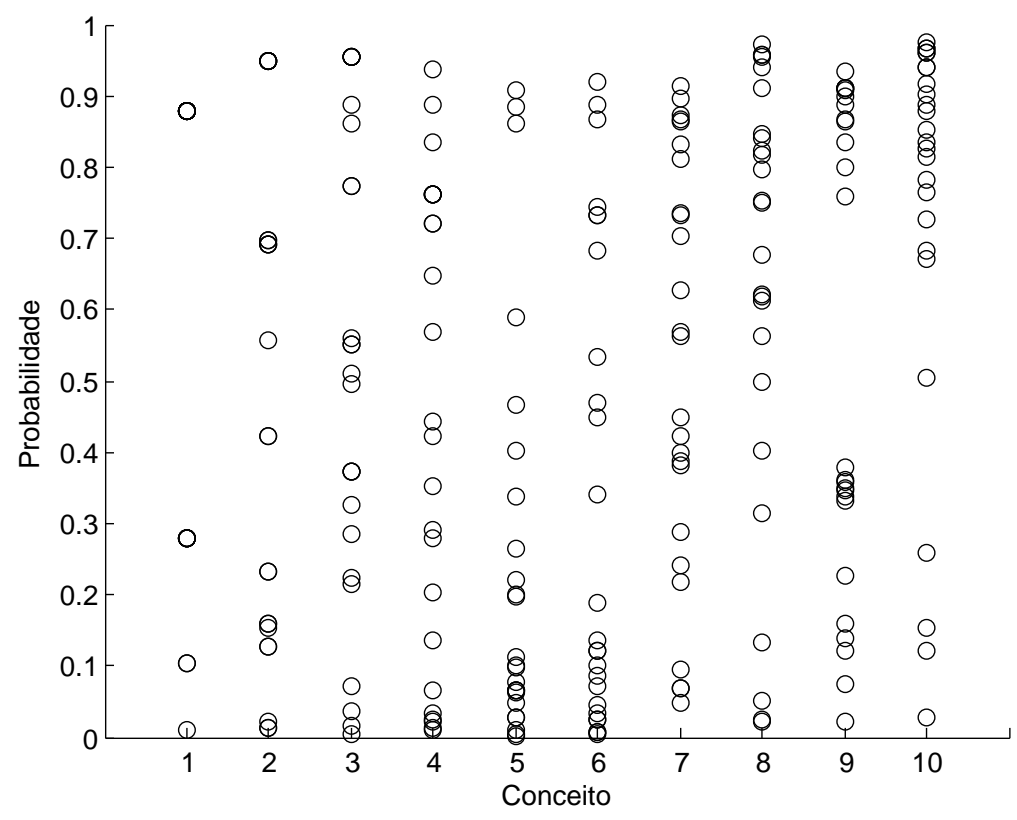

Figura 4.7: Distribuição das probabilidades de conhecimento ao final de cada conceito calculada pela RB para os alunos.

A Figura 4.8 apresenta as habilidades que foram calculadas pelo método EAP para três dos alunos que fizeram uso do SHAE proposto. O Aluno 1 apresentou o melhor desempenho, o Aluno 2 apresentou um desempenho mediano e o Aluno 3 foi o que obteve o pior desempenho entre os alunos. Nesta figura, a primeira inclinação após cada conceito (ascendente ou descendente) se refere à resposta do seu pré-teste, a segunda se refere ao seu pós-teste, a terceira se refere ao seu $2^{\circ}$ pós-teste (caso uma $4^{\circ}$ inclinação esteja presente no conceito) ou à questão de pré-teste do próximo conceito e a $4^{0}$ inclinação, caso exista, refere-se ao pré-teste do próximo conceito.

Percebe-se, ainda em relação à Figura 4.8, que durante a primeira metade do curso ocorreram grandes oscilações nas habilidades calculadas para cada aluno. Isto se deve principalmente ao baixo número de respostas aos testes que o método EAP possui para o cálculo das habilidades.

As Tabelas 4.13, 4.14 e 4.15 apresentam as probabilidades que os três alunos selecionados têm de conhecer os conceitos. Pode ser observado a variação destas probabilidades em função do mecanismo de ajuste do Modelo do Aluno utilizado. Elas também apresentam as probabilidades calculadas pelo ML3P da TRI nos casos de acertos dos testes.

As tabelas também mostram as probabilidades de conhecimento dos conceitos antes da apresentação dos seus pré-testes. A comparação destas probabilidades com as probabilidades de conhecimento iniciais da RB, apresentadas na Figura 4.1, permite visualizar como determinados conceitos influenciam outros conceitos. 


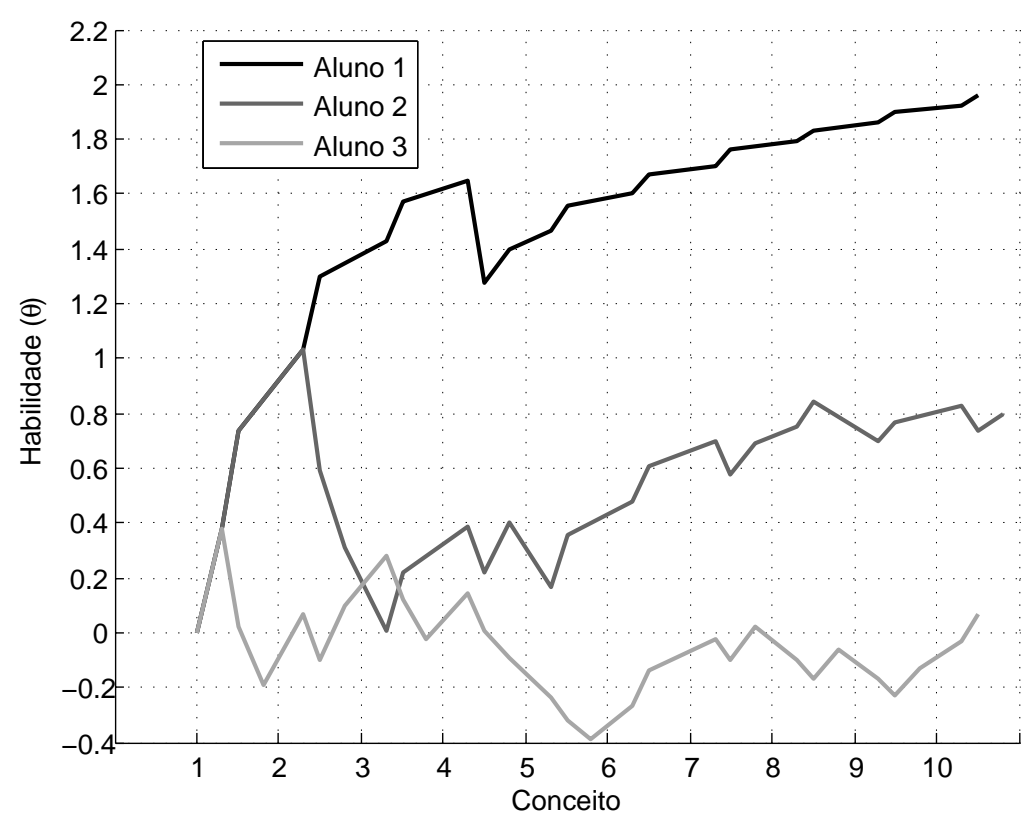

Figura 4.8: Evolução das habilidades dos três alunos do grupo experimental selecionados.

\begin{tabular}{cccccccc}
\hline & \multicolumn{7}{c}{ Probabilidade } \\
\cline { 2 - 8 } Conceito & $\begin{array}{c}\text { Antes } \\
\text { Pré-teste }\end{array}$ & ML3P & $\begin{array}{c}\text { Após } \\
\text { Pré-teste }\end{array}$ & ML3P & $\begin{array}{c}\text { Após } \\
\text { Pós-Teste }\end{array}$ & ML3P & $\begin{array}{c}\text { Após 2 } \\
\text { Pós-Teste }\end{array}$ \\
\hline 1 & $60 \%$ & $55,5 \%$ & $76,9 \%$ & $54,3 \%$ & $87,8 \%$ & - & - \\
2 & $63,9 \%$ & $75,5 \%$ & $84,2 \%$ & $70 \%$ & $94,9 \%$ & - & - \\
3 & $71,7 \%$ & $86,8 \%$ & $86,8 \%$ & $79,4 \%$ & $95,4 \%$ & - & - \\
4 & $67,7 \%$ & $90,4 \%$ & $85 \%$ & - & $51,6 \%$ & $74,6 \%$ & $76,1 \%$ \\
5 & $36,6 \%$ & $86 \%$ & $66,5 \%$ & $77,7 \%$ & $88,5 \%$ & - & - \\
6 & $57,1 \%$ & $89,7 \%$ & $78,2 \%$ & $81,8 \%$ & $92,1 \%$ & - & - \\
7 & $54,1 \%$ & $91,1 \%$ & $76,3 \%$ & $83,8 \%$ & $91,5 \%$ & - & - \\
8 & $79,4 \%$ & $92,1 \%$ & $91,5 \%$ & 85,4 & $97,3 \%$ & - & - \\
9 & $59,2 \%$ & $93 \%$ & $80,2 \%$ & $86,7 \%$ & $93,4 \%$ & - & - \\
10 & $79,2 \%$ & $93,6 \%$ & $91,4 \%$ & $87,7 \%$ & $97,4 \%$ & - & - \\
\hline
\end{tabular}

Tabela 4.13: Probabilidades de conhecimento dos conceitos calculadas para o Aluno 1. 


\begin{tabular}{cccccccc}
\hline & \multicolumn{7}{c}{ Probabilidade } \\
\cline { 2 - 8 } Conceito & $\begin{array}{c}\text { Antes } \\
\text { Pré-teste }\end{array}$ & ML3P & $\begin{array}{c}\text { Após } \\
\text { Pré-teste }\end{array}$ & ML3P & $\begin{array}{c}\text { Após } \\
\text { Pós-Teste }\end{array}$ & ML3P & $\begin{array}{c}\text { Após 2 } \\
\text { Pós-Teste }\end{array}$ \\
\hline 1 & $60 \%$ & $55,5 \%$ & $76,9 \%$ & $54,3 \%$ & $87,8 \%$ & - & - \\
2 & $63,9 \%$ & $75,5 \%$ & $84,2 \%$ & - & $50,1 \%$ & - & $15,8 \%$ \\
3 & $20,3 \%$ & - & $4,5 \%$ & $40,7 \%$ & $7,2 \%$ & - & - \\
4 & $56,3 \%$ & $60,8 \%$ & $70,1 \%$ & - & $30,6 \%$ & $44,8 \%$ & $44,1 \%$ \\
5 & $25,4 \%$ & - & $6 \%$ & $40,2 \%$ & $11,4 \%$ & - & - \\
6 & $41,3 \%$ & $63,4 \%$ & $57,2 \%$ & $50,6 \%$ & $73 \%$ & - & - \\
7 & $47 \%$ & $69,5 \%$ & $65 \%$ & - & $25,8 \%$ & $52,7 \%$ & $42,3 \%$ \\
8 & $47,5 \%$ & $71 \%$ & $65,8 \%$ & $57,3 \%$ & $81,5 \%$ & - & - \\
9 & $54,4 \%$ & - & $18,3 \%$ & $55,4 \%$ & $33,2 \%$ & - & - \\
10 & $68,8 \%$ & $73 \%$ & $82,8 \%$ & - & $47,5 \%$ & $56,3 \%$ & $67,1 \%$ \\
\hline
\end{tabular}

Tabela 4.14: Probabilidades de conhecimento dos conceitos calculadas para o Aluno 2.

\section{Probabilidade}

\begin{tabular}{cccccccc}
\cline { 2 - 7 } Conceito & $\begin{array}{c}\text { Antes } \\
\text { Pré-teste }\end{array}$ & ML3P & $\begin{array}{c}\text { Após } \\
\text { Pré-teste }\end{array}$ & ML3P & $\begin{array}{c}\text { Após } \\
\text { Pós-Teste }\end{array}$ & ML3P & $\begin{array}{c}\text { Após 2 } \\
\text { Pós-Teste }\end{array}$ \\
\hline 1 & $60 \%$ & $55,5 \%$ & $76,9 \%$ & - & $38,4 \%$ & - & $10,5 \%$ \\
2 & $25,2 \%$ & $46,7 \%$ & $38,7 \%$ & - & $10,6 \%$ & $38,4 \%$ & $15,4 \%$ \\
3 & $20 \%$ & $57,9 \%$ & $30,2 \%$ & - & $7,5 \%$ & - & $1,5 \%$ \\
4 & $18,1 \%$ & $54,1 \%$ & $26,4 \%$ & - & $6,3 \%$ & - & $1,2 \%$ \\
5 & $10,4 \%$ & - & $2,1 \%$ & - & $0,4 \%$ & - & $0,07 \%$ \\
6 & $30,2 \%$ & $45,7 \%$ & $37,3 \%$ & $34,4 \%$ & $45 \%$ & - & - \\
7 & $40,1 \%$ & $50,5 \%$ & $50,4 \%$ & - & $16 \%$ & $36,9 \%$ & $21,9 \%$ \\
8 & $34,2 \%$ & - & $8,9 \%$ & - & $1,8 \%$ & $35,6 \%$ & $2,5 \%$ \\
9 & $30,7 \%$ & - & $7,7 \%$ & - & $1,5 \%$ & $34,6 \%$ & $2,1 \%$ \\
10 & $30,7 \%$ & $50,3 \%$ & $40,1 \%$ & $37,7 \%$ & $50,3 \%$ & - & - \\
\hline
\end{tabular}

Tabela 4.15: Probabilidades de conhecimento dos conceitos calculadas para o Aluno 3. 


\section{Conclusão}

A educação baseada na Web se tornou uma importante vertente em Educação à Distância, fornecendo conhecimento sem a limitação de tempo ou espaço. Neste ambiente, a diversidade de características dos alunos é um aspecto relevante, o que torna desejável que o conteúdo fornecido pelos sistemas se adeque às características individuais dos alunos. Também é desejável que estes sistemas contemplem as incertezas e imprecisões que são inerentes aos alunos e suas características.

A Hipermídia Adaptativa, área que se concentra em considerar a heterogeneidade dos usuários durante os mais variados processos (entre eles o de aprendizagem), tem sido alvo de pesquisadores das mais diferentes áreas (como Modelagem do Usuário, Sistemas Tutores Inteligentes e Ciência Cognitiva). As pesquisas desenvolvidas têm contribuído para consolidar a Hipermídia Adaptativa como uma área de fundamental importância.

Os aspectos apresentados serviram como motivação e justificativa para este trabalho. Diante disto, este trabalho propôs um ambiente $W e b$ de ensino à distância que tem como objetivo prover cursos com conteúdo personalizado (adaptado) aos alunos, que faz uso de uma técnica de Inteligência Computacional para a representação das características dos alunos e de técnicas de Hipermídia Adaptativa para prover personalização.

Este ambiente, classificado como um Sistema Hipermídia Adaptativo Educacional, possui como principal característica um Modelo do Aluno que é capaz de lidar com as incertezas referentes ao conhecimento dos alunos (característica dos alunos considerada pelo sistema). O tratamento destas incertezas é possível devido ao uso de uma Rede Bayesiana para a representação deste modelo. O uso desta técnica de Inteligência Computacional permitiu a simplificação da estratégia pedagógica utilizada; poucas regras foram necessárias para a determinação do plano de ensino dos alunos. De um modo geral, as estimativas de conhecimento dos conceitos pelos alunos, fornecidas através do uso desta técnica, é toda a informação que o sistema necessita para fornecer adaptação.

Outro aspecto relevante deste sistema é o uso do Modelo Logístico de 3 Parâmetros, 
da Teoria da Resposta ao Item, na avaliação das respostas fornecidas pelos alunos em testes de habilidade, que são utilizadas para ajustar o Modelo do Aluno.

O experimento realizado demonstrou que o sistema proposto forneceu conteúdo personalizado aos alunos, corroborando a hipótese básica proposta neste trabalho. Em comparação realizada com outro sistema criado, desprovido de mecanismos de adaptação, o sistema proposto possibilitou aos alunos uma melhoria significativa nos índices de retenção de conhecimento, evidenciada pelo teste estatístico t (Student). Os resultados também mostraram que as atividades de reforço (adaptadas) geradas pelo sistema proposto proporcionaram um melhor desempenho dos alunos nos testes que avaliaram estas atividades.

Entretanto, os níveis de satisfação fornecidos pelos alunos após a realização dos cursos ministrados por ambos os sistemas foram semelhantes. O sistema proposto não se sobressaiu ao outro. Estes resultados apontam para uma boa qualidade dos conteúdos criados, criação esta que considerou alguns dos princípios presentes na Teoria da Elaboração.

Vale destacar dois momentos que se mostraram críticos durante a realização deste trabalho. Um deles foi a dificuldade de criação dos conteúdos, que buscavam contemplar as diferenças existentes na característica dos alunos que foi considerada, e dos testes de habilidade utilizados pelos cursos. O outro momento se refere às dificuldades enfrentadas em relação aos alunos durante o experimento (comuns em pesquisas com humanos) como a alta taxa de ausência, problemas disciplinares, falta de motivação e excesso de ansiedade.

\subsection{Principais Contribuições}

Este trabalho trouxe contribuições para as áreas de Hipermídia Adaptativa e Modelagem do Usuário, através da proposta de uma metodologia de ensino que considera as incertezas relacionadas às características dos alunos durante o processo de aprendizagem, recurso este ainda incomum em ambientes hipermídia para fins educacionais.

Esta metodologia foi testada por alunos reais e ela contribuiu para a melhoria do processo de ensino-aprendizagem (objetivo geral desejado por este trabalho).

A metodologia apresentada é diferenciada; durante a fase de pesquisa bibliográfica e revisão da literatura pertinente não foi encontrada uma proposta semelhante. Por este motivo, muito ainda pode ser explorado e melhorado em relação a esta metodologia.

Outra contribuição importante deste trabalho foram os conteúdos e os testes de habi- 
lidade criados para os cursos que foram oferecidos. Eles podem ser utilizados por outras metodologias de ensino, o que permitiria comparações, ou mesmo pela metodologia apresentada neste trabalho, dotada de algumas melhorias, propostas a seguir.

\subsection{Trabalhos Futuros}

Nesta seção são apresentadas algumas sugestões de melhorias para trabalhos futuros. Algumas delas surgiram de limitações existentes na metodologia apresentada.

Quando um número maior de amostras for coletado pelo sistema proposto, pretendese realizar a calibração dos parâmetros dos testes de habilidade, o que permitiria que o Modelo Logístico de 3 Parâmetros fosse utilizado com um potencial maior, resultando em um melhor ajuste do Modelo do Aluno.

Para que o Modelo do Aluno apresentado se torne mais robusto e próximo dos perfis dos alunos, outras características destes alunos, além do conhecimento, também poderiam ser incorporadas a este modelo. Dentre as características de interesse estão os estilos cognitivos e de aprendizagem, que têm sido utilizadas com sucesso em diversas pesquisas que abordam a personalização de conteúdo em aplicações educacionais, como em Leung e Li (2007).

Em relação ao conteúdo criado para os cursos, outros tipos de mídia, além de imagens, poderiam ser utilizados. Como sugestão, poderiam ser criados vídeos para a apresentação de conceitos e exemplos, os quais poderiam ilustrar analogias e esquemas com palavraschave em destaque. Segundo Moran (1995), o recurso audiovisual enriquece o ambiente de ensino e proporciona uma aprendizagem mais significativa. Nela, as pessoas são influenciadas de forma sensorial, emocional e racional.

Ainda em relação ao conteúdo, outros princípios presentes na Teoria da Elaboração, além dos já utilizados, poderiam ser considerados, colaborando para o enriquecimento dos conteúdos. Por exemplo, poderiam ser criados resumos e sínteses para os conceitos (ou grupo de conceitos) apresentados. Estes recursos auxiliariam os alunos a relacionar e integrar os conceitos envolvidos, propiciando um aprendizado mais aprofundado e significativo.

Outra melhoria sugerida seria a agregação à metodologia proposta de uma estratégia que permitisse maior liberdade de escolha aos alunos durante a realização do curso. Em geral, os alunos se sentem mais interessados e motivados quando possuem algum controle 
sobre o processo de ensino, possibilitando que ele se torne mais eficiente. Este princípio também está presente na Teoria da Elaboração.

Como sugestão para permitir maior liberdade aos alunos, poderia ser dada a opção do aluno visualizar, a qualquer momento do curso, os conteúdos já vistos, referentes aos conceitos já apresentados. Também poderiam ser criados, para cada conceito, vários tipos de conteúdos que seriam apresentados como atividades de reforço, nos quais o conceito a ser revisto poderia ser abordado na forma de um exemplo ou problema (que seria resolvido), de modo visual (em que as ideias e características seriam visualizadas através de animações, por exemplo), entre outros. Nestes casos, seria dada a opção do aluno escolher um dentre estes tipos. 


\section{Referências}

ADKINS, S. S. The Worldwide Market for Self-paced eLearning Products and Services: 2010-2015 Forecast and Analysis. Monroe, USA, 2011.

ANDRADE, D. F.; TAVARES, H. R.; VALlE, R. C. Teoria da Resposta ao Item: Conceitos e Aplicações. São Paulo: Associação Brasileira de Estatística, 2000.

ARAUJO, E. A. C. de; ANDRADE, D. F. de; BORTOLOTTI, S. L. V. Teoria da resposta ao item. Revista da Escola de Enfermagem da USP, v. 43, p. 1000-1008, 2009.

AYALA, R. J. de; SCHAFER, W. D.; SAVA-BOLESTA, M. An investigation of the standard errors of expected a posteriori ability estimates. British Journal of Mathematical and Statistical Psychology, v. 48, n. 2, p. 385-405, 1995.

BAKER, F. The Basics of Item Response Theory. 2. ed. College Park, MD: ERIC Clearinghouse on Assessment and Evaluation, 2001.

BARBOSA, A. T. R. Mecanismo de Adaptação Baseado em Redes Neurais Artificiais para Sistemas Hipermídia Adaptativos. Tese (Doutorado) — Universidade Federal de Santa Catarina, 2004.

BIRNBAUM, A. Some latent trait models and their use in inferring an examinee's ability. In: LORD, F. M.; NOVICK, M. R. (Eds.). Statistical Theories of Mental Test Scores. Reading, MA: Addison-Wesley, 1968. p. 397-479.

BOCK, R. D.; MISLEVY, R. J. Adaptive eap estimation of ability in a micro computer environment. Applied Psychological Measurement, v. 6, n. 4, p. 431-444, 1982.

BONDY, J.; MURTY, U. Graph Theory. New York: Springer, 2008.

BRUSILOVSKY, P. Methods and techniques of adaptive hypermedia. User Modeling and User-Adapted Interaction, Springer, v. 6, n. 2-3, p. 87-129, 1996.

Adaptive hypermedia: from intelligent tutoring systems to web-based education. In: PROCEEDINGS OF THE 5th INTERNATIONAL CONFERENCE ON INTELLIGENT TUTORING SYSTEMS, 2000, Montreal, Canada. London, UK: Springer, 2000. p. $1-7$.

. Adaptive hypermedia. User Modeling and User-Adapted Interaction, Kluwer Academic Publishers, v. 11, n. 1-2, p. 87-110, 2001.

BRUSILOVSKY, P.; MILLÁN, E. User models for adaptive hypermedia and adaptive educational systems. In: BRUSILOVSKY, P.; KOBSA, A.; NEJDL, W. (Eds.). The Adaptive Web. Berlin, Germany: Springer, 2007. p. 3-53. 
BUGAY, E. L. O MODELO AHAM - MI: Modelo de Hipermídia Adaptativa Utilizando Inteligências Múltiplas. Tese (Doutorado) - Universidade Federal de Santa Catarina, 2006.

CASTILlO, E.; GUTIÉRREZ, J.; HADI, A. Expert Systems and Probabilistic Network Models. New York: Springer, 1997.

CHAN, H.; DARWICHE, A. On the revision of probabilistic beliefs using uncertain evidence. Artificial Intelligence, Elsevier, v. 163, n. 1, p. 67-90, 2005.

COOPER, G. F. The computational complexity of probabilistic inference using bayesian belief networks. Artificial Intelligence, Elsevier, v. 42, n. 2-3, p. 393-405, 1990.

COSTA, D. R. Métodos Estatísticos em Testes Adaptativos Informatizados. Dissertação (Mestrado) - Universidade Federal do Rio de Janeiro, 2009.

COSTA, S. F. Introdução Ilustrada à Estatística. 4. ed. São Paulo: Harbra, 2005.

de BRA, P.; HOUBEN, G.-J.; WU, H. Aham: a dexter-based reference model for adaptive hypermedia. In: PROCEEDINGS OF THE 10th ACM CONFERENCE ON HYPERTEXT AND HYPERMEDIA, 1999, Darmstadt, Germany. New York: ACM, 1999. p. $147-156$.

DIESTEL, R. Graph Theory. 3. ed. Berlin, Germany: Springer, 2005.

DING, Z. Bayesowl: A Probabilistic Framework for Uncertainty in Semantic Web. Tese (Doutorado) — University of Maryland, 2005.

DRAPER, D. L. Clustering without (thinking about) triangulation. In: PROCEEDINGS OF THE 11th CONFERENCE ON UNCERTAINTY IN ARTIFICIAL INTELLIGENCE, 1995, Montreal, Canada. San Francisco, CA: Morgan Kaufmann, 1995. p. 125-133.

ELMASRI, R.; NAVATHE, S. B. Fundamentals of Database Systems. 5. ed. Boston, MA: Addison-Wesley, 2006.

GUEWEHR, K. Teoria da Resposta ao Item na Avaliação de Qualidade de Vida de Idosos. Dissertação (Mestrado) — Universidade Federal do Rio Grande do Sul, 2007.

HALASZ, F.; SCHWARTZ, M. The dexter hypertext reference model. Communications of the ACM, v. 37, n. 2, p. 30-39, 1994.

HAMBLETON, R.; SWAMINATHAN, H.; ROGERS, H. Fundamentals of Item Response Theory. Newbury Park, CA: Sage Publications, 1991.

HUANG, C.; DARWICHE, A. Inference in belief networks: a procedural guide. International Journal of Approximate Reasoning, v. 15, n. 3, p. 225-263, 1996.

JENSEN, F.; JENSEN, F. V.; DITTMER, S. L. From influence diagrams to junction trees. In: PROCEEDINGS OF THE 10th CONFERENCE ON UNCERTAINTY IN ARTIFICIAL INTELLIGENCE, 1994, Seattle, WA. San Francisco, CA: Morgan Kaufmann, 1994. p. 367-373.

JENSEN, F.; NIELSEN, T. Bayesian Networks and Decision Graphs. 2. ed. New York: Springer, 2007. 
JENSEN, F. V.; LAURITZEN, S. L.; OLESEN, K. G. Bayesian updating in causal probabilistic networks by local computations. Computational Statistics Quaterly, v. 4, p. 269-282, 1990.

KAPLAN, C.; ROCK, D. New directions for intelligent tutoring. AI Expert, v. 10, n. 2, p. 30-40, 1995.

KOCH, N.; WIRSING, M. The munich reference model for adaptive hypermedia applications. In: PROCEEDINGS OF THE 2nd INTERNATIONAL CONFERENCE ON ADAPTIVE HYPERMEDIA AND ADAPTIVE WEB-BASED SYSTEMS, 2002, Malaga, Spain. London, UK: Springer, 2002. p. 213-222.

KOCH, N. P. de. Software Engineering for Adaptive Hypermedia Systems: Reference Model, Modeling Techniques and Development Process. Tese (Doutorado) - LudwigMaximilians-Universität München, 2000.

KORB, K.; NICHOLSON, A. Bayesian Artificial Intelligence. Boca Raton, Florida: Chapman \& Hall/CRC, 2004.

KOSKI, T.; NOBLE, J. Bayesian Networks: an Introduction. Chichester, UK: John Wiley \& Sons, 2009.

LADEIRA, M.; VICARI, R. M.; COELHO, H. Redes Bayesianas Multiagentes. 1999. Tutorial apresentado no $2^{\circ}$ Encontro Nacional de Inteligência Artificial. Rio de Janeiro.

LAURITZEN, S. L.; SPIEGELHALTER, D. J. Local computations with probabilities on graphical structures and their application to expert systems. Journal of the Royal Statistical Society. Series B (Methodological), v. 50, n. 2, p. 157-224, 1988.

LEUNG, E. W. C.; LI, Q. A model for personalized course material generation based on student learning abilities and interests. In: LIU, W.; LI, Q.; LAU, R. (Eds.). Advances in Web Based Learning. Berlin, Germany: Springer, 2006. p. 25-37.

An experimental study of a personalized learning environment through open-source software tools. IEEE Transactions on Education, v. 50, n. 4, p. 331-337, 2007.

LORD, M. F. A Theory of Test Scores. New York: Psychometric Society, 1952.

LUCAS, P. J.; GAAG, L. C. van der; ABU-HANNA, A. Bayesian networks in biomedicine and health-care. Artificial Intelligence in Medicine, Elsevier, v. 30, n. 3, p. 201-214, 2004.

LUNA, J. E. O. Algoritmos EM para Aprendizagem de Redes Bayesianas a partir de Dados Incompletos. Dissertação (Mestrado) — Universidade Federal de Mato Grosso do Sul, 2004.

MATURAnA, M. C. Aplicação de Redes Bayesianas na Análise da Contribuição do Erro Humano em Acidentes de Colisão. Dissertação (Mestrado) - Universidade de São Paulo, 2009.

MAYO, M. J. Bayesian Student Modelling and Decision-Theoretic Selection of Tutorial Actions in Intelligent Tutoring Systems. Tese (Doutorado) - University of Canterbury, 2001. 
MINAYO, M. C. de S.; SANCHES, O. Quantitativo-qualitativo: oposição ou complementaridade?. Cadernos de Saúde Pública, v. 9, n. 3, p. 237-248, 1993.

MORAN, J. M. O vídeo na sala de aula. Comunicação $\mathscr{G}$ Educação, p. 27-35, 1995.

NAïM, P. et al. Réseaux Bayésiens. 2. ed. Paris: Eyrolles, 2004.

NEAPOLITAN, R. Learning Bayesian Networks. Upper Saddle River, NJ: Prentice Hall, 2004.

NICHOLAS, A.; MARTIN, B. Merging adaptive hypermedia and intelligent tutoring systems using knowledge spaces. In: PROCEEDINGS OF THE 5th INTERNATIONAL CONFERENCE ON ADAPTIVE HYPERMEDIA AND ADAPTIVE WEB-BASED SYSTEMS, 2008, Hannover, Germany. Berlin, Germany: Springer, 2008. p. 426-430.

OLIVEIRA, J. M. P. de. Modelo de Referência para Sistemas Hipermídia Adaptativos Educacionais. Dissertação (Mestrado) — Instituto Tecnológico de Aeronáutica, 2004.

OPPERMANN, R.; RASHEV, R.; KINSHUK, K. Adaptability and adaptivity in learning systems. In: BEHROOK, A. (Eds.). Knowledge Transfer. London, UK: Pace, 1997. v. 2, p. $173-179$.

PALAZZO, L. A. M. Sistemas de Hipermídia Adaptativa. 2002. Minicurso apresentado na XXI Jornada de Atualização em Informática. Florianópolis.

PASQUALI, L.; PRIMI, R. Fundamentos da teoria da resposta ao item: TRI. Avaliação Psicológica, v. 2, n. 2, p. 99-110, 2003.

PEARL, J. Probabilistic Reasoning in Intelligent Systems: Networks of Plausible Inference. San Francisco, CA: Morgan Kaufmann, 1988.

. Jeffrey's rule, passage of experience, and neo-bayesianism. In: KYBURG, H. E.; LOUI, R. P.; CARLSON, G. N. (Eds.). Knowledge Representation and Defeasible Reasoning. Dordrecht: Kluwer Academic Publishers, 1990. p. 245-265.

PRENTZAS, J.; HATZILYGEROUDIS, I. Intelligent Educational Systems for Individualized Learning. 2002. Workshop on Computer Science and Information Technologies CSIT2002. Patras, Greece.

PUGA, S. G. Sistemas Hipermídia Adaptativos para a Educação Baseada na Web: Uma Visão Semiótica. Tese (Doutorado) — Universidade de São Paulo, 2008.

QUEIROZ, C. de N. Redes Bayesianas no Gerenciamento e Mensuração de Riscos Operacionais. Dissertação (Mestrado) — Universidade de São Paulo, 2008.

REIGELUTH, C. M.; STEIN, F. S. The elaboration theory of instruction. In: REIGELUTH, C. M. (Eds.). Instructional Design Theories and Models: An Overview of their Current States. Hillsdale, NJ: Lawrence Erlbaum, 1983. p. 335-382.

RUSSELL, S.; NORVIG, P. Inteligência Artificial: tradução da segunda edição. Rio de Janeiro: Campus/Elsevier, 2004. 
SANTOS, V. L. F. dos. Teoria de Resposta ao Item: Uma Abordagem Generalizada das Curvas Características dos Itens. Dissertação (Mestrado) - Universidade Federal do Rio de Janeiro, 2009.

SILBERSCHATZ, A.; KORTH, H. F.; SUDARSHAN, S. Database Systems Concepts. 5. ed. New York: McGraw-Hill, 2005.

SILVA, G. T. da. Adaptação em um Sistema Educacional Hipermídia Baseada na Classificação de Perfis de Usuários. Dissertação (Mestrado) — Universidade Federal de Santa Catarina, 2005.

SILVA, W. T. da; LADEIRA, M. Mineração de dados em redes bayesianas. Anais do XXII Congresso da Sociedade Brasileira de Computação, v. 2, p. 235-286, 2002.

VALLE, R. da C. Teoria da Resposta ao Item. Dissertação (Mestrado) — Universidade de São Paulo, 1999.

VALTORTA, M.; KIM, Y.-G.; VOMLEL, J. Soft evidential update for probabilistic multiagent systems. International Journal of Approximate Reasoning, Elsevier, v. 29, n. 1, p. 71-106, 2002.

WIKIPÉDIA, A Enciclopédia Livre. Inteligência Artificial. 2011. Disponível em: <http://pt.wikipedia.org/wiki/Inteligência_artificial>. Acesso em: 20 fevereiro 2011.

WOLF, C. Construction of an Adaptive E-learning Environment to Address Learning Styles and an Investigation of the Effect of Media Choice. Tese (Doutorado) - RMIT University, 2007.

XIANG, Y. Probabilistic Reasoning in Multiagent Systems: a Graphical Models Approach. New York: Cambridge University Press, 2002.

ZANCHETT, P. S. Sistema de Hipermídia Adaptativa como Suporte à Orientação de Usuários Idosos. Dissertação (Mestrado) — Universidade Federal de Santa Catarina, 2006. 


\section{APÊNDICE A - Conteúdos e Testes Criados}

Conforme exposto no Capítulo 4, os instrumentos de pesquisa utilizados neste trabalho forneceram um mini-curso sobre o MER. Para exemplificar o material criado, este apêndice apresenta os conteúdos e testes criados para um dos dez conceitos que foram abordados neste mini-curso. O material a ser apresentado, referente ao conceito Atributo, segue a metodologia apresentada no Capítulo 3.

\section{A.1 Conteúdo de Nível Básico}

Os próximos parágrafos abordam, em detalhes, as principais características que os atributos podem ter.

Cada entidade possui valores para cada um de seus atributos, estes valores refletem as características da entidade. Por exemplo, uma entidade Pessoa pode possuir os seguintes valores para seus atributos: nome (João Carlos, por exemplo), CPF (123.456.789-22, por exemplo), data de nascimento (01/10/1983), endereço (rua 4, no800, apartamento 302, Setor Bueno, Goiânia), sexo (Masculino), idade e telefone. Os valores dos atributos que descrevem cada entidade ocupam a maior parte dos dados armazenados no banco de dados.

O MER especifica alguns tipos de atributos, são eles:

- Atributo simples ou composto - geralmente, o endereço de uma pessoa é composto por partes menores, como rua, seu número, número do apartamento, bairro e cidade. O endereço é um exemplo de atributo composto. Um atributo composto é aquele que pode ser dividido em subpartes (partes menores), ou seja, ele pode ser dividido em outros atributos mais básicos. Atributos compostos são úteis quando 
em algumas ocasiões são referenciados por inteiro e em outras ocasiões é referenciada apenas alguma subparte do atributo (em alguns momentos pode ser interessante mostrar apenas a cidade em que a pessoa mora, por exemplo). Se um atributo for sempre referenciado como um todo (por inteiro), não existe razão para dividi-lo em subpartes. Um atributo simples é aquele que não é dividido em atributos mais básicos, como o sexo e o CPF de uma Pessoa;

- Atributo de valor único ou multivalorado (múltiplos valores) - o nome, a data de nascimento e o CPF são exemplos de atributos que recebem apenas um valor por Pessoa (uma pessoa não pode ter dois números de CPF, por exemplo), estes são exemplos de atributos de valor único. A maioria dos atributos de uma entidade possui um único valor. Entretanto, em alguns casos, um atributo pode possuir mais de um valor (podendo ser vários) para uma mesma entidade, tais atributos são chamados de multivalorados. Por exemplo, uma pessoa pode ter um, dois, três ou até mesmo mais números de telefone, o que torna o telefone, neste caso, um atributo multivalorado. Uma pessoa também pode ter mais de um endereço (como residencial e profissional, por exemplo);

- Atributo derivado - é fácil perceber que a idade de uma pessoa pode ser determinada a partir da sua data de nascimento e da data atual. Um atributo cujo valor, como a idade, pode ser obtido através dos valores de outros atributos é chamado de derivado. Alguns valores de atributos das entidades de um conjunto de entidades podem ser derivados de atributos de entidades de outros conjuntos de entidades. Por exemplo, um atributo número de empregados de um Departamento pode ser calculado contando-se o número de Empregados (do conjunto de entidades Empregado) relacionados com o Departamento. O valor de um atributo derivado não é armazenado, mas pode ser calculado quando necessário.

Dos exemplos anteriores, pode-se notar que um atributo pode pertencer a mais de um tipo, por exemplo, o CPF foi considerado um atributo simples e de valor único, e o endereço foi considerado um atributo composto e multivalorado. A figura abaixo ilustra uma entidade Pessoa com alguns de seus atributos, merecendo destaque a representação do atributo composto endereço. 


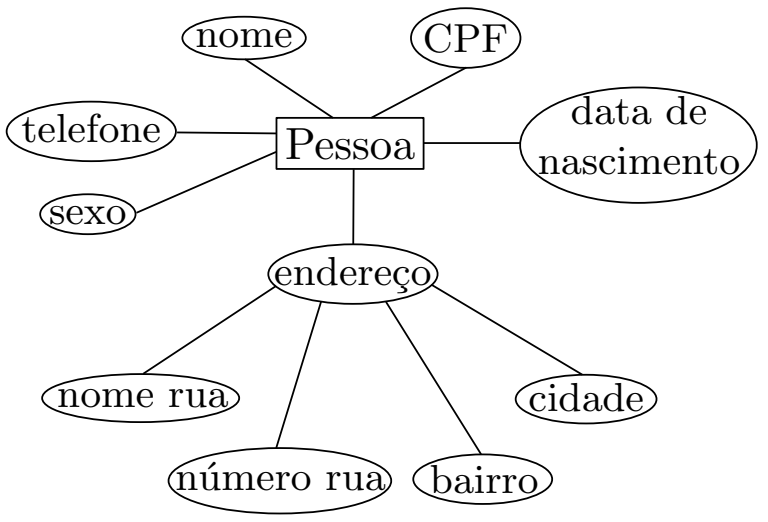

Em alguns casos, uma entidade em particular pode não possuir um valor para algum de seus atributos, neste caso, este atributo receberá um valor nulo. Por exemplo, uma pessoa que mora em uma casa receberá um valor nulo para o atributo número do apartamento (o que indica que esse atributo não é aplicável a esta pessoa), que faz parte do atributo composto endereço; uma pessoa também pode receber um valor nulo para o atributo telefone (neste caso, o atributo é desconhecido, visto que uma pessoa pode ou não possuir um número de telefone).

Cada atributo de uma entidade está associado a um conjunto de valores, ou domínio, que este atributo pode receber. Por exemplo, o atributo sexo de uma pessoa pode receber apenas os valores "masculino" ou "feminino", enquanto que o atributo telefone poderia ter como domínio apenas números inteiros; no caso da idade, o domínio poderia ser o conjunto dos números inteiros pertencentes ao intervalo de 0 a 130 .

\section{A.2 Conteúdo de Nível Intermediário}

Os próximos parágrafos abordam, em detalhes, as principais características que os atributos podem ter.

Cada entidade possui valores para cada um de seus atributos, estes valores refletem as características da entidade. Por exemplo, uma entidade Pessoa pode possuir os seguintes valores para seus atributos: nome (João Carlos, por exemplo), endereço (por exemplo: rua 4, nº80, apartamento 302, Setor Bueno, Goiânia), CPF, data de nascimento, sexo, idade e telefone. Os valores dos atributos que descrevem cada entidade ocupam a maior parte dos dados armazenados no banco de dados.

O MER especifica alguns tipos de atributos, são eles:

- Atributo simples (atômico) ou composto - um atributo composto é aquele que 
pode ser dividido em subpartes, ou seja, ele pode ser dividido em outros atributos mais básicos (também chamados de componentes), que possuem significados independentes. Por exemplo, o endereço de uma pessoa pode ser dividido em rua, seu número, número do apartamento, bairro e cidade. Os atributos compostos são úteis quando em algumas ocasiões são referenciados por inteiro e em outras ocasiões é referenciado apenas algum componente do atributo. Se um atributo for sempre referenciado como um todo, não existe razão para dividi-lo em subpartes. Um atributo simples é aquele que não é dividido em componentes, como o sexo e o CPF de uma Pessoa;

- Atributo de valor único ou multivalorado (múltiplos valores) - a maioria dos atributos em uma determinada entidade possui um único valor. Este tipo de atributo é chamado de atributo de valor único. O nome, o sexo e o CPF de uma Pessoa são exemplos de atributos de valor único. Em alguns casos, entretanto, um atributo pode ter um conjunto de valores (vários valores) para uma mesma entidade, estes atributos são chamados de multivalorados. Por exemplo, uma pessoa pode ter um, dois ou até mesmo mais números de telefone e, neste caso, o telefone é considerado um atributo multivalorado;

- Atributo derivado - o valor para este tipo de atributo pode ser derivado dos valores de outros atributos. Por exemplo, através do atributo data de nascimento de uma pessoa e da data atual, pode-se calcular a idade desta pessoa; desta forma, a idade é um exemplo de atributo derivado. Neste caso, a data de nascimento pode ser referenciada como um atributo base ou armazenado. O valor de um atributo derivado não é armazenado no banco, mas é calculado quando necessário. Alguns valores de atributos das entidades de um conjunto de entidades podem ser derivados de atributos de entidades de outros conjuntos de entidades. Por exemplo, um atributo número de empregados de um Departamento pode ser calculado contando-se o número de Empregados (do conjunto de entidades Empregado) relacionados com o Departamento.

Dos exemplos anteriores, pode-se notar que um atributo pode pertencer a mais de um tipo, por exemplo, o atributo sexo foi considerado simples e de valor único, enquanto que a idade foi caracterizada como um atributo derivado que, por natureza, também é simples e de valor único. A figura abaixo ilustra uma entidade Pessoa com alguns de seus atributos, merecendo destaque a representação do atributo composto endereço. 


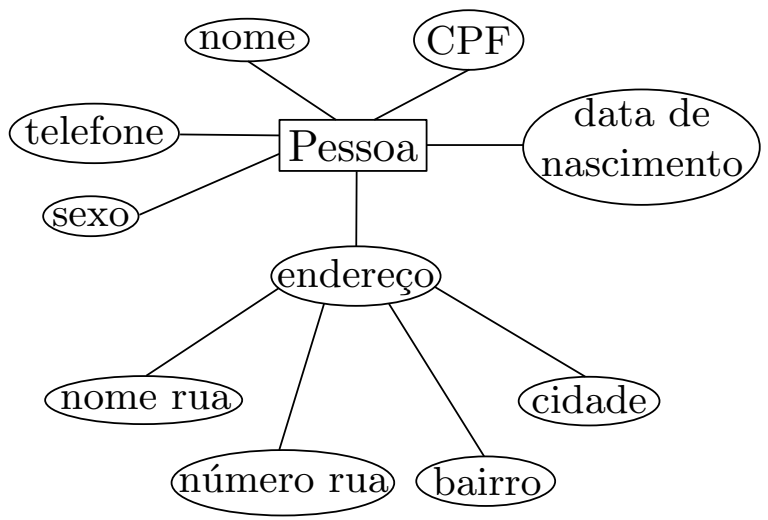

Em alguns casos, uma entidade em particular pode não possuir um valor para algum de seus atributos, neste caso, este atributo receberá um valor nulo. Por exemplo, uma pessoa que mora em uma casa não possui um valor para o atributo número do apartamento, que faz parte do atributo composto endereço. Neste caso, o valor nulo indica que o atributo não é aplicável àquela entidade. Um valor nulo também pode indicar que o valor do atributo é desconhecido (o valor pode ou não existir) ou omisso (o valor existe, mas não se tem este valor). Por exemplo, caso o valor do atributo sexo de uma pessoa seja nulo, o seu valor está omisso; caso o valor do atributo telefone esteja nulo, o seu valor é desconhecido, visto que uma pessoa pode não possuir um telefone.

Cada atributo de uma entidade está associado a um conjunto de valores, ou domínio, que este atributo pode receber. Por exemplo, o atributo sexo de uma pessoa pode receber apenas os valores "masculino" ou "feminino", enquanto que o domínio do atributo idade poderia ser o conjunto dos números inteiros pertencentes ao intervalo de 0 a 130 .

\section{A.3 Conteúdo de Nível Avançado}

Os próximos parágrafos abordam, em detalhes, as principais características que os atributos podem ter.

Cada entidade possui valores para cada um de seus atributos, estes valores refletem as características da entidade. Por exemplo, uma entidade Pessoa pode possuir os seguintes valores para seus atributos: nome (João Carlos, por exemplo), endereço (por exemplo: rua 4, no 800, apartamento 302, Setor Bueno, Goiânia), CPF, data de nascimento, sexo, idade e telefone. Os valores dos atributos que descrevem cada entidade ocupam a maior parte dos dados armazenados no banco de dados.

O MER especifica alguns tipos de atributos, são eles: 
- Atributo simples (atômico) ou composto - um atributo composto é aquele que pode ser dividido em subpartes, ou seja, ele pode ser dividido em outros atributos mais básicos (também chamados de componentes), que possuem significados independentes. Por exemplo, o endereço de uma pessoa pode ser dividido em rua, número da rua, número do apartamento, bairro e cidade. Os atributos compostos são úteis quando em algumas ocasiões são referenciados por inteiro e em outras ocasiões é referenciado apenas algum componente do atributo. Se um atributo for sempre referenciado como um todo, não existe razão para dividi-lo em subpartes. Para se conhecer significado completo de um atributo composto, faz-se necessário conhecer os valores dos seus componentes. De uma certa forma, os atributos compostos ajudam a agrupar atributos que são relacionados, tornando a modelagem mais clara. Um atributo simples é aquele que não é dividido em componentes, ou seja, é aquele cujo significado está completamente informado no valor do atributo. O sexo e o CPF de uma Pessoa são exemplos de atributos simples;

- Atributo de valor único ou multivalorado - a maioria dos atributos em uma determinada entidade possui um único valor. Este tipo de atributo é chamado de atributo de valor único. Em alguns casos, entretanto, um atributo pode ter um conjunto de valores para uma mesma entidade, estes atributos são chamados de multivalorados. Por exemplo, o nome e o CPF de uma Pessoa são atributos de valor único, enquanto que o telefone, caso uma Pessoa possa ter mais de um número, seria um atributo multivalorado;

- Atributo derivado - o valor para este tipo de atributo pode ser derivado dos valores de outros atributos. Por exemplo, através do atributo data de nascimento de uma pessoa e da data atual pode-se calcular a idade desta pessoa, desta forma, a idade é um exemplo de atributo derivado. Neste caso, a data de nascimento pode ser referenciada como um atributo base ou armazenado. O valor de um atributo derivado não é armazenado no banco, mas é calculado quando necessário. Alguns valores de atributos das instâncias (entidades) de um conjunto de entidades também podem ser derivados de atributos de instâncias de outros conjuntos de entidades.

Um atributo pode pertencer a mais de um tipo da atributo. Como apresentado, a idade de uma Pessoa foi caracterizada como um atributo derivado e que, por natureza, também é um atributo simples e de valor único.

Em alguns casos, uma entidade em particular pode não possuir um valor para algum de seus atributos, neste caso, este atributo receberá um valor nulo. Por exemplo, uma pessoa 
que mora em uma casa não possui um valor para o atributo número do apartamento, que faz parte do atributo composto endereço. Neste caso, o valor nulo indica que o atributo não é aplicável àquela entidade. Um valor nulo também pode indicar que o valor do atributo é desconhecido (o valor pode ou não existir) ou omisso (o valor existe, mas não se tem este valor). Por exemplo, caso o valor do atributo sexo de uma pessoa seja nulo, o seu valor está omisso; caso o valor do atributo telefone esteja nulo, o seu valor é desconhecido, visto que uma pessoa pode não possuir um telefone.

Cada atributo de uma instância do conjunto de entidades está associado a um conjunto de valores, ou domínio, que este atributo pode receber. Por exemplo, o atributo sexo de uma pessoa pode receber apenas os valores "masculino" ou "feminino", enquanto que o domínio do atributo idade poderia ser o conjunto dos números inteiros pertencentes ao intervalo de 0 a 130. Formalmente, um atributo de um conjunto de entidades é uma função que mapeia deste conjunto para um domínio.

\section{A.4 Conteúdo Simplificado de Nível Intermediário}

Um atributo simples também é comumente chamado de atributo atômico.

As subpartes em que um atributo composto pode ser dividido também são chamadas de componentes, deste modo, um atributo composto pode ser dividido em componentes.

Como foi visto, o atributo derivado idade de uma Pessoa pode ser obtido através da sua data de nascimento e da data atual. Neste caso, a data de nascimento pode ser referenciada como um atributo base ou armazenado.

Além de um atributo de uma entidade receber um valor nulo quando este atributo não é aplicável a esta entidade e quando o seu valor é desconhecido, um valor nulo também pode indicar que o valor do atributo é omisso, em que o valor existe, mas não se tem este valor. Por exemplo, caso o valor do atributo sexo de uma Pessoa seja nulo, o seu valor está omisso.

\section{A.5 Conteúdo Simplificado de Nível Avançado}

Para se conhecer significado completo de um atributo composto, faz-se necessário conhecer os valores dos seus componentes. De uma certa forma, os atributos compostos ajudam a agrupar atributos que são relacionados, tornando a modelagem mais clara. 
Como visto, cada atributo de uma entidade está associado a um conjunto de valores, ou domínio, que este atributo pode receber. Formalmente, um atributo de um conjunto de entidades é uma função que mapeia deste conjunto para um domínio.

\section{A.6 Pré-teste}

Como já mencionado, as entidades possuem atributos que as descrevem. Considere uma entidade Pessoa, que pode possuir os seguintes atributos: nome, CPF, data de nascimento, endereço, telefone e idade. Selecione, dentre as alternativas abaixo, a que você considera errada:

- Uma pessoa não pode possuir mais de um número de telefone;

- O atributo endereço, para tornar mais claro o que se deseja descrever dele, poderia ser subdividido em partes menores, como, por exemplo, rua, CEP, bairro e cidade;

- É natural imaginar que o atributo idade receba como possíveis valores apenas números inteiros, como o número 17, por exemplo;

- Ainda em relação ao atributo idade, o mesmo poderia ser obtido através da data de nascimento da pessoa e da data atual.

O primeiro item apresentado é o item que o aluno deveria selecionar para acertar a questão.

\section{A.7 Pós-teste}

Considerando o que foi apresentado sobre os atributos, selecione a alternativa que você considera verdadeira:

- O atributo endereço sempre é modelado como um atributo composto;

- Os valores dos atributos derivados são calculados através de outros atributos e, em alguns casos, podem ser armazenados no banco de dados;

- Caso o projetista do banco de dados determine que é necessário obter apenas um número de telefone por Pessoa, então, nesta entidade, o telefone poderia ser modelado como um atributo de valor único; 
- Um atributo recebe um valor nulo apenas quando o seu valor é desconhecido;

- Nenhuma das alternativas anteriores é verdadeira.

O terceiro item apresentado é o item que o aluno deveria selecionar para acertar a questão.

\section{A.8 $2^{\circ}$ Pós-teste}

Considerando as características dos atributos, selecione a alternativa que você considera verdadeira:

- O atributo telefone não pode ser modelado como um atributo de valor único;

- Um atributo derivado de uma entidade sempre é obtido de outros atributos desta mesma entidade;

- Nem todo atributo precisa ter associado a ele um domínio;

- Quando um atributo não se aplica à entidade e quando o seu valor não é conhecido são motivos que levam com que este atributo receba um valor nulo.

O quarto item apresentado é o item que o aluno deveria selecionar para acertar a questão. 


\section{APÊNDICE B - Sistema Adaptativo}

Este apêndice apresenta exemplos e maiores detalhes sobre alguns aspectos do sistema proposto neste trabalho, apresentados no Capítulo 4.

\section{B.1 TPCs da Rede Bayesiana}

A Figura B.1 apresenta as TPCs da RB que compõe o Modelo do Aluno. Estas tabelas foram definidas com o auxílio de um especialista no domínio abordado e elas resultaram nas probabilidades iniciais que o alunos têm de conhecer ou não os conceitos envolvidos, apresentadas na Figura 4.1.

\section{B.2 Mecanismo de Mensagens e Dicas}

A Tabela B.1 apresenta algumas das mensagens utilizadas pelo sistema para interagir com o aluno. Elas têm como principais funções permitir que o aluno saiba qual foi o resultado de uma atividade que acabou de realizar e indicar qual será a consequência deste resultado (próxima etapa a ser percorrida no curso).

A Figura B.2 ilustra um exemplo de mensagem exibida pelo sistema. Ela é apresentada ao aluno logo após o erro do pré-teste.

A Figura B.3 ilustra uma dica que pode ser visualizada pelo aluno no decorrer do curso. Estas dicas permitem que o aluno reveja algum conceito que foi visto anteriormente no curso ou algum cenário que é constantemente utilizado.

Deve-se ressaltar que o mecanismo de mensagens e dicas também foi utilizado pelo sistema tradicional (desprovido de adaptação). Entretanto, as mensagens utilizadas por este sistema se diferenciam um pouco das mensagens utilizadas pelo sistema adaptativo. Esta diferença se deve principalmente à simplicidade dos mecanismos utilizados pelo sistema tradicional. 


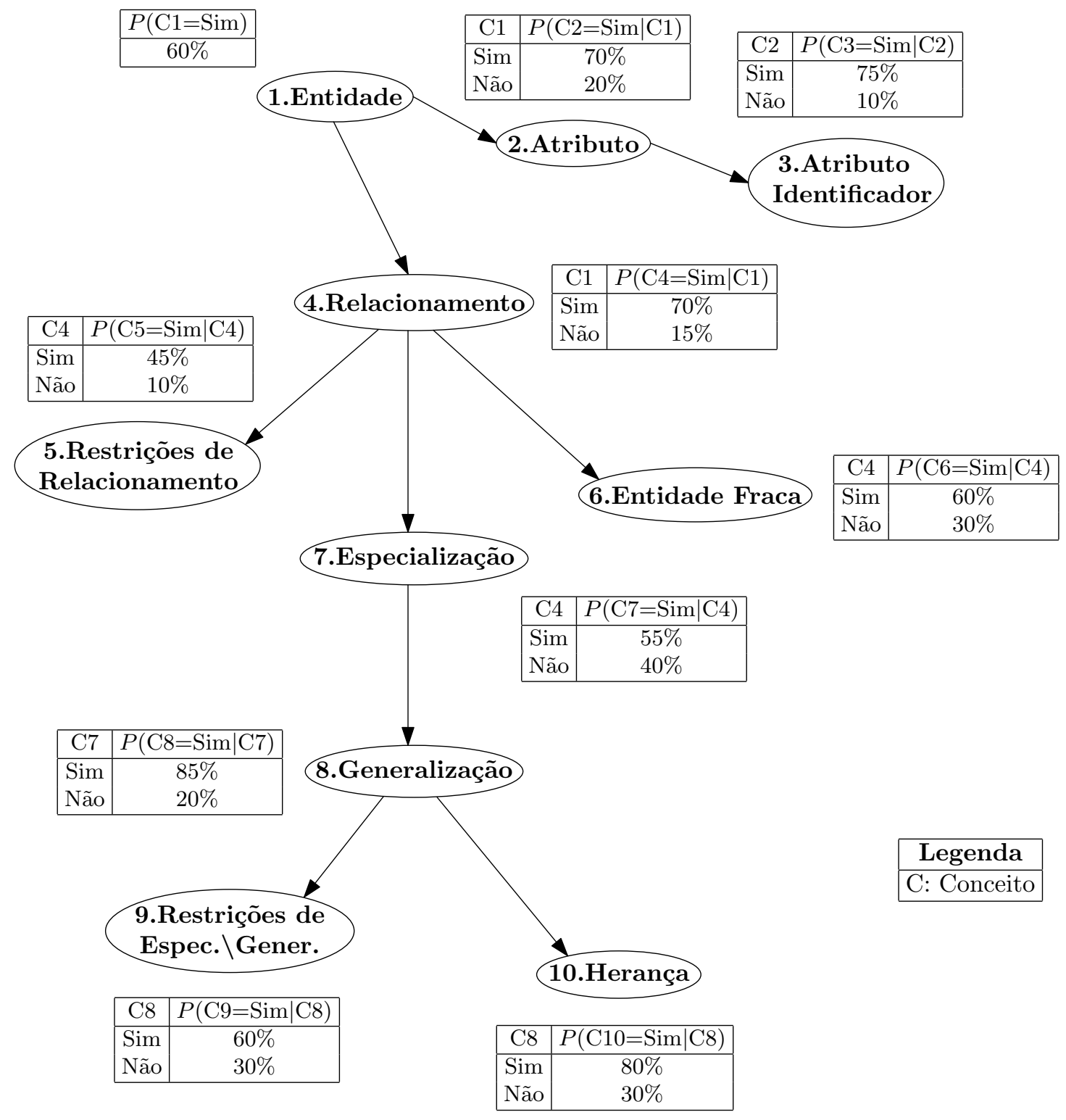

Figura B.1: TPCs da RB criada. Em que o estado "Sim" representa o aluno conhecer o conceito envolvido e o estado "Não", o contrário. São apresentadas apenas as probabilidades referentes ao estado "Sim" de cada conceito. 


\begin{tabular}{|c|c|}
\hline Momento & Mensagem \\
\hline $\begin{array}{l}\text { Antes da apresentação do } \\
\text { primeiro pré-teste. }\end{array}$ & $\begin{array}{l}\text { A seguir será apresentada uma questão que envolve o } 1^{\circ} \\
\text { conceito a ser apresentado (questão de pré-teste), leia esta } \\
\text { questão com atenção antes de respondê-la. }\end{array}$ \\
\hline $\begin{array}{l}\text { Antes da apresentação dos } \\
\text { pós-testes e } 2^{\circ} \text { pós-teste. }\end{array}$ & $\begin{array}{l}\text { A seguir será apresentada uma questão que avaliará o con- } \\
\text { teúdo que foi apresentado (questão de pós-teste), leia esta } \\
\text { questão com atenção antes de respondê-la. }\end{array}$ \\
\hline $\begin{array}{l}\text { Antes da apresentação do } \\
\text { pré-teste, após o acerto do } \\
\text { pós-teste ou } 2^{\circ} \text { pós-teste. }\end{array}$ & $\begin{array}{l}\text { Parabéns, você respondeu corretamente a questão apre- } \\
\text { sentada! A seguir será apresentada uma questão que } \\
\text { envolve o novo conceito que será apresentado (questão } \\
\text { de pré-teste), leia esta questão com atenção antes de } \\
\text { respondê-la. }\end{array}$ \\
\hline $\begin{array}{l}\text { Antes da apresentação do } \\
\text { pré-teste, após o erro do } 2^{\circ} \\
\text { pós-teste. }\end{array}$ & $\begin{array}{l}\text { Você errou a questão que foi apresentada. De qualquer } \\
\text { forma, a seguir será apresentada uma questão que envolve } \\
\text { o novo conceito que será apresentado (questão de pré- } \\
\text { teste), leia esta questão com atenção antes de respondê-la. }\end{array}$ \\
\hline $\begin{array}{l}\text { Apresentação do conteúdo } \\
\text { após acerto do pré-teste. }\end{array}$ & $\begin{array}{l}\text { Parabéns, você respondeu corretamente a questão apre- } \\
\text { sentada! Por favor leia com atenção o conteúdo que será } \\
\text { apresentado. }\end{array}$ \\
\hline $\begin{array}{l}\text { Após erro do pós-teste, em } \\
\text { que será apresentado o con- } \\
\text { teúdo de reforço. }\end{array}$ & $\begin{array}{l}\text { Você errou a questão que foi apresentada. Outro conteúdo } \\
\text { envolvendo o mesmo conceito será apresentado (atividade } \\
\text { de reforço), por favor leia-o com atenção. }\end{array}$ \\
\hline $\begin{array}{l}\text { Antes da apresentação do } \\
\text { conteúdo simplificado, após } \\
\text { acerto do pós-teste. }\end{array}$ & $\begin{array}{l}\text { Parabéns, você respondeu corretamente a questão apre- } \\
\text { sentada! A seguir será apresentado um conteúdo adicio- } \\
\text { nal, que tem por objetivo aprofundar o seu conhecimento } \\
\text { no conceito envolvido. }\end{array}$ \\
\hline
\end{tabular}

Tabela B.1: Algumas mensagens utilizadas pelo sistema proposto para interagir com o aluno. 


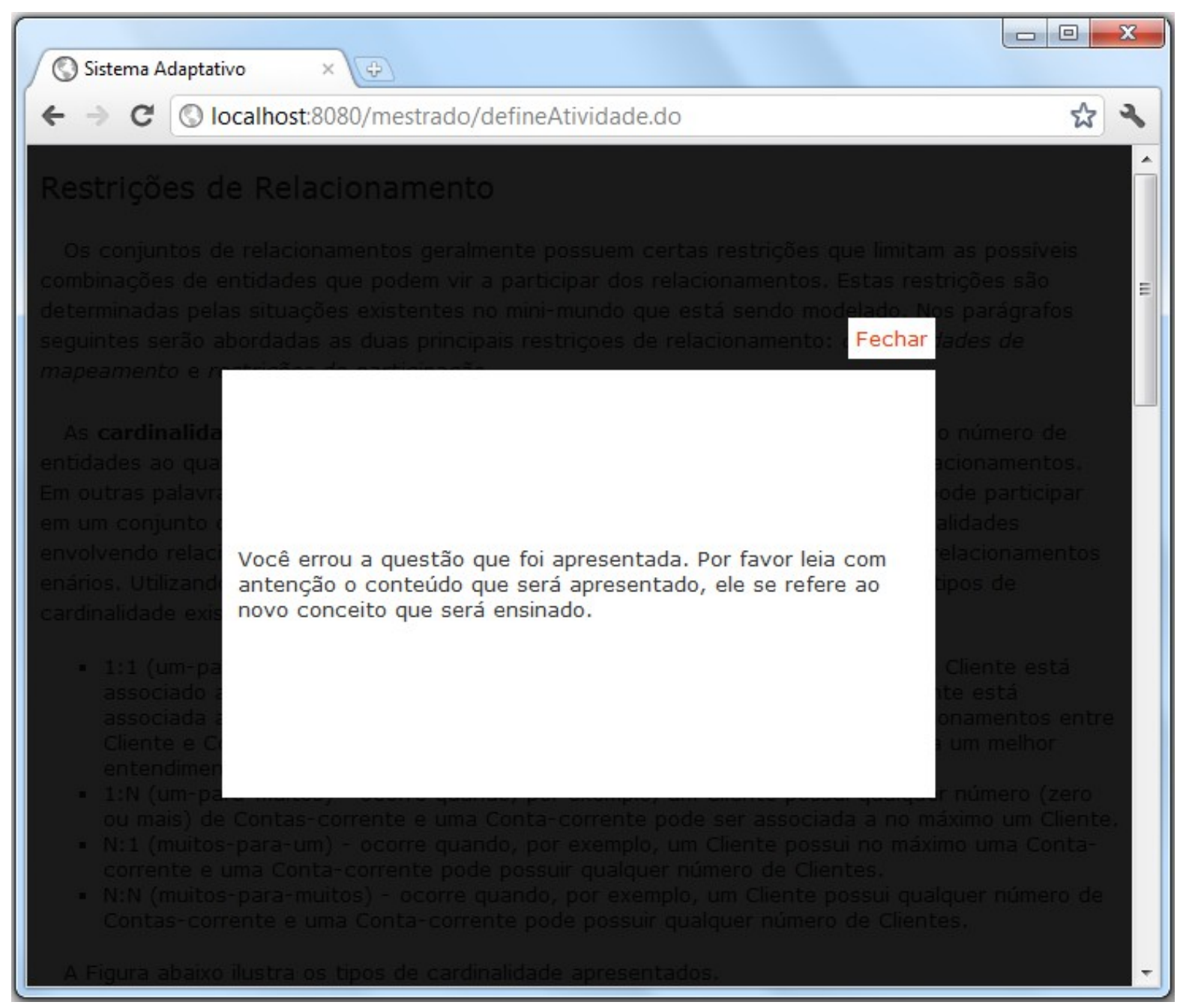

Figura B.2: Mensagem apresentada ao aluno logo após o erro do pré-teste. 


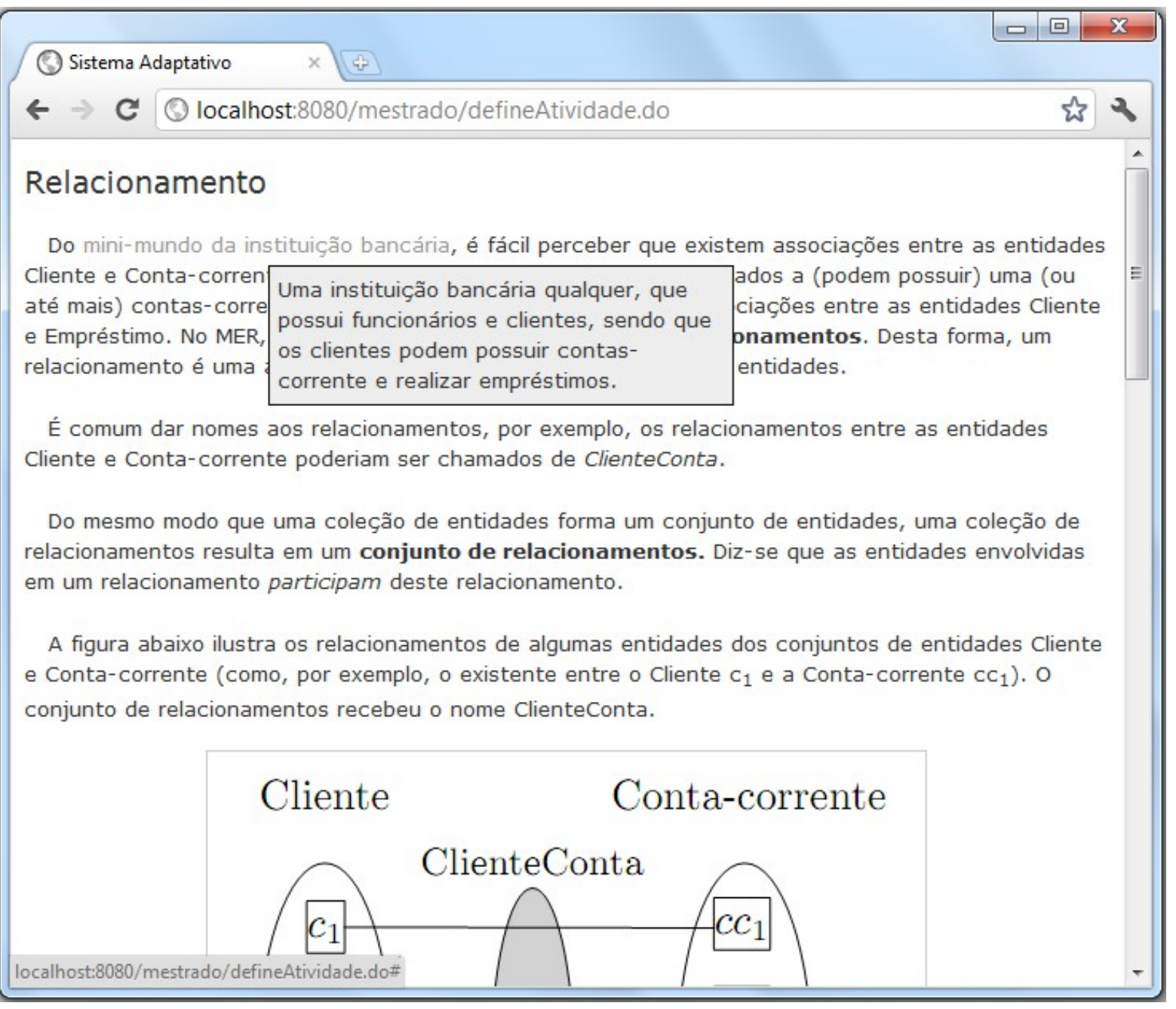

Figura B.3: Dica que permite ao aluno rever um cenário muito utilizado no curso. 


\section{B.3 Questionários}

As Figuras B.4 e B.5 apresentam, respetivamente, os questionários para o levantamento do histórico dos alunos e para a avaliação do sistema utilizado (representado pelo curso oferecido). Além de serem utilizados pelo sistema adaptativo, estes questionários também foram utilizados pelo sistema tradicional.

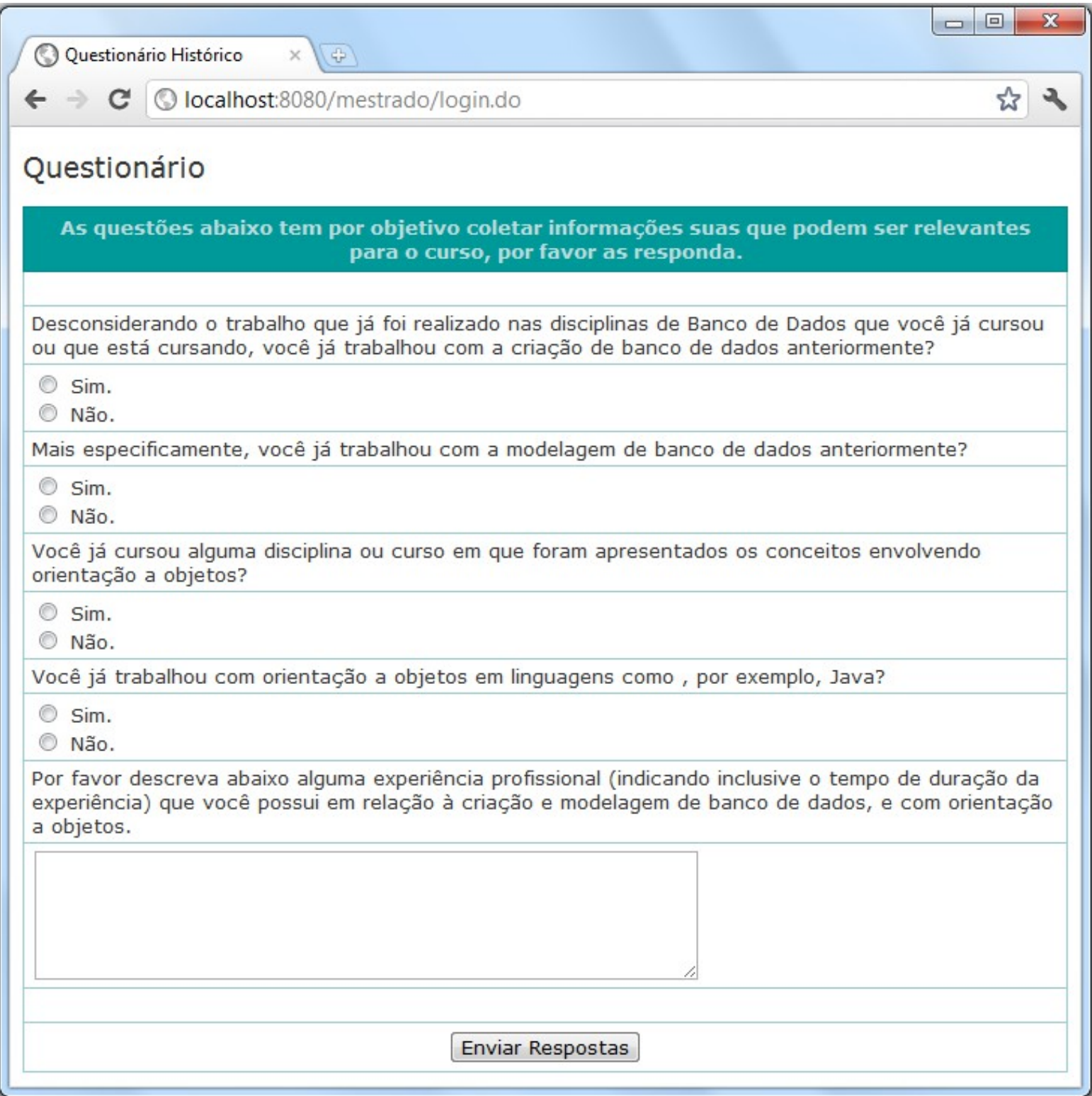

Figura B.4: Questionário para o levantamento do histórico do aluno. 


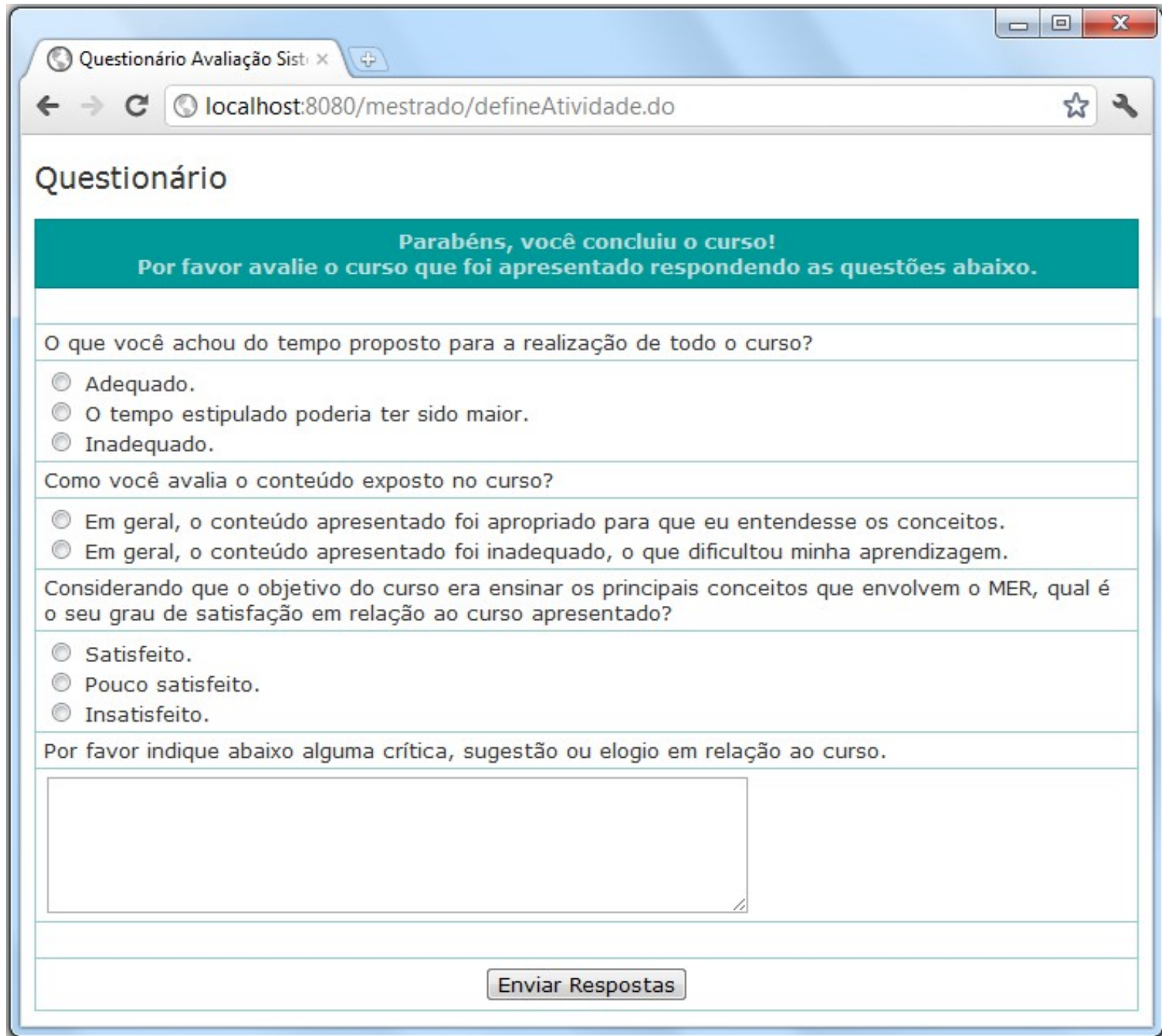

Figura B.5: Questionário de avaliação do sistema. 


\section{APÊENDICE C - Resultados Complementares}

Este apêndice apresenta dados que foram obtidos no experimento realizado e que complementam os resultados expostos no Capítulo 4.

As Tabelas C.1 e C.2 apresentam, respectivamente, os acertos obtidos para cada conceito nos testes realizados nos sistemas tradicional e adaptativo. O número de erros obtidos nos pré-testes e pós-testes em cada conceito pode ser obtido subtraindo-se os acertos obtidos em cada um destes tipos de testes pelo número de alunos que fizeram uso de cada sistema (25 alunos, neste caso). Como no sistema tradicional as atividades de reforço e, consequentemente, os $2^{\circ}$ pós-testes não são obrigatórios, foi informado na Tabela C.1 o total de alunos que optaram por realizar as atividades de reforço em cada conceito.

As Tabelas C.3 e C.4 apresentam, respectivamente, alguns resultados obtidos pelos alunos nos cursos que foram oferecidos pelos sistemas adaptativo e tradicional. Entre estes resultados estão o tempo gasto para a realização do curso, o desempenho obtido nos testes e a habilidade calculada ao final do curso. A ordem de apresentação dos alunos nestas tabelas segue o desempenho, em ordem decrescente, que eles obtiveram nos pós-testes.

Como forma de exemplificar que conteúdos adaptados (personalizados) foram apresentados aos alunos no decorrer do curso oferecido pelo sistema adaptativo, a Tabela C.5 apresenta a sequência de conteúdos que foi visualizada pelos 3 alunos que foram selecionados no Capítulo 4 e que já tiveram alguns dos seus resultados apresentados. O Aluno 1 obteve um ótimo desempenho no curso (este aluno está representado como o aluno 1 da Tabela C.3), o Aluno 2 obteve um desempenho mediano (ele pode ser identificado como o aluno 14 da Tabela C.3), enquanto que o Aluno 3 obteve o pior desempenho entre os alunos (ele pode ser identificado como o aluno 25 da Tabela C.3). 


\begin{tabular}{|c|c|c|c|}
\hline Conceito & Teste & $\mathrm{N}^{\mathrm{o}}$ de Acertos & $\begin{array}{l}\text { Total de } 2^{\circ} \text { Pós- } \\
\text { testes Realizados }\end{array}$ \\
\hline 1 & Pós-teste & 19 & - \\
\hline 1 & $2^{\mathrm{o}}$ Pós-teste & 4 & 6 \\
\hline 2 & Pós-teste & 21 & - \\
\hline 2 & $2^{\circ}$ Pós-teste & 2 & 4 \\
\hline 3 & Pós-teste & 12 & - \\
\hline 3 & $2^{\mathrm{o}}$ Pós-teste & 9 & 11 \\
\hline 4 & Pós-teste & 6 & - \\
\hline 4 & $2^{\circ}$ Pós-teste & 8 & 16 \\
\hline 5 & Pós-teste & 6 & - \\
\hline 5 & $2^{\circ}$ Pós-teste & 8 & 15 \\
\hline 6 & Pós-teste & 7 & - \\
\hline 6 & $2^{\mathrm{o}}$ Pós-teste & 4 & 11 \\
\hline 7 & Pós-teste & 12 & - \\
\hline 7 & $2^{\mathrm{o}}$ Pós-teste & 5 & 9 \\
\hline 8 & Pós-teste & 11 & - \\
\hline 8 & $2^{\mathrm{o}}$ Pós-teste & 8 & 11 \\
\hline 9 & Pós-teste & 15 & - \\
\hline 9 & $2^{\circ}$ Pós-teste & 5 & 6 \\
\hline 10 & Pós-teste & 17 & - \\
\hline 10 & $2^{\mathrm{o}}$ Pós-teste & 4 & 5 \\
\hline
\end{tabular}

Tabela C.1: Acertos obtidos em cada conceito nos testes realizados no sistema tradicional. 


\begin{tabular}{|c|c|c|}
\hline Conceito & Teste & $\mathrm{N}^{\mathrm{o}}$ de Acertos \\
\hline 1 & Pré-teste & 16 \\
\hline 1 & Pós-teste & 22 \\
\hline 1 & $2^{\mathrm{o}}$ Pós-teste & 0 \\
\hline 2 & Pré-teste & 19 \\
\hline 2 & Pós-teste & 15 \\
\hline 2 & $2^{\circ}$ Pós-teste & 6 \\
\hline 3 & Pré-teste & 22 \\
\hline 3 & Pós-teste & 16 \\
\hline 3 & $2^{\mathrm{o}}$ Pós-teste & 7 \\
\hline 4 & Pré-teste & 25 \\
\hline 4 & Pós-teste & 3 \\
\hline 4 & $2^{\circ}$ Pós-teste & 16 \\
\hline 5 & Pré-teste & 17 \\
\hline 5 & Pós-teste & 10 \\
\hline 5 & $2^{\circ}$ Pós-teste & 8 \\
\hline 6 & Pré-teste & 13 \\
\hline 6 & Pós-teste & 12 \\
\hline 6 & $2^{\mathrm{o}}$ Pós-teste & 7 \\
\hline 7 & Pré-teste & 24 \\
\hline 7 & Pós-teste & 12 \\
\hline 7 & $2^{\circ}$ Pós-teste & 10 \\
\hline 8 & Pré-teste & 20 \\
\hline 8 & Pós-teste & 18 \\
\hline 8 & $2^{\mathrm{o}}$ Pós-teste & 6 \\
\hline 9 & Pré-teste & 16 \\
\hline 9 & Pós-teste & 19 \\
\hline 9 & $2^{\circ}$ Pós-teste & 6 \\
\hline 10 & Pré-teste & 22 \\
\hline 10 & Pós-teste & 19 \\
\hline 10 & $2^{\circ}$ Pós-teste & 5 \\
\hline
\end{tabular}

Tabela C.2: Acertos obtidos em cada conceito nos testes realizados no sistema adaptativo. 


\begin{tabular}{|c|c|c|c|c|c|}
\hline \multirow{2}{*}{ Aluno } & \multirow{2}{*}{$\begin{array}{c}\text { Tempo Total } \\
\text { Gasto }\end{array}$} & \multicolumn{3}{|c|}{$\mathrm{N}^{\mathrm{O}}$ de Acertos } & \multirow{2}{*}{$\begin{array}{c}\text { Habilidade } \\
\text { Final }\end{array}$} \\
\hline & & Pré-testes & Pós-testes & $2^{\circ}$ Pós-testes & \\
\hline 1 & $1 \mathrm{~h} 08 \mathrm{~min} 33 \mathrm{~s}$ & 10 & 9 & 1 & 1,96 \\
\hline 2 & $57 \mathrm{~min} 36 \mathrm{~s}$ & 9 & 8 & 2 & 1,52 \\
\hline 3 & $1 \mathrm{~h} 46 \mathrm{~min} 19 \mathrm{~s}$ & 9 & 7 & 3 & 1,39 \\
\hline 4 & $2 \mathrm{~h} 30 \mathrm{~min} 30 \mathrm{~s}$ & 9 & 7 & 3 & 1,38 \\
\hline 5 & $1 \mathrm{~h} 41 \mathrm{~min} 13 \mathrm{~s}$ & 9 & 7 & 2 & 1,21 \\
\hline 6 & $1 \mathrm{~h} 16 \mathrm{~min} 04 \mathrm{~s}$ & 7 & 7 & 3 & 1,04 \\
\hline 7 & $59 \mathrm{~min} 47 \mathrm{~s}$ & 6 & 7 & 1 & 0,55 \\
\hline 8 & $2 \mathrm{~h} 03 \mathrm{~min} 54 \mathrm{~s}$ & 5 & 7 & 2 & 0,52 \\
\hline 9 & $2 \mathrm{~h} 02 \min 18 \mathrm{~s}$ & 10 & 6 & 3 & 1,27 \\
\hline 10 & 1h 12min 04s & 9 & 6 & 3 & 1,12 \\
\hline 11 & $1 \mathrm{~h} 55 \mathrm{~min} 36 \mathrm{~s}$ & 9 & 6 & 2 & 0,98 \\
\hline 12 & 1h $04 \min 09 \mathrm{~s}$ & 8 & 6 & 4 & 1,10 \\
\hline 13 & $57 \mathrm{~min} 33 \mathrm{~s}$ & 7 & 6 & 3 & 0,80 \\
\hline 14 & $52 \mathrm{~min} 53 \mathrm{~s}$ & 7 & 6 & 3 & 0,80 \\
\hline 15 & 1h 10min 19s & 6 & 6 & 1 & 0,32 \\
\hline 16 & 1h $10 \mathrm{~min} 29 \mathrm{~s}$ & 9 & 5 & 4 & 1,02 \\
\hline 17 & $1 \mathrm{~h} 01 \mathrm{~min} 25 \mathrm{~s}$ & 9 & 5 & 4 & 1,03 \\
\hline 18 & $1 \mathrm{~h} 03 \mathrm{~min} 34 \mathrm{~s}$ & 9 & 5 & 2 & 0,77 \\
\hline 19 & 1h $23 \mathrm{~min} 30 \mathrm{~s}$ & 8 & 5 & 3 & 0,73 \\
\hline 20 & $1 \mathrm{~h} 17 \min 53 \mathrm{~s}$ & 8 & 5 & 1 & 0,46 \\
\hline 21 & $1 \mathrm{~h} 41 \mathrm{~min} 05 \mathrm{~s}$ & 7 & 5 & 1 & 0,26 \\
\hline 22 & $1 \mathrm{~h} 49 \mathrm{~min} 44 \mathrm{~s}$ & 4 & 5 & 5 & 0,36 \\
\hline 23 & $1 \mathrm{~h} 41 \mathrm{~min} 18 \mathrm{~s}$ & 7 & 4 & 5 & 0,65 \\
\hline 24 & $1 \mathrm{~h} 24 \mathrm{~min} 34 \mathrm{~s}$ & 6 & 4 & 6 & 0,60 \\
\hline 25 & $1 \mathrm{~h} 55 \mathrm{~min} 01 \mathrm{~s}$ & 7 & 2 & 4 & 0,07 \\
\hline
\end{tabular}

Tabela C.3: Tempo total gasto, habilidade final e o desempenho nos testes obtidos pelos alunos no curso oferecido pelo sistema adaptativo. 


\begin{tabular}{|c|c|c|c|c|}
\hline \multirow{2}{*}{ Aluno } & \multirow{2}{*}{$\begin{array}{c}\text { Tempo Total } \\
\text { Gasto }\end{array}$} & \multicolumn{2}{|c|}{ Total de Acertos } & \multirow{2}{*}{$\begin{array}{c}\mathrm{N}^{\mathrm{o}} \text { de } 2^{\circ} \text { Pós- } \\
\text { testes Realizados }\end{array}$} \\
\hline & & Pós-testes & $2^{\circ}$ Pós-testes & \\
\hline 1 & $2 \mathrm{~h} 12 \min 10 \mathrm{~s}$ & 8 & 2 & 2 \\
\hline 2 & 1h $35 \mathrm{~min} 11 \mathrm{~s}$ & 8 & 1 & 2 \\
\hline 3 & 1h $27 \mathrm{~min} 59 \mathrm{~s}$ & 7 & 3 & 3 \\
\hline 4 & $53 \mathrm{~min} 11 \mathrm{~s}$ & 7 & 3 & 3 \\
\hline 5 & 1h 09min 06s & 7 & 2 & 3 \\
\hline 6 & $1 \mathrm{~h} 46 \mathrm{~min} 55 \mathrm{~s}$ & 7 & 0 & 1 \\
\hline 7 & 1h $23 \min 58 \mathrm{~s}$ & 6 & 3 & 4 \\
\hline 8 & 1h $38 \mathrm{~min} 28 \mathrm{~s}$ & 6 & 2 & 4 \\
\hline 9 & 1h $07 \mathrm{~min} 00 \mathrm{~s}$ & 6 & 1 & 2 \\
\hline 10 & 1h $15 \mathrm{~min} 30 \mathrm{~s}$ & 6 & 1 & 4 \\
\hline 11 & $1 \mathrm{~h} 06 \mathrm{~min} 37 \mathrm{~s}$ & 5 & 4 & 5 \\
\hline 12 & $1 \mathrm{~h} 22 \mathrm{~min} 38 \mathrm{~s}$ & 5 & 4 & 4 \\
\hline 13 & $1 \mathrm{~h} 15 \mathrm{~min} 11 \mathrm{~s}$ & 5 & 4 & 5 \\
\hline 14 & 1h $25 \min 29 \mathrm{~s}$ & 5 & 2 & 3 \\
\hline 15 & 1h $43 \mathrm{~min} 11 \mathrm{~s}$ & 5 & 2 & 2 \\
\hline 16 & $59 \mathrm{~min} 14 \mathrm{~s}$ & 4 & 4 & 6 \\
\hline 17 & 1h $42 \mathrm{~min} 10 \mathrm{~s}$ & 4 & 2 & 5 \\
\hline 18 & 1h $19 \min 35 \mathrm{~s}$ & 4 & 1 & 1 \\
\hline 19 & $1 \mathrm{~h} 14 \mathrm{~min} 16 \mathrm{~s}$ & 4 & 1 & 2 \\
\hline 20 & $1 \mathrm{~h} 07 \min 55 \mathrm{~s}$ & 4 & 0 & 2 \\
\hline 21 & $1 \mathrm{~h} 36 \mathrm{~min} 19 \mathrm{~s}$ & 3 & 5 & 7 \\
\hline 22 & $1 \mathrm{~h} 00 \mathrm{~min} 07 \mathrm{~s}$ & 3 & 3 & 7 \\
\hline 23 & $1 \mathrm{~h} 04 \mathrm{~min} 35 \mathrm{~s}$ & 3 & 2 & 7 \\
\hline 24 & 1h $07 \min 27 \mathrm{~s}$ & 2 & 3 & 7 \\
\hline 25 & $2 \mathrm{~h} 04 \mathrm{~min} 20 \mathrm{~s}$ & 2 & 2 & 3 \\
\hline
\end{tabular}

Tabela C.4: Tempo total gasto e o desempenho nos testes obtidos pelos alunos no curso oferecido pelo sistema tradicional. 


\begin{tabular}{|c|c|c|c|c|}
\hline Conceito & $\begin{array}{c}\text { Tipo } \\
\text { Conteúdo }\end{array}$ & Aluno 1 & Aluno 2 & Aluno 3 \\
\hline 1 & Após pré-teste & Intermediário & Intermediário & Intermediário \\
\hline 1 & Reforço & - & - & Básico \\
\hline 1 & Simplificado & Avançado & Avançado & - \\
\hline 2 & Após pré-teste & Avançado & Avançado & Básico \\
\hline 2 & Reforço & - & Intermediário & Básico \\
\hline 2 & Simplificado & - & - & - \\
\hline 3 & Após pré-teste & Avançado & Básico & Básico \\
\hline 3 & Reforço & - & - & Básico \\
\hline 3 & Simplificado & - & - & - \\
\hline 4 & Após pré-teste & Avançado & Intermediário & Básico \\
\hline 4 & Reforço & Intermediário & Básico & Básico \\
\hline 4 & Simplificado & - & - & - \\
\hline 5 & Após pré-teste & Intermediário & Básico & Básico \\
\hline 5 & Reforço & - & - & Básico \\
\hline 5 & Simplificado & Avançado & - & - \\
\hline 6 & Após pré-teste & Intermediário & Intermediário & Básico \\
\hline 6 & Reforço & - & - & - \\
\hline 6 & Simplificado & Avançado & - & - \\
\hline 7 & Após pré-teste & Intermediário & Intermediário & Intermediário \\
\hline 7 & Reforço & - & Básico & Básico \\
\hline 7 & Simplificado & Avançado & - & - \\
\hline 8 & Após pré-teste & Avançado & Intermediário & Básico \\
\hline 8 & Reforço & - & - & Básico \\
\hline 8 & Simplificado & - & - & - \\
\hline 9 & Após pré-teste & Avançado & Básico & Básico \\
\hline 9 & Reforço & - & - & Básico \\
\hline 9 & Simplificado & - & - & - \\
\hline 10 & Após pré-teste & Avançado & Avançado & Básico \\
\hline 10 & Reforço & - & Básico & - \\
\hline 10 & Simplificado & - & - & Intermediário \\
\hline
\end{tabular}

Tabela C.5: Sequência de conteúdos apresentada aos 3 alunos selecionados. 